\title{
Investigation of Metallic, Ceramic, and Polymeric Materials for Engineered Barrier Applications in Nuclear-Waste Packages
}

R. E. Westerman

October 1980

Prepared for the U.S. Department of Energy under Contract DE-AC06-76RLO 1830

Pacific Northwest Laboratory Operated for the U.S. Department of Energy by Battelle Memorial Institute 


\title{
NOTICE
}

This report was prepared as an account of work sponsored by the United States Government. Neither the United States nor the Department of Energy, nor any of their employees, nor any of their contractors, subcontractors, or their employees, makes any warranty, express or implied, or assumes any legal liability or responsibility for the accuracy, completeness or usefulness of any information, apparatus, product or process disclosed, or represents that its use would not infringe privately owned rights.

The views, opinions and conclusions contained in this report are those of the contractor and do not necessarily represent those of the United States Government or the United States Department of Energy.

\author{
PACIFIC NORTHWEST LABORATORY \\ operated by \\ BATTELLE \\ for the \\ UNITED STATES DEPARTMENT OF ENERGY \\ Under Contract EY-76-C-06-1830
}
Printed in the United States of America
Available from
National Technical Information Service
United States Department of Commerce
5285 Port Royal Road
Springfield, Virginia 22151

Price: Printed Copy $\$$.

$\because$ Microfiche $\$ 3.00$

$\begin{array}{cc}\text { •Pages } & \begin{array}{c}\text { NTIS } \\ \text { Selling Price }\end{array} \\ 001-025 & \$ 4.00 \\ 026-050 & \$ 4.50 \\ 051-075 & \$ 5.25 \\ 076-100 & \$ 6.00 \\ 101-125 & \$ 6.50 \\ 126-150 & \$ 7.25 \\ 151-175 & \$ 8.00 \\ 176-200 & \$ 9.00 \\ 201-225 & \$ 9.25 \\ 226-250 & \$ 9.50 \\ 251-275 & \$ 10.75 \\ 276-300 & \$ 11.00\end{array}$


PNL -3484

UC -70

\section{0}

INVESTIGATION OF METALLIC, CERAMIC, AND POLYMERIC MATERIALS FOR ENGINEERED BARRIER APPLICATIONS IN NUCLEAR-WASTE PACKAGES

R. E. Westerman

Contributors:

H. T. Fullam

B. Griggs

S. G. Pitman

W. E. Skiens

October 1980

Prepared for the U.S. Department of Energy under contract DE-AC06-76RLO 1830

Pacific Northwest Laboratory Richland, Washington 99352 


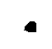

$\bullet$

$\checkmark$

, 
SUMMARY

An effort to develop licensable engineered barrier systems for the longterm $(\sim 1,000 \mathrm{yr}$ ) containment of nuclear wastes under conditions of deep continental geologic disposal has been underway at Pacific Northwest Laboratory since January 1979, under the auspices of the High-Level Waste Immobilization Program (HLWIP). This program is funded by the Division of Waste Products, U.S. Department of Energy. In the present work, the barrier system comprises the "hard" or structural elements of the package: the canister, the over$\operatorname{pack}(s)$, and the hole sleeve.

A number of candidate metallic, ceramic, and polymeric materials are undergoing mechanical and corrosion screening tests to determine their potential usefulness in barrier-system applications. Materials demonstrating adequate properties in the screening tests will be subjected to more detailed property tests, and, eventually, cost/benefit analyses, to determine their ultimate applicability to barrier-system design concepts.

Two titanium alloys were investigated in the mechanical property portion of the studies: Grade 2 (comercial purity) and Grade 12 (a titanium-nickelmolybdenum alloy). These alloys are considered prime candidates for barriersystem applications because of their already-demonstrated corrosion resistance in elevated-temperature corrosive environments. Tensile, impact, fracture toughness, and corrosion fatigue properties have been determined on both sheet and plate stock of these two alloys. It has been found that the mechanical properties of Grade 2 are superior to those of the Grade 12 alloy, except in the case of tensile and yield strengths. The comparisons include fatiguecrack-growth rate, fatigue-crack-growth rate in a simulated Hanford groundwater, fracture toughness, impact toughness, and dynamic fracture toughness. There is a significant difference in the fracture toughness behavior of the two alloys.

So far there is no evidence that presence of a simulated Hanford ground water at $\sim 94^{\circ} \mathrm{C}$ promotes the rate of crack growth in either material 
under fatigue conditions over conditions found in an air environment. The effect of other ground-water environments on corrosion fatigue-crack-growth rates has not yet been determined.

Stressed specimen corrosion tests were used to evaluate the reaction of a number of candidate metallic barrier materials with two potential repository environments, i.e., a simulated Hanford ground water and a Waste Isolation Pilot Plant (WIPP) intrusion brine $\left(\mathrm{NaCl}-\mathrm{MgCl}_{2}\right)$ at $250^{\circ} \mathrm{C}$. The Hanford groundwater system involves a partially equilibrating slow flow of simulated ground water through crushed basalt at $250^{\circ} \mathrm{C}$ before the water is brought in contact with the corrosion specimens. Several oxygen levels have been examined. The brine studies utilize an essentially static autoclave system with occasional samp ling.

Corrosion samples of 300 and 400 series stainless steels, Inconels, Hastelloy C-276, titanium, Zircaloy, copper-nickel alloys and cast irons were prepared as U-bend specimens with simulated welds. These electrically isolated samples have been exposed in Inconel autoclaves at $250^{\circ} \mathrm{C}$ for as long as 6 mo. The titanium alloys show outstanding corrosion resistance in both the Hanford groundwater and brine media. The high-nickel alloys and Zircaloy-2 also show very good corrosion properties. Cast-iron materials suffered a significant, but not intolerable, corrosion in the Hanford ground-water medium; in the WIPP brines they were very severely attacked.

Experiments more relevant to anticipated repository conditions involving a slow flow of ground water through crushed rock at temperatures up to $250^{\circ} \mathrm{C}$ in a gamma radiation field up to $10^{6} \mathrm{rad} / \mathrm{h}$ are in the advanced planning stage.

Screening experiments were conducted to evaluate a large number of ceramic materials. The principal method used to screen the candidates was to subject samples of each material to a series of leaching tests to determine their relative resistances to attack by the leach solutions. A total of 14 ceramic materials, including two grades of alumina, plus graphite and basalt, were evaluated under both static and flow conditions using three different leach solutions: demineralized water, a synthetic Hanford ground water, and a synthetic WIPP brine solution. Test temperatures were in the range of $90^{\circ}$ to 
$250^{\circ} \mathrm{C}$. The ceramic materials screened were $99 \% \mathrm{Al}_{2} \mathrm{O}_{3}, 99.8 \% \mathrm{Al}_{2} \mathrm{O}_{3}$, mullite $\left(2 \mathrm{Al}_{2} \mathrm{O}_{3} \cdot \mathrm{SiO}_{2}\right)$, vitreous silica $\left(\mathrm{SiO}_{2}\right), \mathrm{BaTiO}_{3}, \mathrm{BaZrO}_{3}, \mathrm{CaTiO}_{3}, \mathrm{CaZrO}_{3}, \mathrm{CaTiSiO}_{5}$ $\mathrm{TiO}_{2}, \mathrm{ZrO}_{2}, \mathrm{ZrSiO}_{4}$, Pyroceram 9617, and Marcor Code 9658 machinable glass ceramic. Average leach rates were determined from analyses of the leach solutions and/or sample weight-loss measurements. After testing, selected specimens were subjected to ceramographic examination to determine if localized attack or alteration reactions had occurred.

Based on all of the results obtained, five of the materials, namely graphite, the two grades of alumina, $\mathrm{TiO}_{2}$ and $\mathrm{ZrO}_{2}$, exhibited much greater resistance to attack by the leach solutions than the other materials tested. Some of the other materials exhibited good leach resistance in one or two tests but, on an overall basis, were inferior to the five materials mentioned. In addition, most of the materials with poor leach resistance also appeared to be susceptible to alteration reactions, especially at $150^{\circ} \mathrm{C}$ and above.

Initially, 11 generic types of polymers were selected for evaluation. These included samples from all three of the major polymeric materials categories: thermoplastics, thermosets, and elastomers. All of these materials are commercially available. A number of specific materials were selected within each generic type which best represented that type of polymer for this application. The generic materials were: polyamide-imide, polyarylene, polyimide, polyolefin, polyphenylene sulfide, polysulfone, fluoropolymer, epoxy, furan, silicone, and ethylene-propylene terpolymer (EPDM) rubber. A total of more than 30 materials were tested either as neat polymers, such as polyolefins or fluoropolymers, or as composites containing glass fibers, other reinforcing materials, or fillers (e.g., polyimides, and polyphenylene sulfide) to enhance properties.

In these initial studies, samples were exposed to deionized water in auto$\mathrm{Claves}$ at $150^{\circ} \mathrm{C}, 200^{\circ} \mathrm{C}$, or $250^{\circ} \mathrm{C}$ (the maximum exposure temperature used depended upon the properties exhibited by the individual materials). Samples were also exposed to ionizing radiation (gamma) to a total dose of $5 \times 10^{8}$ rads. These exposures are intended as screening studies to further guide the 
selection of those polymers which hold promise as elements in barrier design. After exposure under the noted conditions, the surviving materials were tested for residual properties--tensile strength, elongation, and impact strength.

In testing at $150^{\circ} \mathrm{C}$, a number of polymers retain their properties: polyphenylene oxide, polymethypentene, polysulfones, and glass-reinforced polyimides. After $7 \mathrm{~d}$ at $200^{\circ} \mathrm{C}$, only furan, EPDM rubbers, filled polyphenylene sulfide, metal-filled epoxy, and fluoropolymer samples remained intact and retained good mechanical properties. Only EPDM rubber, polyphenylene sulfide, furan, and fluoropolymer materials survived the $250^{\circ} \mathrm{C}$ test. Polymers that appeared little affected by gamma doses of $5 \times 10^{8}$ rads were polyphenylene sulfide, polyimide, furan, and metal-filled epoxy. Both EPDM and fluoropolymer samples, although suffering considerable loss in elongation (caused by increased crosslinking) still retained good tensile strengths after radiation exposure. Impact measurements confirm the finding of the tensile measurements.

The most promising candidates for further study and potential use in engineered barrier systems are EPDM rubber, filled polyphenylene sulfide, fluoropolymer, and furan derivatives. 


\section{CONTENTS}

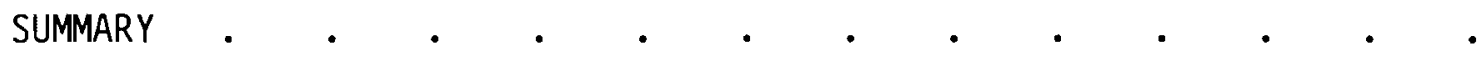

FIGURES

TABLES

xiv

INTRODUCTION

BACKGROUND

PROGRAM OBJECTIVE

APPROACH

METALLIC MATERIALS MECHANICAL PROPERTIES EVALUATION - S. G. Pitman

INTRODUCTION

MATERIAL SELECTION

EXPERIMENTAL METHODS

Tensile Tests

Fatigue-Crack-Growth Rate Tests (Air) . . . . . 20

Fatigue-Crack-Growth Rate (Environment) . . . . . 21

Fracture Toughness (Static) . . . . . . . . 23

Dynamic Fracture Toughness and Impact Toughness . . . 27

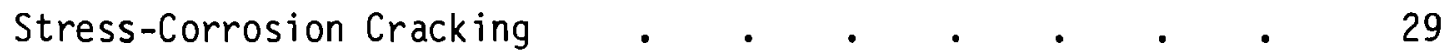

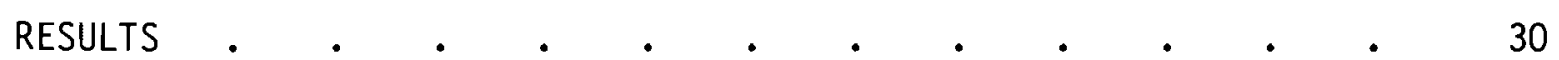

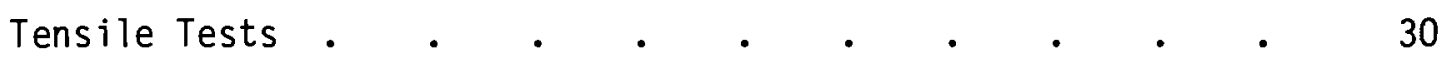

Fatigue-Crack-Growth Rate Tests . . . . . . . 31

Static Fracture Toughness Tests . $\quad$ • . . . . . 35

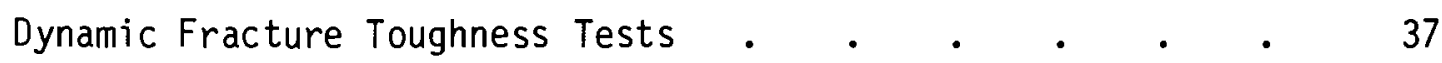

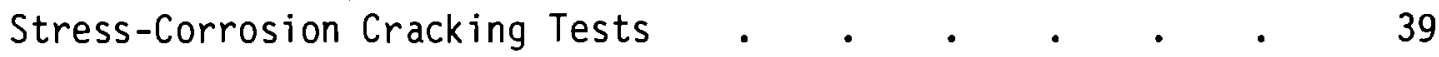

CONCLUSIONS 
METALLIC MATERIALS CORROSION PROPERTIES EVALUATION - B. Griggs • $\quad$ • 47

INTRODUCTION

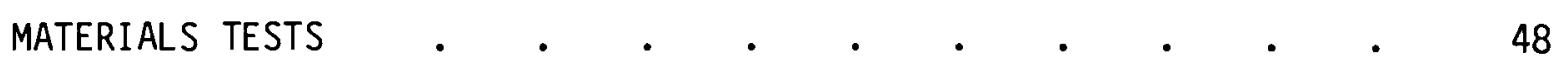

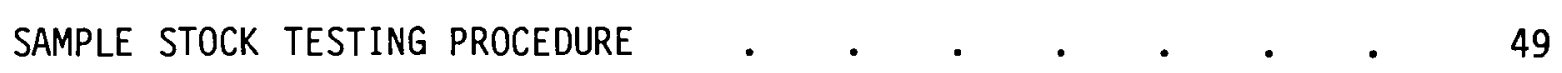

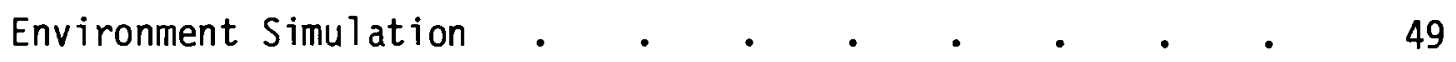

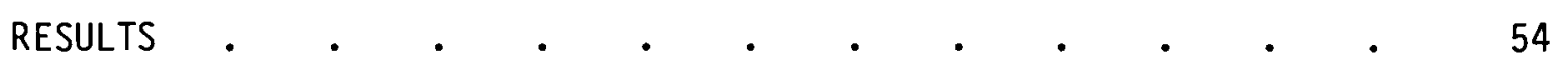

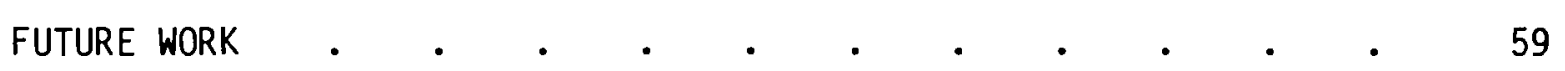

CERAMIC MATERIALS - H. T. Fullam . . . . . . . . . . . 63

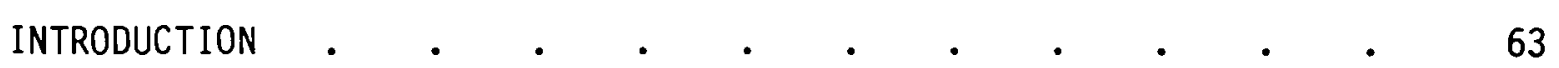

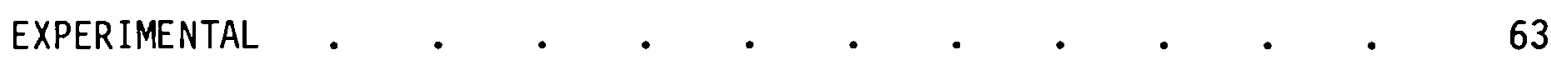

Static Leach Tests . . . . . . . . . . 65

Static Hydrothermal Leach Tests . . . . . . . 65

Dynamic (Flow) Leach Tests $\left(90^{\circ} \mathrm{C}\right)$. $\quad . \quad . \quad . \quad .66$

Dynamic (Flow) Leach Tests $\left(250^{\circ} \mathrm{C}\right) \quad$. $\quad . \quad . \quad . \quad .67$

Material/Repository Reaction Test . . • . . . . 67

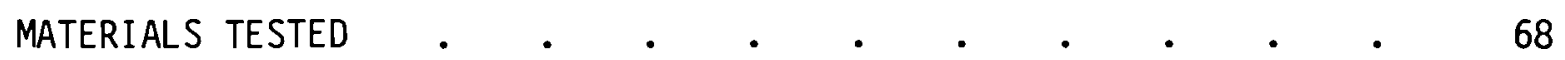

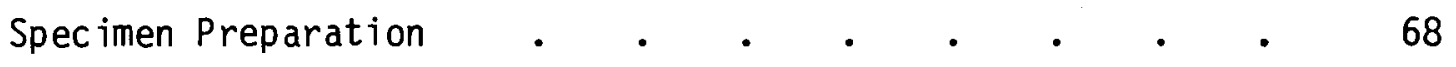

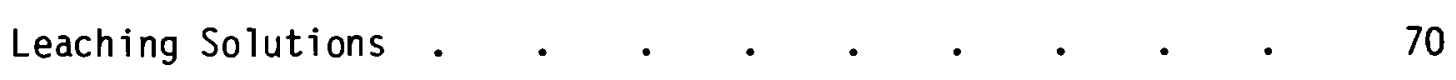

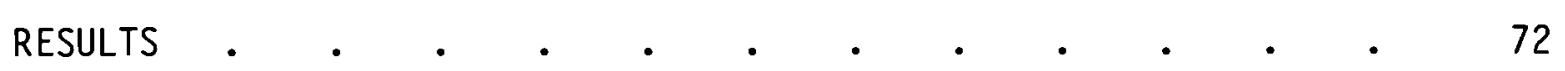

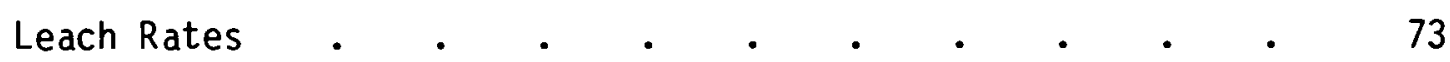

Dynamic (Flow) Leach Test $\left(250^{\circ} \mathrm{C}\right) \quad$. . . . . . 74

Dynamic Flow Leach Tests $\left(90^{\circ} \mathrm{C}\right)$. $\quad$. $\quad$ • $\quad$ • 77

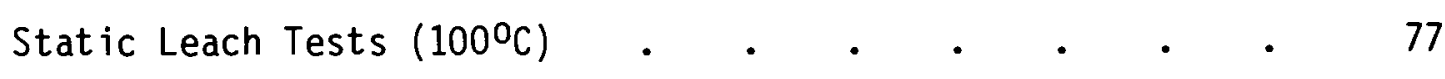

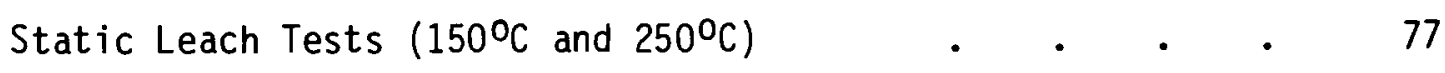

Comparison of Materials . . . . . . . . . 78

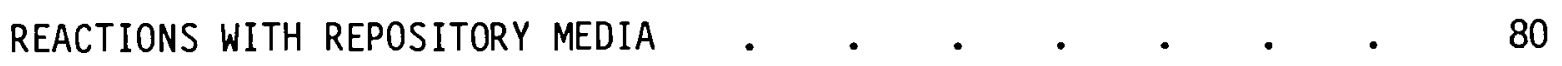




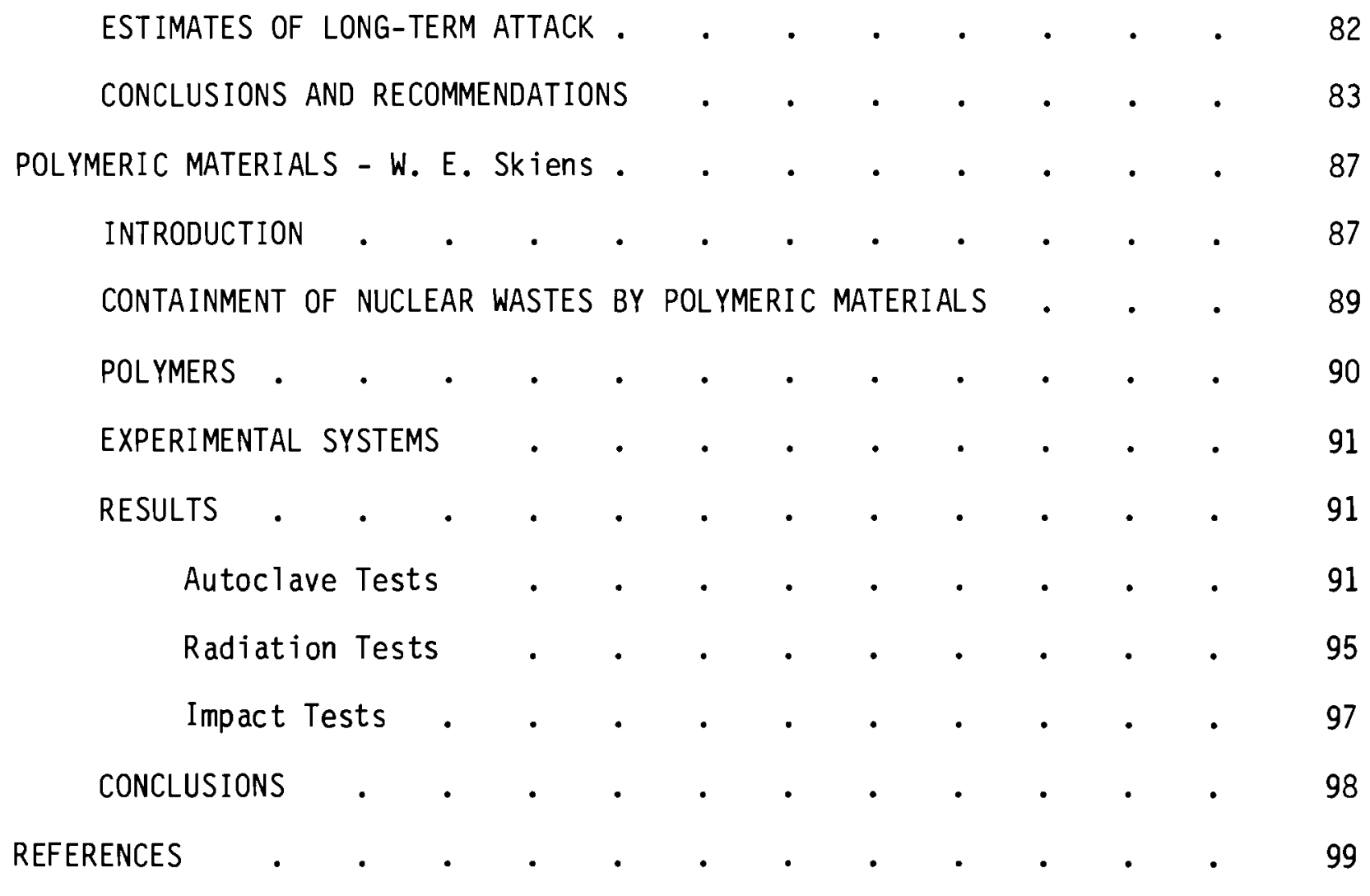


-

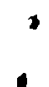

1

•

:

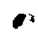




\section{FIGURES}

1 Pictorial Representation of Geologic Disposal Concept . $\quad$. 5

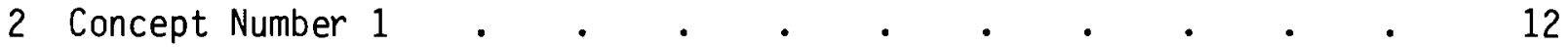

3 Concept Number 2 . 2 .

4 Concept Number 3 . 3 .

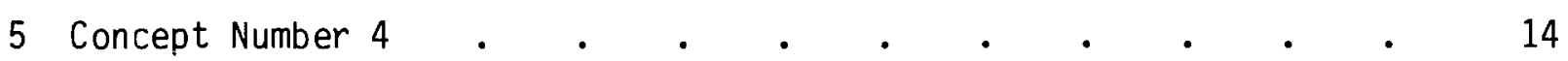

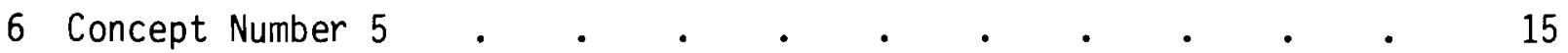

7 Concept Number 6 . 6 .

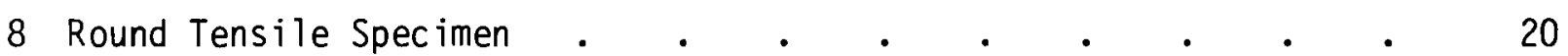

9 Compact Tension Specimen (ASTM E399) Modified to Accept a Clip Gage for Load-Line Displacement Measurement . . . . . . 21

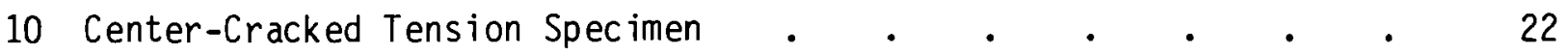

11 Environmental Test System for Fatigue-Crack-Growth Rate Testing

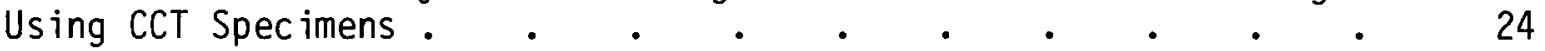

12 Schematic of Test Records for Multiple-Specimen J-Integral

13 a) Schematic of Heat-Tinted Specimen Showing Fatigue-Precracked Area, Stable Crack Extension, and Final Fracture; b) Schematic of Specimen Cross Section Showing Stretch Zone and Area of Material Separation Within Heat-Tinted Zone.

14 Schematic of R-Curve from Multiple-Specimen J-Integral Tests

15 Wedge-Opening Load Specimen Used for Stress-Corrosion Cracking Evaluation in Autoclave Tests . $. \quad . \quad . \quad . \quad . \quad . \quad 28$

16 Residual Stress Specimen Used in Stress-Corrosion Cracking Tests

17 Yield Strengths as a Function of Temperature for Grade-2

18 Yield Strength as a Function of Temperature for Grade-2 Titanium 
19 Comparison of Fatigue-Crack-Growth Rates of TL and LT

Orientations of Grade 2 Titanium Plate . . . . . . . . 33

20 Comparison of Fatigue-Crack-Growth Rates of TL and LT

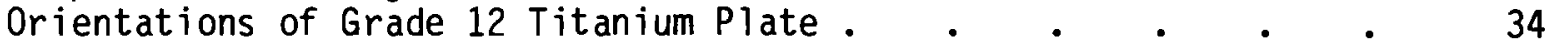

21 Comparison of Environmental Fatigue-Crack-Growth Rates of TL and LT Orientations of Grade 2 Titanium Sheet . . . .

22 Comparison of Environmental Fatigue-Crack-Growth Rates of TL

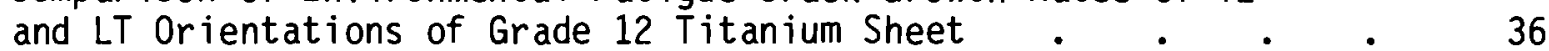

23 Fatigue-Crack-Growth Rate of Grades 2 and 12 Titanium, LT Orientation

24 Comparison of Fatigue-Crack-Growth Rates Grades 2 and and 12

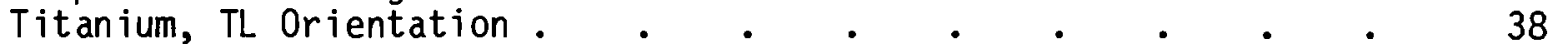

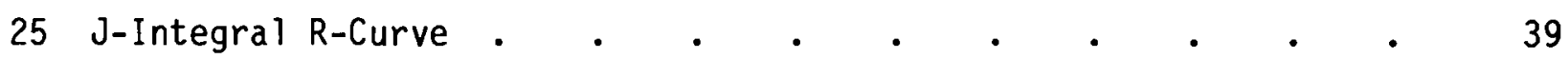

26 The Effect of Temperature on the Impact Energy of Grade 2

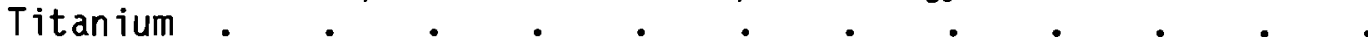

27 The Effect of Temperature on the Impact Energy of Grade 12

Titanium

28 The Effect of Temperature on the Static and Dynamic Yield

Strengths of Grade 2 Titanium . . . . . . . .

29 The Effect of Temperature on the Static and Dynamic Yield

Strengths of Grade 12 Titanium

30 The Static and Dynamic Fracture Toughness of Grade 2

Titanium

31 The Static and Dynamic Fracture Toughness of Grade 12

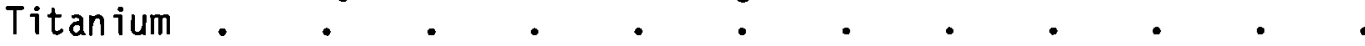

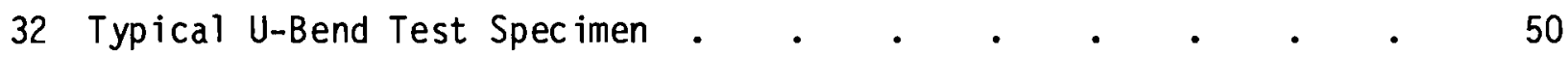

33 Autoclave Facility Used in Hanford Ground-Water Corrosion Tests

34 Section of Basalt Rock (Grande Ronde-Flow E) After 3 Months in Simulated Hanford Groundwater at $250^{\circ} \mathrm{C}$

35 Radiation/Corrosion Test Facility. 


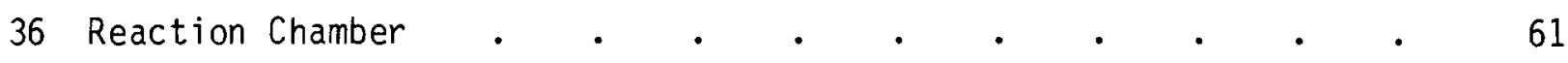

37 ( $a, b, c, d, e, f)$ Photomicrographs of Ceramic Specimens Before and

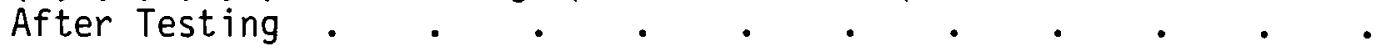




\section{TABLES}

1 Summary of Environmental Fatigue-Crack-Growth Rate Tests . . 23

2 Chemical Analysis of Simulated Repository Water . . . . 25

3 Summary of Static Tensile Data for Grades-2 and -12 Titanium Plate . • • • • • • • • • • . 32

4 Synthetic Hanford Ground Waters Formulation . . . . . 51

5 Brine Solution Composition . . . . . . . . . 53

6 Corrosion of Samples in Simulated Hanford Ground Water at $250^{\circ} \mathrm{C}$

7 Corrosion of Samples in $\mathrm{MgCl}_{2}-\mathrm{NaCl} \mathrm{Brine}$ at $250^{\circ} \mathrm{C}$. . . 56

8 Titanium Crevice Specimens Exposed in Hanford Ground Water

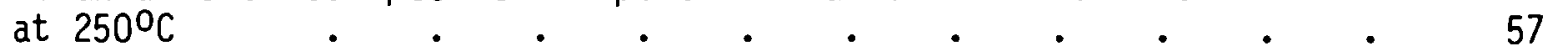

9 Materials Evaluated in the Screening Tests . . . . . 69

10 Average Leach Rates for Ceramic Materials Exposed to Flowing Demineralized Water at $250^{\circ} \mathrm{C}$. . . . . . . 75

11 Extent of Localized Attack or Alteration Reactions in Ceramic Materials Exposed to Flowing Demineralized Water at $250^{\circ} \mathrm{C}$. $\quad 76$

12 Relative Resistance of Ceramic Materials to Leaching Under Various Conditions--in Order of Decreasing Resistance . . .

13 Estimated Corrosion of Ceramic Materials Exposed to Flowing Demineralized Water at $250^{\circ} \mathrm{C}$. $\quad . \quad$. . . . .

14 Polymers Autoclaved in Flowing Deionized Water at Various Temperatures • • • • • • • • • • . 92

15 Testing of Polymers Exposed to Gamma Radiation . . . . 96

16 Impact Testing of Selected Polymers . . . . . . 97 


\section{INTRODUCTION}

A program directed toward the development of licensable engineered barrier systems for the long-term containment of high-level nuclear waste under conditions of deep geologic disposal has been underway at the Pacific Northwest Laboratory (PNL) since January 1979. The work has been funded by the U.S. Department of Energy (DOE), Division of Waste Products, as Task 3 of the PNL High-Level Waste Immobilization Program.

Metallic, ceramic, and polymeric materials are being investigated by means of mechanical property and materials degradation screening studies to determine the suitability of these materials for use as structural barriers in nuclearwaste packages. Individual materials from these broad material classes that have adequate mechanical properties and resistance to environment-induced degradation will be considered for application to waste package concepts. In-depth testing of these final candidates, with cost-benefit assessment of the materials and associated concepts, will provide the technological/economic basis for the final package design.

This report describes the status of the present program and the experimental results obtained through July 1980. The work is presented by subtask, and each major section is authored by the investigator primarily responsible for the work in his subtask. The sections are: "Metallic Materials Mechanical Properties Evaluation"; "Metallic Materials Corrosion Properties Evaluation"; Ceramic Materials"; and "Polymeric Materials". 
$\cdot$
$i$
$i$
$\cdot$ 


\section{BACKGROUND}

The concept for high-level nuclear-waste disposal ${ }^{(a)}$ currently receiving the most attention in the United States involves deep emplacement of waste in continental geologic formations. A geologic site for emplacement of waste will be selected after extensive, detailed studies of the physical, chemical, mechanical, seismic, and hydrologic properties of the spec ific geologic formation and the surrounding region have been conducted. A thorough understanding of the geologic formation is extremely important since it is expected to act over long time periods as the ultimate barrier to radionuclide migration to the biosphere.

Though the geologic medium is viewed as the ultimate barrier protecting the biosphere from excessive concentrations of radioactive materials, there is a recognition $(b)$ of the desirability of the added protection that would be provided by a localized system of engineered barriers that would last for $1,000 \mathrm{yr} .{ }^{(c)}$ Such a barrier system would offer primary protection to the biosphere during the early disposal period in which the geology is potentially most vulnerable to failure because of the high thermal loadings from the deposited waste. The toxicity of the waste is also highest during this period. (After 300 to 2,000 $\mathrm{yr}$, the ingestion toxicity of the high-level waste would be less than that of the ore that was used to generate the waste/ fuel initially. The large time span reflects different assumptions in the

(a) This report specifically addresses the disposal of solidified high-level waste. However, it is also generally applicable to the disposal of spent fuel.

(b) Report to the President by the Interagency Review Group on Nuclear Waste Management, TID-29442, March 1979; Management of Commercially Generated Radioactive Waste, Draft Environmental Impact Statement, D0E/EIS-0046-D, April 1979; 10 CFR 60, Subpart E, Proposed Draft 7, August 1979; 40 CFR 191, Subpart B, Proposed Draft 7, November 1979; NWTS Waste Package Program Plan, ONWI-96 (draft), May 1980.

(c) If a time period is specified for near-field radionuclide containment, it will likely be matched to the main fission-product heat-liberation period, which is essentially over in $\sim 400 \mathrm{yr}$. The time period of $1,000 \mathrm{yr}$ chosen in the current program reflects a conservative approach to barrier system design by requiring that the barrier system last for twice the period of high fission-product activity. 
nature of the ore and the associated calculations.) In addition, the engineered barrier system offers the biosphere protection from inadvertent intrusion by man in the future. This protection is primarily derived because wastes are constrained to the near-field region associated with each canister, which reduces the probability that an exploratory drill, for example, would enter an area of dangerously high radioactivity. Thus, the engineered barrier system would protect the biosphere even though the geologic barrier had been breached.

A pictorial representation of the features associated with conventional continental geologic disposal is shown in Figure 1. The present task is involved only with the barriers lying between the waste form and the backfill material, i.e., the canister, the overpack, and the hole sleeve(a) (if one exists). Ordinarily the waste form is included in the term "engineered barriers"; however, in the present program the waste form is not considered a part of the 1,000-yr containment since the development of this important radionuclide-containing feature is the subject of other extensive research and development efforts. Eventually, the characteristics of the waste form that affect radionuclide dispersibility, such as solubility and leachability, must be factored into the overall analys is of the engineered barrier system. For the present, the leaching and solubility characteristics of typical waste glasses and spent fuel pellets will be used in predicting the behavior of the waste form(s). If additional improvements are made in waste forms, these characteristics will be modified accordingly. It is recognized that active discussions are required with groups investigating waste forms and the characteristics of geologic media.

Note (Figure 1) that all of the engineered barriers considered in the present program lie within that part of the overall disposal system defined as the "package."

(a) The canister is the primary waste container. The overpack is a secondary container surrounding the canister and is transported and emplaced along with the canister. The hole sleeve is a cylindrical pipe-like element placed in the borehole to ease emplacement and retrievability. The hole sleeve might also serve as an engineered barrier. 


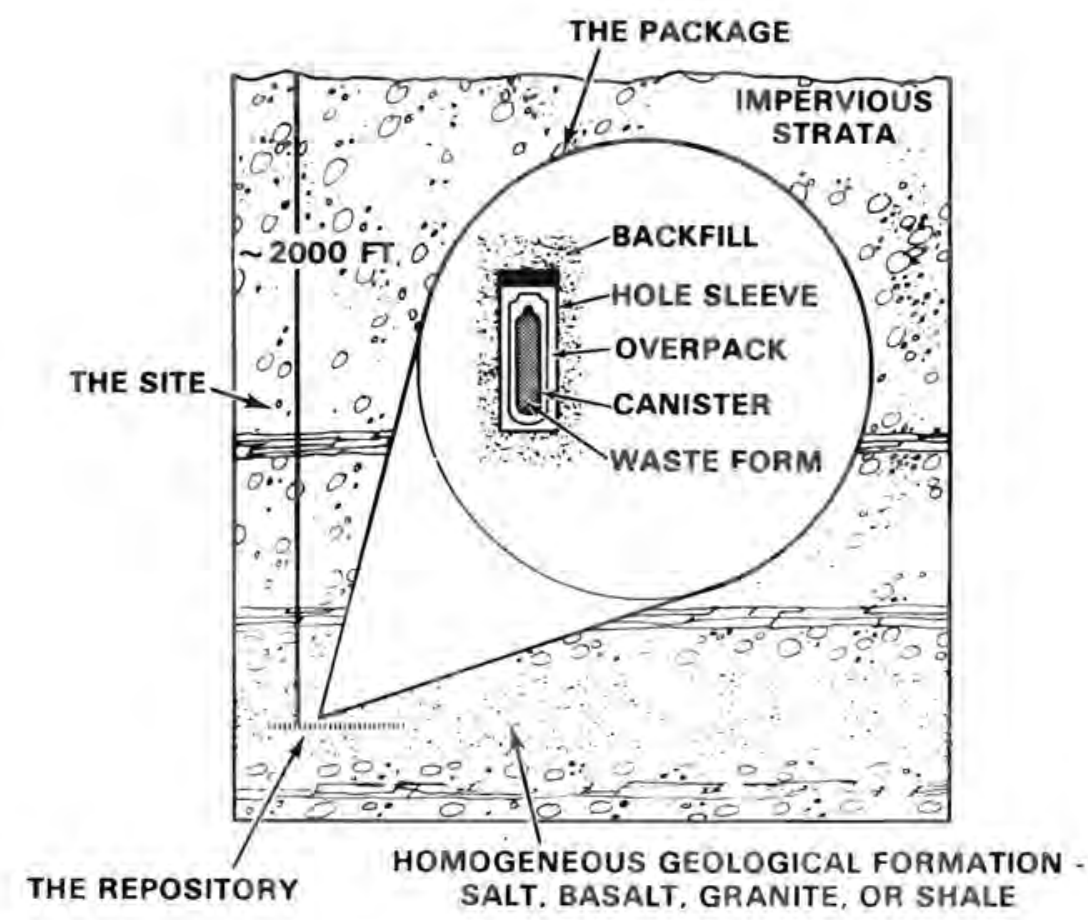

\section{FIGURE 1. Pictorial Representation of Geologic Disposal Concept}

We recognize that a formal decision has not been made to proceed with a 1,000-yr engineered barrier system. However, it appears obvious that some barrier system will be incorporated in the very-near field of the repository. Because of the long lead time required for the development of any substantive barrier system, including such requirements as the development of a corrosion/ crack propagation data base that can be extrapolated out to the time periods of interest, a strong barrier development effort must be mounted before official barrier performance criteria become available. If at a later date the required barrier longevity is defined to be less than 1,000 yr, then the present program should readily fulfill the requirements of the lesser objectives. 
. . 
The objective of the program is the development of materials and preliminary design concepts for application to licensable engineered barrier systems for the primary containment of high-level radioactive wastes in geologic repositories. The barrier elements considered consist of the canister, the overpack, and the hole sleeve. The individual barrier elements will be designed to contribute substantially to a barrier system that will hold radioisotope release rates to near-zero values in the near-field geology for time periods of $\sim 1,000 \mathrm{yr}$.

The engineered barrier system must be designed to resist design-basis accidents, and the individual elements of the barrier system must be designed to resist common-cause failure. 
:

1

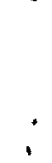




\section{APPROACH}

The development of an effective, licensable nuclear-waste package is a complex task requiring close cooperation between the materials specialists responsible for the barrier system elements, the groups responsible for wasteform development, and the groups responsible for characterization of the repository environment. The present engineered-barrier development task represents only a part of the total effort involved, but it in itself must be guided by a comprehensive plan because of the inherent complexities in materials selection and their testing under repository-relevant conditions. The plan is flexible since new data and new requirements are expected as the developmental work proceeds. Also, the plan does not dictate, or fundamentally depend on, the specific laboratory(ies) performing the various work elements.

The elements of the plan are presented below in approximate correspondence to the logical chronological order of accomplishment:

- Establishment of Package Longevity Requirements--In the present task, longevity has been set at 1,000 yr. It is possible that this longevity requirement eventually will be more closely matched to the fission-product heat-liberation period, which essentially ends in ح400 $\mathrm{yr}$. The time period of 1,000 $\mathrm{yr}$ chosen in the current task reflects a conservative approach to barrier system design by requiring that the barrier system last for approximately twice the period of high fission-product activity.

- Selection of Promising Candidate Barrier Materials--Metallic, ceramic, polymeric, and graphitic (a) materials are all potentially useful in barrier-system applications. Candidate materials from each of these broad material classes have been selected for corrosion and mechanical testing relevant to expected barrier service conditions.

(a) Graphitic materials offer great potential in their own right as barrier materials. In the current effort, however, they are included with the ceramic materials. 
The materials were selected on the basis of detailed literature surveys, vendor recommendations, and consultations with other research and development organizations.

- Development of Preliminary Packaging Concepts--A group of preliminary packaging concepts utilizing materials from the major material classes mentioned above have been developed for purposes of discussion. These concepts are presented in Figures 2 through 7 . The oxygen activity in the environment was considered a major factor in the development of these concepts, primarily because of its profound effect on the stability of metals.

No detailed engineering analyses have been performed on any of the concepts presented; therefore, the range of applicability of materials potentially sensitive to heat and radiation, such as polymers and concretes, has yet to be defined.

- Performance of Screening Studies to Identify Most Promising Materials--The candidate barrier materials, selected initially on the basis of literature surveys and consultations with other investigators, are undergoing laboratory-scale corrosion and mechanicalproperty screening tests. These tests will serve to reduce the initial large number of candidate materials to the few that can be tested in the in-depth fashion required for actual barrier service certification. Where possible, the tests will be performed under conditions relevant to specific candidate repositories, e.g., WIPP brine and Hanford basalt.

- Anticipation of Barrier Material Failure Mechanisms and Performance of Rigorous Conservative Tests--Materials appearing most useful to barrier system applications after completion of the screening studies will be tested in a rigorous fashion to reveal any susceptibility to degradation under severe-service simulation conditions. Where known potential susceptibilities exist, such as hydrogen embrittlement of titanium alloys, the phenomena will be investigated in depth to determine safe application limits. 
The severity of the test(s) will be relied upon, in general, to reveal unanticipated modes of material degradation.

- Final Designs of Site-Specific Barrier Systems Based on Applicable Materials, Engineering Analys is of Systems, and Cost-Benefit Assessments--Many satisfactory solutions to the problem of nuclear waste packaging exist. The most efficient solution to the problem will require a careful analysis of all engineering factors associated with a repository as well as the economic aspects of all package components.

It is part of the operating philosophy of the present program that at least two long-lived barriers, exclusive of the waste form and the geologic medium, will be designed into each package system. Each of the barriers will offer a high statistical probability of lasting for the full, desired package lifetime. Common-cause failure will be anticipated and avoided. This approach provides assurance of barrier redundancy.

- Prototype Waste Packages U1timately Validated by In-Situ Studies--It is anticipated that the prototype waste packages (including, by definition, the appropriate barrier systems) will be validated eventually by means of in-situ tests that are wholly relevant to the specific disposal sites for which the packages are intended. The in-situ tests should duplicate the most severe conditions expected in each environment, including the effects of temperature, pressure, stress, and radiation. (It is possible that these in-situ studies could be best accomplished in "pseudo"-sites, i.e., large pressure vessels containing site-relevant environments.)

At the present time the barrier program at PNL is primarily involved in conducting screening studies, although some in-depth investigations are underway, notably in the mechanical testing area. The actual status of the subtask work elements, and the results obtained to date, are presented in the following sections of the report, each authored by the principal PNL investigator in that technical area: 


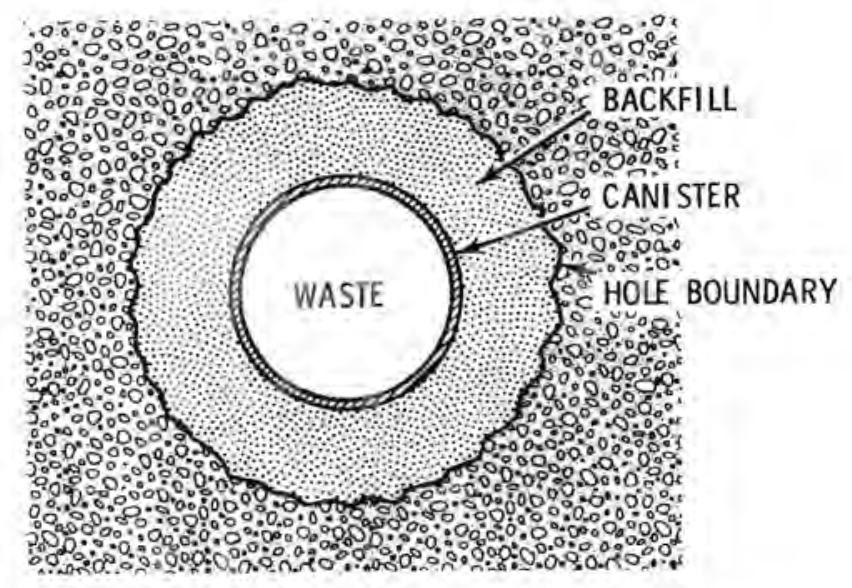

- Number of engineered barriers, exclusive of waste form: 2 (canister, backfill)

- Materials for canister

- Oxidizing environment: Ti-base, $\mathrm{Zr}$-base, $\mathrm{Fe}-\mathrm{Cr}$. $\mathrm{Ni}-\mathrm{Cr}$ alloys; ceramics, graphite

- Anoxic environment: Cu-base, Fe-base alloys; possibly $\mathrm{Fe}-\mathrm{Cr}$, $\mathrm{Ni}-\mathrm{Cr}$ alloys; ceramics, graphite

- Emplacement procedure: Canister placed in hole, backfill added

- Backfill may be used to adjust Eh and pH of environment, to promote canister longevity

- Canister processing must not adversely affect canister longevity, if canister is to be considered a barrier

FIGURE 2. Concept Number 1. Simplest engineered barrier system. Compatible with either anoxic or oxidizing conditions but not with both

- Metallic Materials Mechanical Properties Evaluation--S. G. Pitman

- Metallic Materials Corrosion Properties Evaluation--B. Griggs

- Ceramic Materials--H. T. Fullam

- Polymeric Materials--W. E. Skiens. 


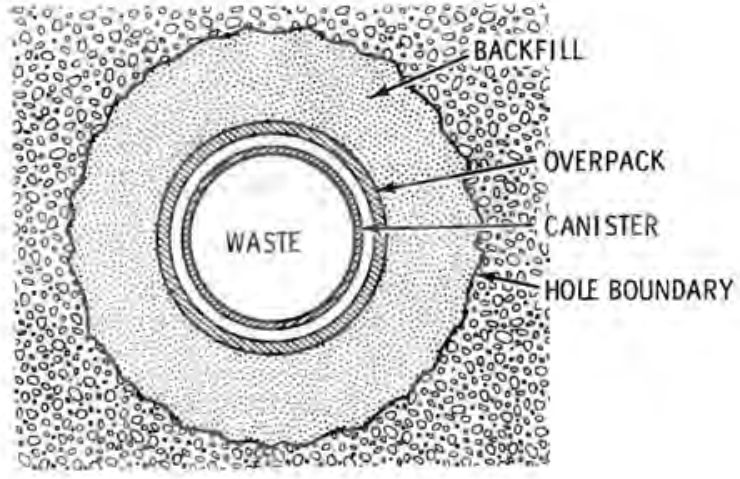

- Number of engineered barriers, exclusive of waste form: 3 (canister, overpack, backfill)

- Materials for canister, overpack: Ti-base, Zi-base, $\mathrm{Fe}-\mathrm{Cr}$, or $\mathrm{Ni}-\mathrm{Cr}$ alloys; ceramics, graphite

- Emplacement procedure: overpacked conister placed in hole, backfill added

- In principle, overpack could be replaced by borehole sleeve

FIGURE 3. Concept Number 2. Engineered barrier system compatible with oxidizing conditions, utilizing an overpacked canister

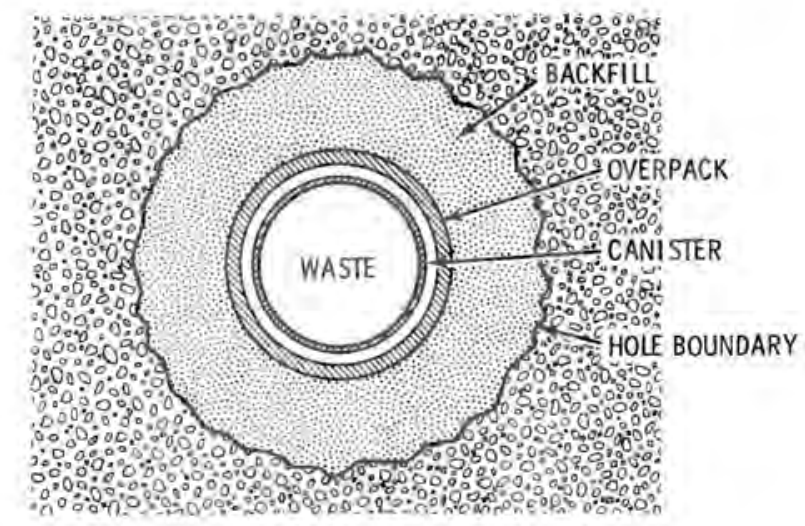

- Number of engineered barriers, exclusive of waste form: 3 (canister, overpack, backfill)

- Materials for canister, overpack: Cu, Cü-base alloys: $\mathrm{Fe}$-base, Ni-base alloys; ceramics, graphite

- Emplacement procedure: overpacked canister placed in hole, backfill added

- In principle, overpack could be replaced by borehole sleeve

FIGURE 4. Concept Number 3. Engineered barrier system compatible with anoxic conditions utilizing an overpacked canister 


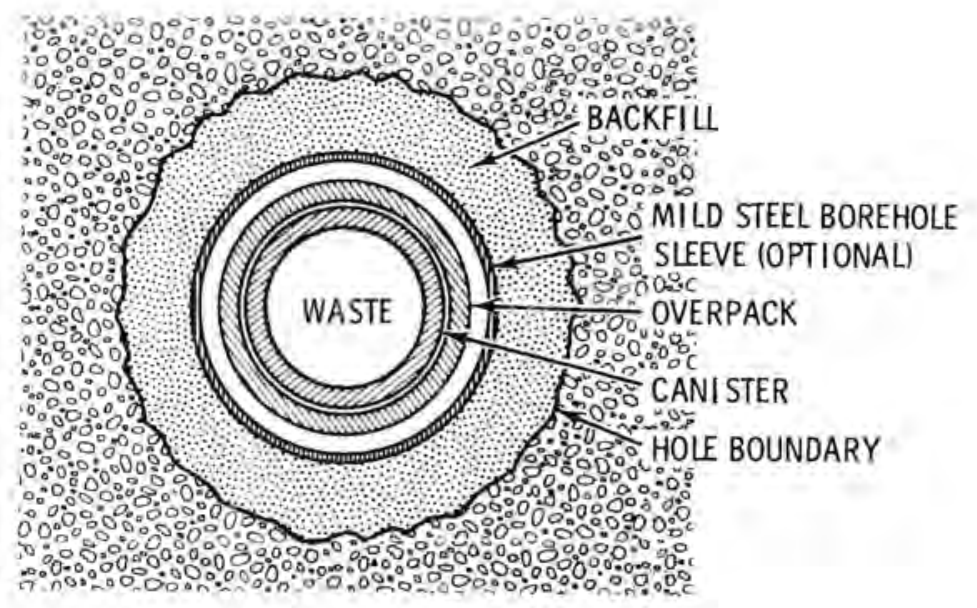

- Number of engineered barriers, exclusive of waste form: 3 (canister, overpack, backfi!!!

- Materials for overpack: Ti-base, $\mathrm{Zr}$-base alloys; $\mathrm{Ni}-\mathrm{Cr}$. $\mathrm{Fe}-\mathrm{Cr}$ alloys; ceramics; graphite

- Materials for canister: Cu, Cu-base alloys; Fe-base, Ni-base alloys

- Emplacement procedure: Overpacked canister placed in sleeved borehole. If borehole is not sleeved, overpacked canister is placed in borehole, backfill then added. Note that the borehole sleeve is not considered a barrier in this concept.

FIGURE 5. Concept Number 4. Engineered barrier system compatible with both oxidizing and anoxic environments. Overpack resistant to oxidizing conditions, canister resistant to anoxic conditions 


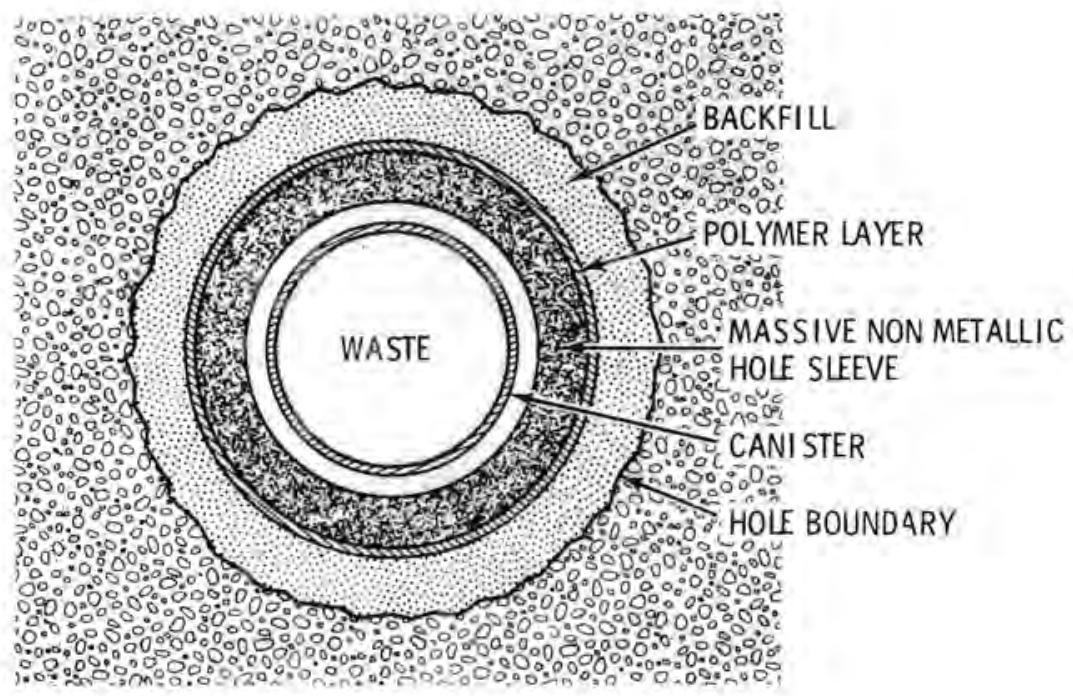

- Number of engineered barriers, exclusive of waste form: 4 (canister, concrete, polymer, backfill)

- Materials for canister: Cu, Cu-base alloys; Fe-base, $\mathrm{Ni}$-base alloys

- Materials for hole sleeve: Concrete; polymer concrete; ceramic; graphite

- Emplacement procedure: Canister placed in hole sleeve. Concrete hole sleeve sealed. Polymer containment sealed. Backfill added.

FIGURE 6. Concept Number 5. Engineered barrier system compatible with both anoxic and oxidizing conditions featuring massive nonmetallic hole sleeve 


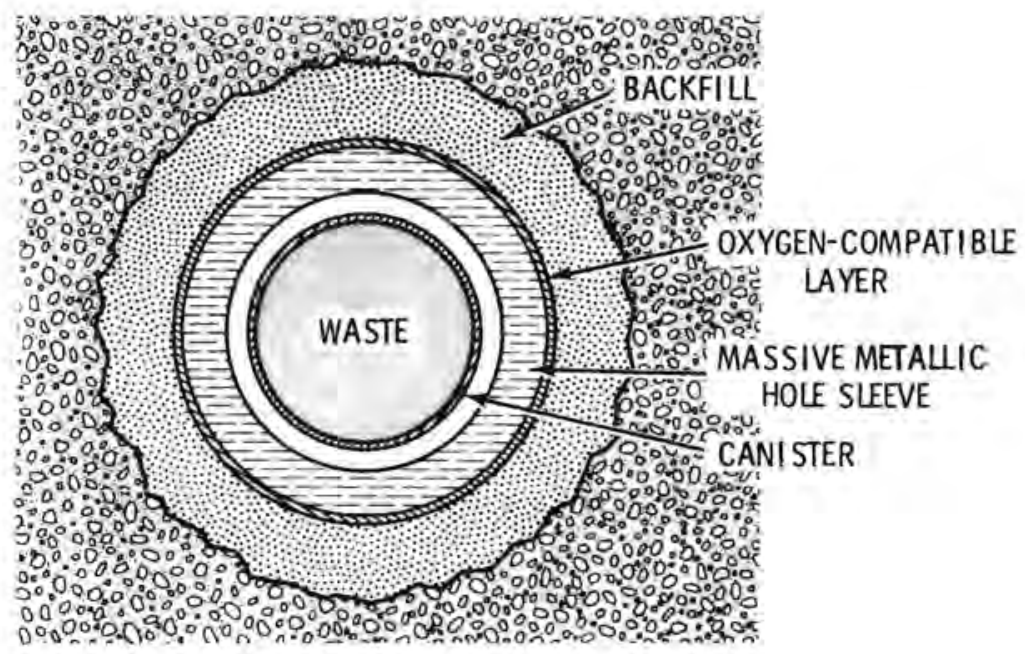

- Number of engineered barriers, exclusive of waste form: 4 (canister, hole sleeve, hole sleeve protective layer, backfill)

- Materials for canister: $\mathrm{Cu}, \mathrm{Cu}$-base alloys; Fe-base, Ni-base alloys

- Materials for hole sleeve: Cast iron; Cu, Cu-base alloys

- Materials for oxygen-compatible layer: Ti-base, $\mathrm{Zr}$-base alloys; polymer

- Emplacement procedure: Canister placed in hole sleeve. Hole sleeve sealed. Oxygen-compatible layer sealed. Backfill added.

FIGURE 7. Concept Number 6 . Engineered barrier system compatible with both oxidizing and anoxic conditions featuring a massive metallic hole sleeve 


\title{
METALLIC MATERIALS MECHANICAL PROPERTIES EVALUATION
}

\author{
S. G. Pitman
}

\section{INTRODUCTION}

The objective of this work is to evaluate the pertinent mechanical properties of candidate alloys useful in engineered barrier systems applications and the effects of repository environments on these properties.

Mechanical properties studied in this task include those which have significance as design parameters, e.g., tensile strength and fracture toughness, and those properties which are most likely to be used to assess environmental degradation, e.g., resistance to crack growth under stress-corrosion or corrosion-fatigue conditions. This approach will permit selection of suitable materials for use in engineered barrier systems while providing some pertinent design information on these alloys. It is worth noting that the program is currently in the material selection stage; therefore, not all of the data presented here is expected to be of significance in engineering design.

Several different techniques for material selection are being used in this task, including static stress-corrosion tests, static and dynamic fracture roughness tests, fatigue-crack-growth rate tests, and environmental fatiguecrack-growth rate tests. A brief explanation of the relevance of this testing approach follows.

The toughness of a material is generally defined as the ability of the material to carry a load (or deform plastically) in the presence of a notch, or some other form of $\mathrm{flaw}$ or defect. Materials that demonstrate a high degree of fracture toughness can tolerate high stress concentrations without failing by crack propagation. Stress concentrations can, in general, be increased by either increasing the stress or by increasing the size of the flaw(s) in a structural member. $\mathrm{Flaws}$ are present in any structure; their initial size can be controlled, or at least defined, by inspection techniques. The magnitude of stress in a structure is determined by design considerations and is a 
combination of both residual and applied stresses. Knowing the fracture toughness $^{(a)}$ of a material, it is possible to calculate allowable flaw sizes for a given stress level, or to calculate the maximum allowable stress knowing the detectable flaw length. Therefore, one of the principal objectives of the present task is to determine basic fracture toughness data on the most promising candidate barrier materials.

Fatigue-crack-growth rate data are being used in three ways: as an aid to material selection, as an assessment of environmental degradation, and as a design parameter. The fatigue-crack-growth rate of a material is especially useful for assessing susceptibility to environmental degradation since a growing fatigue crack continually exposes fresh metal to the environment. This continual film-breaking associated with fatigue makes fatigue-crack-growth rate testing a more severe, and therefore conservative, evaluation of the ability of a material to withstand environmental attack. The environmental fatigue crack-growth rate test is primarily an accelerated test which can evaluate the effects of environments on materials and which can also provide useful design information. Fatigue-crack-growth rate data in air and repository environments are particularly useful when employed with fracture toughness data and anticipated stress levels to predict growth of a crack under repository conditions.

Other environmental tests involving statically loaded specimens were performed under the corrosion subtask (see the section of this document entitled "Metallic Materials Corrosion Properties Evaluation").

\section{MATERIAL SELECTION}

Extensive mechanical and environmental testing is relatively expensive and time consuming. For this reason, complete characterization tests could

(a) The fracture toughness of a material that tends to fail in a brittle fashion is generally expressed in terms of $\mathrm{K}_{\mathrm{IC}}$, the critical stress concentration necessary to cause a crack to grow under given environmental conditions. The fracture toughness of materials that exhibit some ductility during the crack propagation process is generally described in terms of $\mathrm{J}_{\mathrm{I}} \mathrm{c}$. The metallic materials tested in this task fall in the latter category. 
not be carried out on each material of interest. Instead, a parallel testing approach was taken, in which thorough testing was begun on the most promising materials at the same time that a screening program was in progress. A corrosion screening program was initiated to identify possible candidate barrier materials. The best candidates from the screening program will be considered for further mechanical and corrosion characterization.

Titanium alloys Grades 2 and $12^{(a)}$ were chosen as the first materials for thorough characterization on the basis of a literature review, preliminary environmental data, and work done by other researchers (Braithwaite and Molecke 1979; Braithwaite, Magnani and Munford 1979). These alloys have good strength and ductility and excellent corrosion resistance in many environments. Grade 12 is noted for its resistance to pitting and crevice corrosion at elevated temperatures.

It should be emphasized that no alloy or alloys have been finally selected for barrier application; the current work is intended simply to evaluate the pertinent mechanical properties of two candidate alloys considered to be especially promising on the basis of available evidence.

\section{EXPERIMENTAL METHODS}

\section{Tensile Tests}

Tensile tests were conducted between $20^{\circ}$ and $250^{\circ} \mathrm{C}$ using specimens of the type shown in Figure 8. At room temperature, strain was monitored with an extensometer until after the yield point had been reached; at higher temperatures the load versus crosshead displacement was monitored. Each specimen was loaded at a constant crosshead rate of $0.001 \mathrm{in./min}$ unt $i 1$ the yield point was exceeded. The crosshead rate was then changed to $0.005 \mathrm{in.} / \mathrm{min}$ until fracture.

Yield strength and ultimate tensile strength were calculated using the load at $0.2 \%$ elongation and the maximum load, respectively. Percent

(a) Grade 2 is a commercial purity titanium grade; Grade 12 contains nominally $0.8 \mathrm{wt} \% \mathrm{Ni}$ and $0.3 \mathrm{wt} \%$ Mo. 


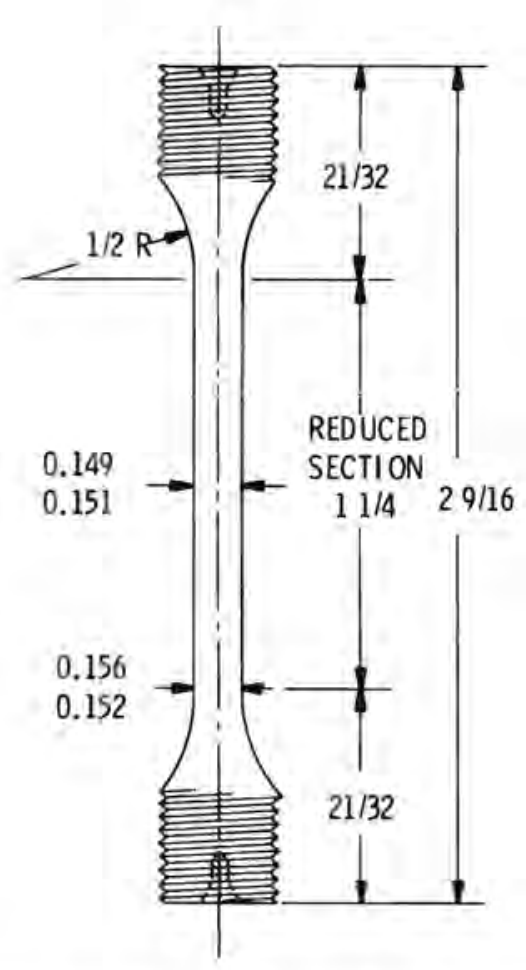

FIGURE 8. Round Tensile Specimen (all dimensions in inches)

elongation was determined from the extension of a 1-in. gage section. Reduction of area was calculated using the diameter of the specimens before the test and the average diameter of the fracture surface after the test.

\section{Fatigue-Crack-Growth Rate Tests (Air)}

Tests of the fatigue-crack-growth rate were conducted in air using center-cracked tension (CCT) and compact tension (CT) specimens. These methods allowed both alloys to be tested in sheet and plate form. Two orientations of each alloy, at room temperature and $90^{\circ} \mathrm{C}$, are to be tested, but the test matrix is not yet complete.

The compact-tension specimen, shown in Figure 9, was used for fatiguecrack-growth rate characterization of the titanium plate. Both visual (trave1ling microscope) and compliance techniques were used to determine the crack length. These tests were conducted at $10 \mathrm{~Hz}$ frequency. Crack length was 


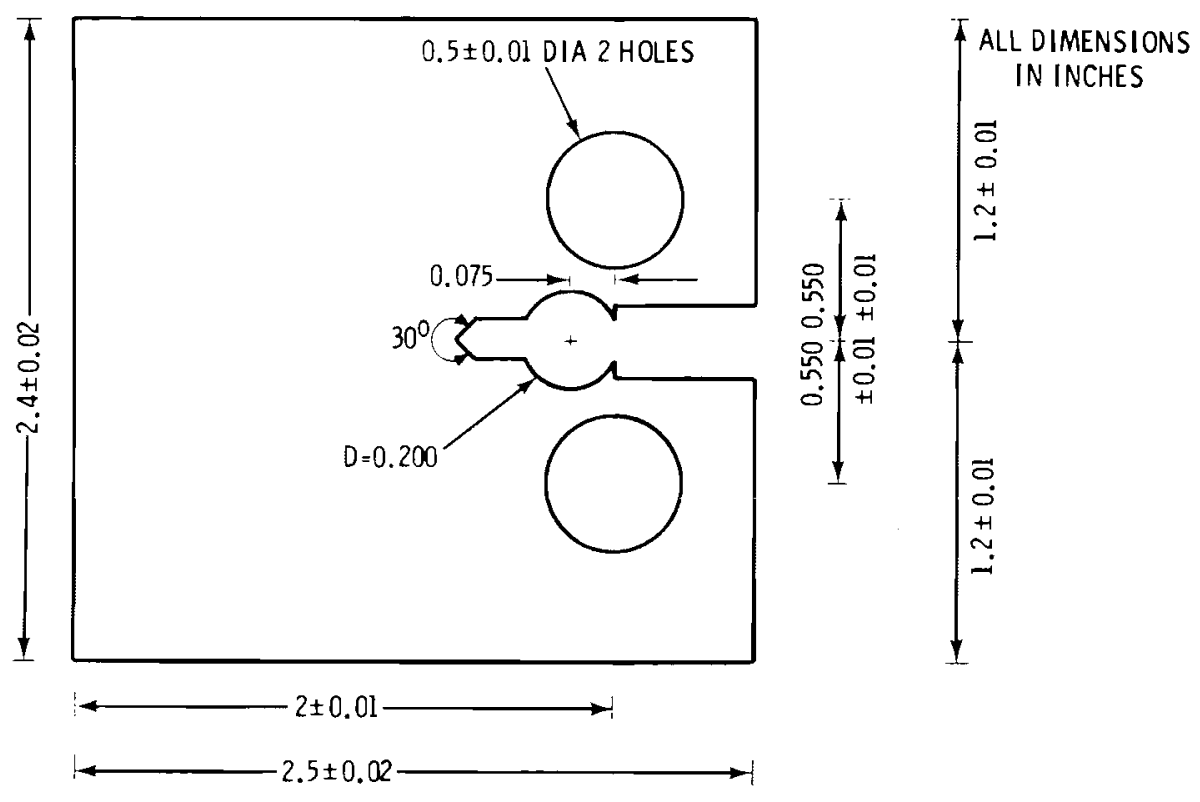

FIGURE 9. Compact Tension Specimen (ASTM E399) Modified to Accept a Clip Gage for Load-Line Displacement Measurement

measured at 0.05-in. intervals, and average stress over each interval was calculated as per ASTM E399 (Plane-Strain Fracture Toughness of Metallic Materials E399-78).

Center-cracked (CCT) tension specimens, as shown in Figure 10, were used to evaluate the crack-growth characteristics of titanium sheet. These tests were performed at 5 and $10 \mathrm{~Hz}$, using procedures and data analysis as presented by Westinghouse Electric Corporation (1978). Stress intensity for the CCT specimens was calculated by the formula (Tada et al. 1973):

$$
K_{I C}=\sigma \sqrt{\pi a} F(a / b)
$$

where a equals crack length; $b$ equals specimen length; and where $F(a / b)$ is approximated by $\left(1-0.025(a / b)^{2}+0.06(a / b)^{4} \sqrt{\sec a n t \pi a / 2 b}\right.$.

Fatigue-Crack-Growth Rate (Environment)

Fatigue-crack-growth rate tests were conducted in a simulated repository environment at $87^{\circ}$ to $90^{\circ} \mathrm{C}$. Tests were performed on sheet specimens of 


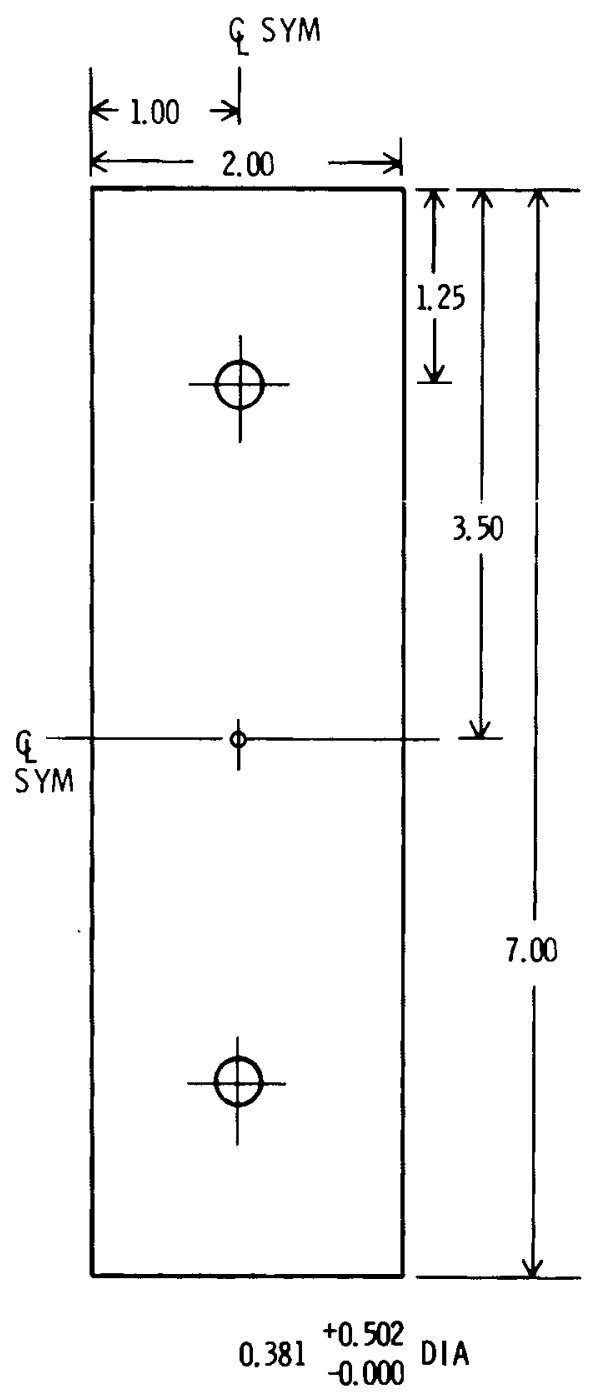

FIGURE 10. Center-Cracked Tension Specimen (all dimensions in inches)

titanium alloys 2 and 12 in both longitudinal (LT) ${ }^{(a)}$ and transverse (TL) or $i-$ entations. A summary of the tests is given in Table 1.

For the environmental tests, a system was set up to circulate a preheated simulated ground-water solution through a chamber surrounding the cracked area

(a) The first letter refers to the direction of loading, i.e., longitudinal (rolling direction) in this case; the second letter refers to the direction of crack propagation, in this case transverse (perpendicular to the rolling direction). 
TABLE 1. Summary of Environmental Fatigue-Crack-Growth Rate Tests

\begin{tabular}{|c|c|c|c|}
\hline $\begin{array}{l}\text { Specimen } \\
\text { Number }\end{array}$ & Material & Orientation & Temperature \\
\hline M267 & $T i-12$ & $\overline{L T}$ & $87^{\circ}$ to $90^{\circ} \mathrm{C}$ \\
\hline M268 & $\mathrm{Ti}-12$ & $T L$ & $90^{\circ} \mathrm{C}$ \\
\hline M269 & $T i-2$ & LT & $90^{\circ} \mathrm{C}$ \\
\hline M270 & $T i-2$ & $T L$ & $90^{\circ} \mathrm{C}$ \\
\hline M271 & $T i-2$ & $T L$ & $90^{\circ} \mathrm{C}$ \\
\hline M272 & $\mathrm{Ti}-12$ & $T L$ & $90^{\circ} \mathrm{C}$ \\
\hline M273 & $T i-2$ & $T L$ & $90^{\circ} \mathrm{C}$ \\
\hline
\end{tabular}

of the specimen. This test system, illustrated in Figure 11, uses a siphon system and a screw-clamp flow control method. Temperature is controlled using a copper-constantan thermocouple inside a stainless steel sheathing and a power-proportioning controller. The flowing environmental solution is preheated by wrapping the inlet tube around heating elements.

Chemical analysis of the simulated ground-water solution used for these environmental tests is given in Table 2. The solution is made up to simulate one Hanford basalt ground-water chemistry. Oxygen control of the solution was not attempted in these studies, although it is recognized that the solution's oxygen fugacity is a particularly important parameter and one that must be carefully controlled in truly site-relevant studies. These tests are intended primarily to discover possible material problems at an early stage, not to provide design data. It is anticipated that further tests will be run under more site-relevant conditions when the definition of such conditions becomes available.

Fracture Toughness (Static)

Static fracture toughness tests were performed on 1/2-in. plate of titanium Grades 2 and 12 at room temperature using compact tension specimens, as shown in Figure 9. Because an initial test showed that the plate thickness was not sufficient for $\mathrm{plane}$ strain to exist at fracture, standard linear elastic fracture toughness tests are not applicable. The J-integral test was chosen as the most thoroughly developed elastic-plastic fracture toughness 


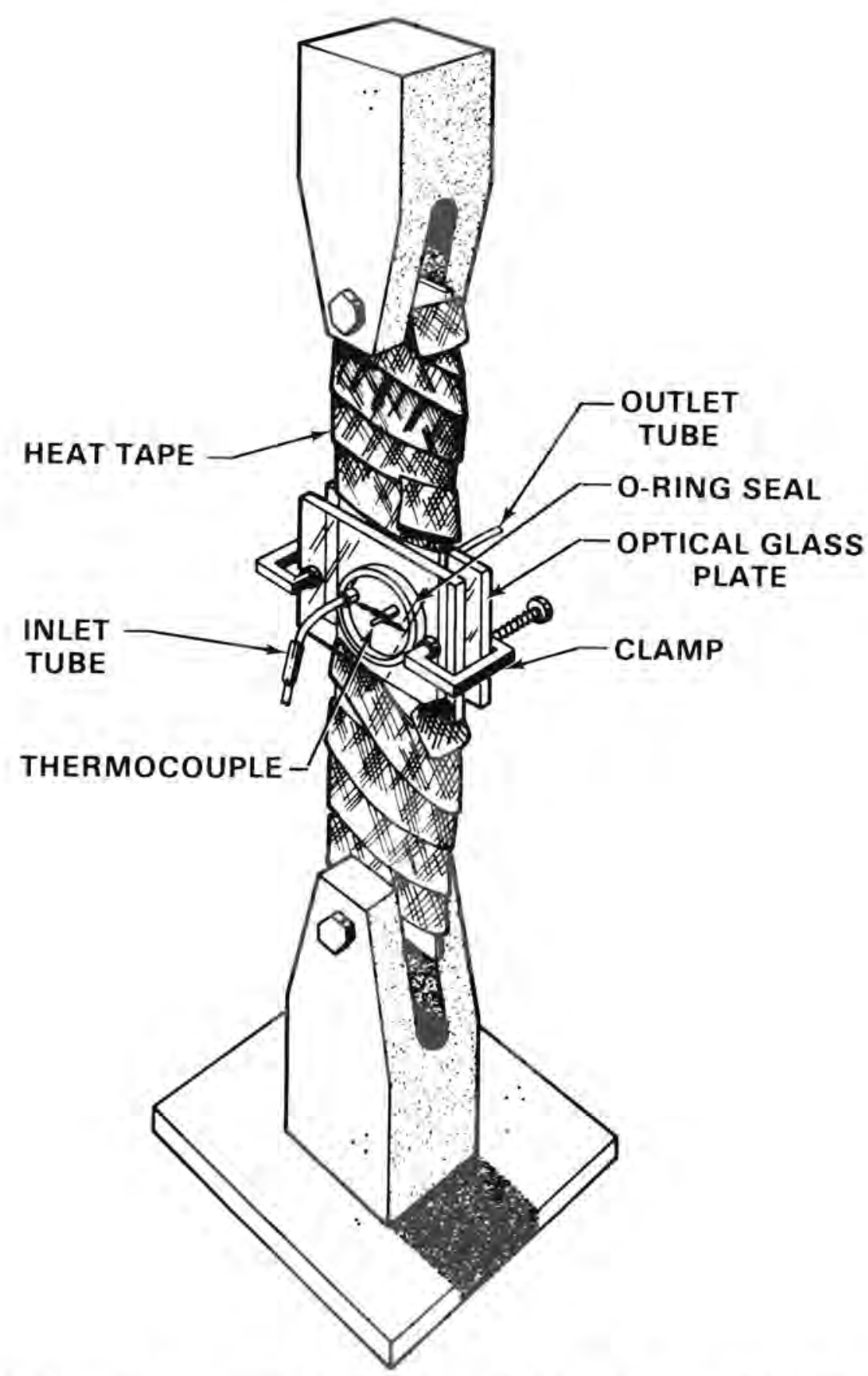

FIGURE 11. Environmental Test System for Fatigue-Crack-Growth Rate Testing Using CCT Specimens

test; however, it should be emphasized that $J$-integral test methods have not yet been approved as standard by the American Society of Testing and Materials. A proposed standard does exist (Clark 1979), and tests were performed in accordance with the proposed standard, where applicable. 
TABLE 2. Chemical Analysis of Simulated Repository Water ( $\mathrm{pH}:$ 9.50; Conductivity ( $\mathrm{Mho}$ ): 472)

\begin{tabular}{|c|c|c|c|}
\hline $\begin{array}{l}\text { Solution } \\
\text { Makeup }\end{array}$ & $\begin{array}{c}\text { Concentration, } \\
\mathrm{ppm}\end{array}$ & $\begin{array}{l}\text { Solution } \\
\text { Makeup } \\
\end{array}$ & $\begin{array}{c}\text { Concentration, } \\
\text { ppm }\end{array}$ \\
\hline $\mathrm{HCO}_{3}^{-}$ & 139.8 & $\mathrm{Ca}$ & 1.5 \\
\hline $\mathrm{CO}_{3}^{=}$ & 22.0 & $\mathrm{Mg}$ & 0.63 \\
\hline $\mathrm{SO}_{4}=$ & 1.2 & $\mathrm{Na}$ & 100 \\
\hline $\mathrm{F}^{-}$ & 6.7 & $\mathrm{Si}$ & 0.2 \\
\hline $\mathrm{Cl}^{-}$ & 43.9 & & \\
\hline
\end{tabular}

Both single- and multiple-specimen J-integral tests were performed on the Grade 2 titanium. The multiple-specimen tests were used to check the validity of the single-specimen R-curves. The J-integral tests for Grade 12 titanium have not yet been completed.

The multiple-specimen J-integral test is illustrated in Figure 12. The test is performed by precracking several compact tension specimens to $a / b=$ 0.60 and loading each specimen to a different displacement. This technique produces a series of specimens with various amounts of crack extension. The specimens are then heat tinted to clearly mark the area of crack extension, then broken. The areas of fatigue precracking and crack extension can then be distinguished by the color and texture of the fracture surface as shown in Figure 13. The amount of crack extension is measured at nine equally spaced intervals across the crack front. $J$ is calculated according to the formula (Merkle and Corten 1974):

$$
J=\alpha_{1} \frac{2 A}{B b}+\alpha_{2} \frac{2 P \delta}{B b}
$$

where $\alpha_{1}$ and $\alpha_{2}$ are the Merkle-Corten coefficients, $A$ is the area under the load-displacement curve, $P$ is load, $\delta$ is displacement, and $B$ and $b$ are plate thickness and remaining ligament, respectively.

The value of $\mathrm{J}$ at the onset of material separation, $\mathrm{J}_{\mathrm{I} c}$, is found by determining the amount of apparent crack extension which corresponds to actual 


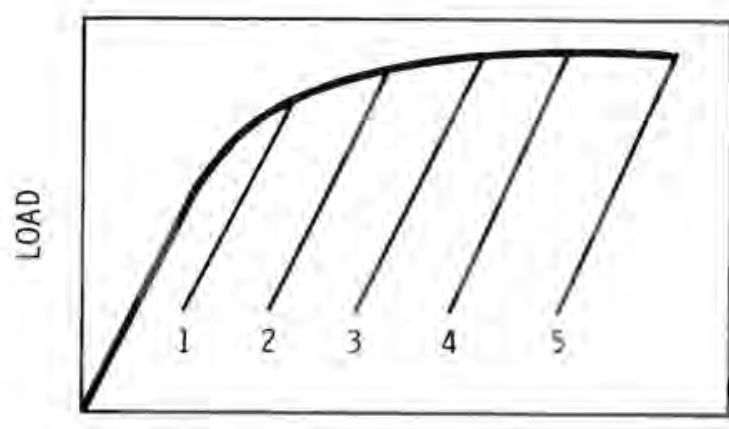

DISPLACEMENT

FIGURE 12. Schematic of Test Records for Multiple-Specimen J-Integral Tests

(a)

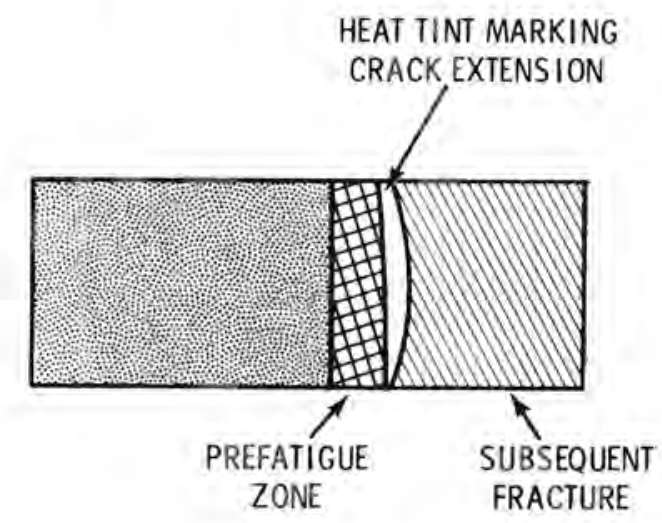

(b)

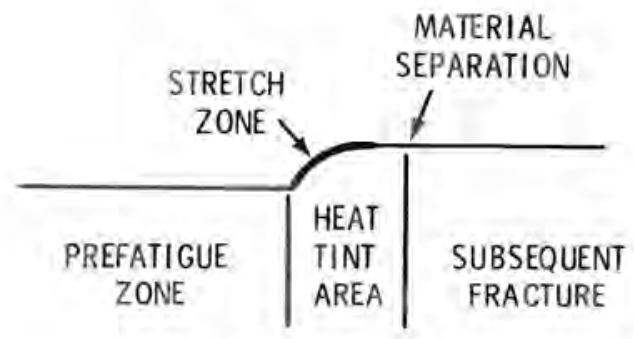

FIGURE 13. a) Schematic of Heat-Tinted Specimen Showing FatiguePrecracked Area, Stable Crack Extension, and Final Fracture; b) Schematic of Specimen Cross Section Showing Stretch Zone and Area of Material Separation Within Heat-Tinted Zone

material separation, which requires that a distinction be made between cracktip blunting and actual material separation. The limit of material stretching or crack-tip blunting is described by the blunting line in Figure 14 . To the 
left of the blunting line $\left(J=2 \sigma_{f} \Delta a\right)$, no crack extension has occurred. $\sigma_{f}$ in the expression is known as the flow stress and is approximated by averaging yield and ultimate strengths. The apparent crack extension is caused by stretching of the material at the crack tip. The intersection of the $\mathrm{J}$ versus $\Delta$ a curve with the blunting line defines initial separation of the material (Landes and Begley 1974); therefore, this point is defined as J IC, or the value of $J$ at initial crack extension.

The single-specimen J-integral test uses the same principles as the multiple-specimen test, except that crack extension is monitored during the test using a compliance procedure. In this way, the J-integral R-curve can be constructed from a single specimen. A typical R-curve is shown in Figure 15.

The validity of the single-specimen R-curve can be verified using multiple-specimen data points. This procedure was followed for the titanium Grade 2 alloy.

Dynamic Fracture Toughness and Impact Toughness

Impact testing was performed using an instrumented pendulum system. Records of load versus time were obtained fom an instrumented tup attached to the pendulum. Charpy V-notch specimens were used for the impact toughness tests, and precracked Charpy specimens were used for the dynamic fracture

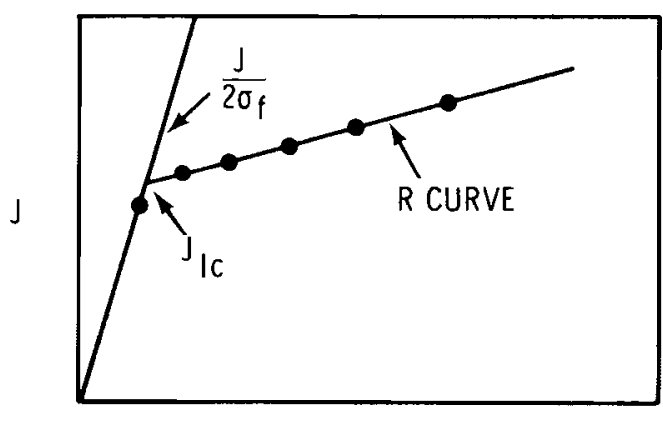

$\Delta \mathrm{a}$

FIGURE 14. Schematic of R-Curve from Multiple-Specimen J-Integral Tests. Blunting is shown as the criterion for determining $\mathrm{J}_{\mathrm{I}} \mathrm{c}$ 
WOL SPECIMEN

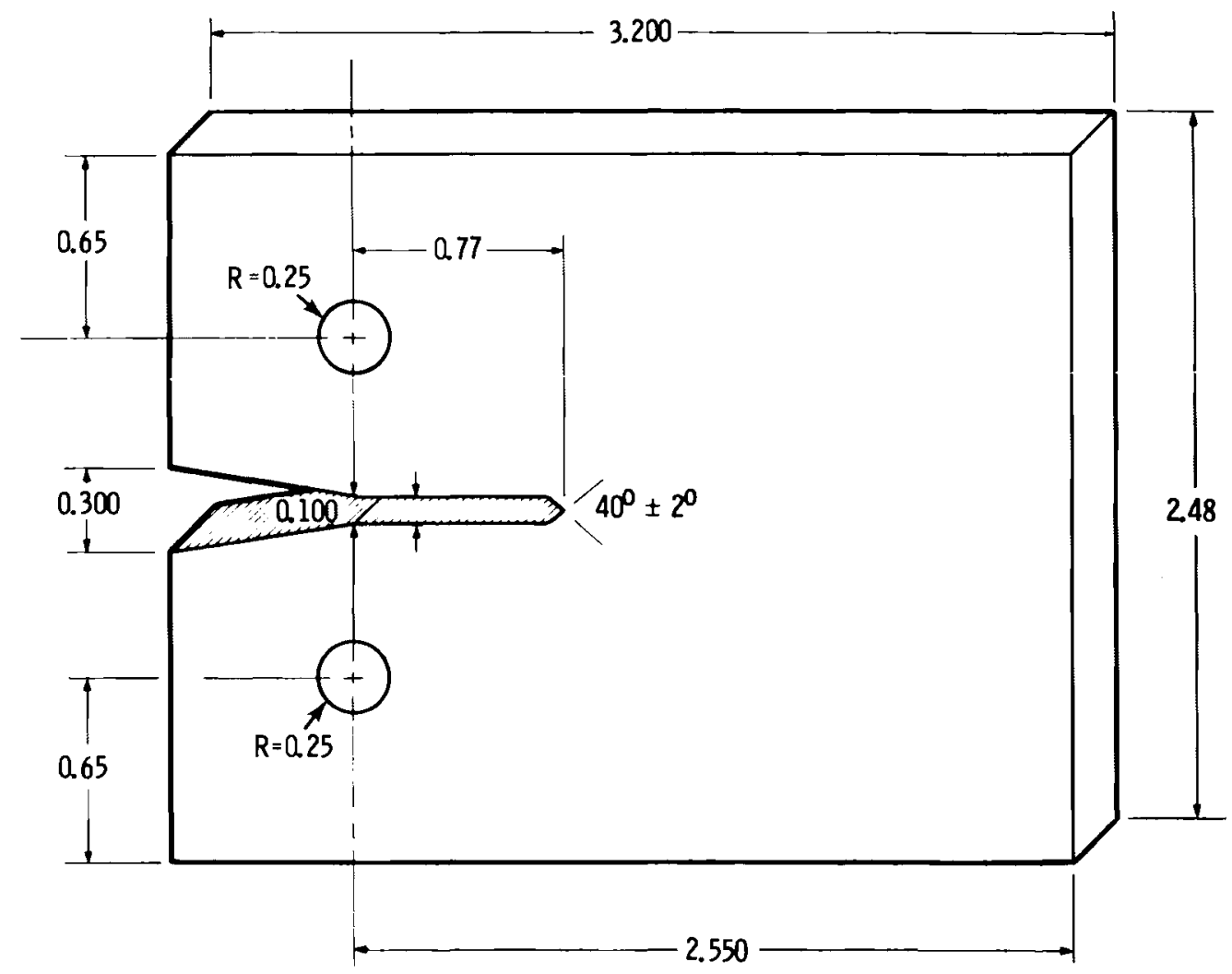

ALL DIMENSIONS

IN INCHES

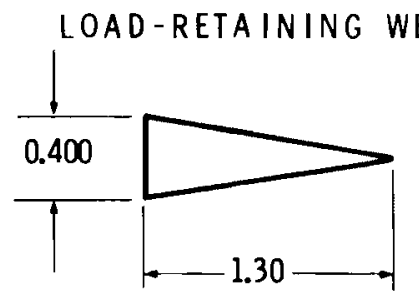

FIGURE 15. Wedge-Opening Load Specimen Used for Stress-Corrosion Cracking Evaluation in Autoclave Tests

toughness tests. Tests were performed over the interval $20^{\circ}$ to $250^{\circ} \mathrm{C}$ for longitudinal and transverse orientations of titanium alloys 2 and 12. 


\section{Stress-Corrosion Cracking}

Two types of specimens were used to evaluate the susceptibility of Grades 2 and 12 titanium to stress-corrosion cracking in a simulated repository environment: wedge-opening load (WOL) and residual stress specimens. Each WOL specimen (shown in Figure 15), was loaded to high stress intensity before inserting the wedge. The wedge was pressed in to increase the load on the specimen. External load was recorded during the wedge loading process so that stress intensity could be determined. Crack length at the specimen surface was also recorded before the specimens were put into autoclaves. The specimens were exposed for $89 \mathrm{~d}$ at $250^{\circ} \mathrm{C}$ in a Hanford ground-water simulated repository environment.

Two residual-stress specimens of Grade 12 titanium were included in the autoclave tests. These specimens (Figure 16) were plastically deformed in compression, then allowed to spring back, producing residual tensile stresses in the material in either side of the hole. A susceptibility to stress-corrosion cracking under various stress states could be indicated by this economic type of specimen.

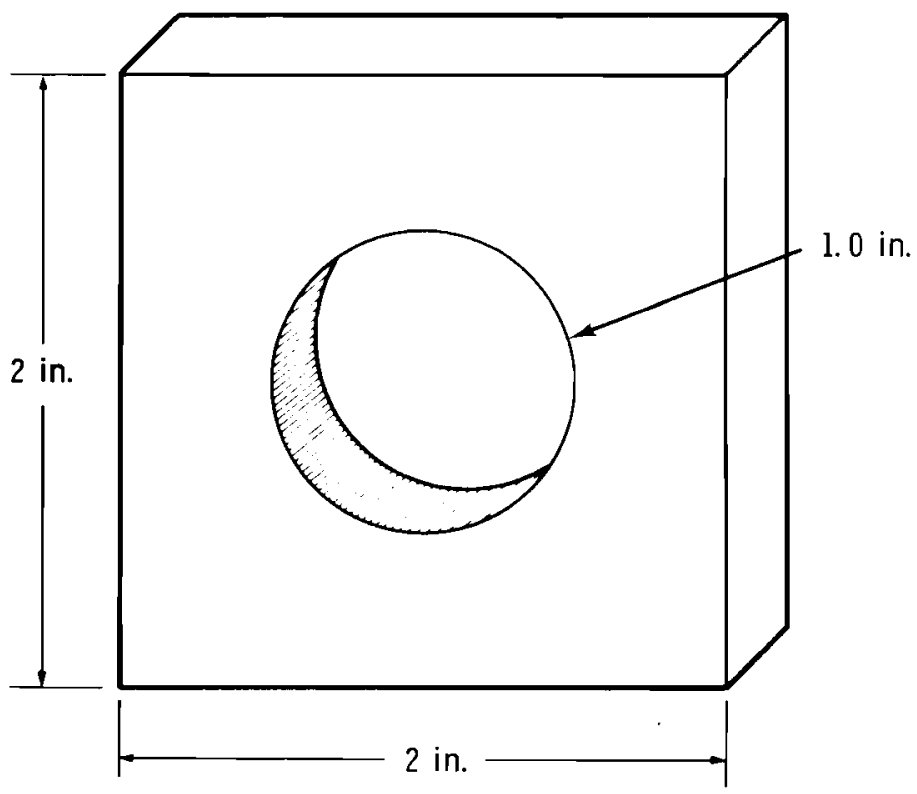

FIGURE 16. Residual Stress Specimen Used in Stress-Corrosion Cracking Tests (dimensions in inches) 


\section{RESULTS}

Not all series of tests planned under this task are complete. In the case of uncompleted series, the results to date are reported and the necessary tests to complete the text matrix are described.

\section{Tensile Tests}

Yield strength was calculated from static tensile tests and from impact tests from $20^{\circ}$ to $250^{\circ} \mathrm{C}$ (a) The effects of temperature on static and dynamic yieild strength of titanium Grades 2 and 12 are shown in Figures 17

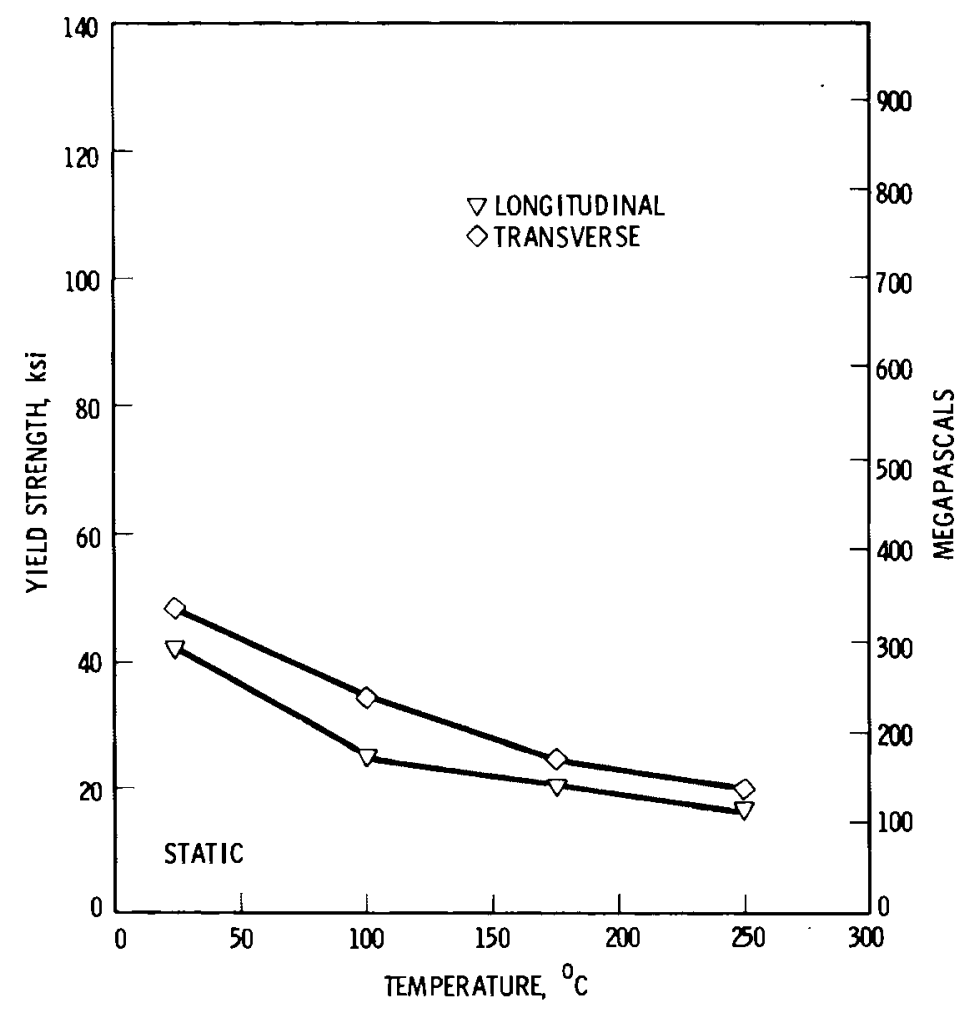

FIGURE 17. Yield Strengths as a Function of Temperature for Grade-2 Titanium

(a) Yield strength was calculated by the relationship developed by Green and Hundy (1956):

$$
\sigma_{y}=33.3 P_{g y}
$$

where $\sigma_{y}$ is the uniaxial yield strength, $k s i$, and $P_{\text {gy }}$ is the load at general yield in pounds. $P_{g y}$ is obtained from the load-deflection trace produced by an instrumented impact test machine and corresponds to the load at which the trace begins to deviate from linearity. 
and 18. The yield strength of each material is lower in the longitudinal than in the transverse orientation. The degree of anisotropy is greater for Grade 12; however, this may represent a difference in plate processing rather than a difference in properties caused by the alloying elements.

The yield strength of Grade 2 titanium decreases more rapidly with increasing temperature than does the yield strength of Grade 12 . Other tensile properties of the titanium alloys are given in Table 3 . Both alloys are quite ductile over the temperature range of interest. Percent reduction of area increases with temperature, but percent elongation remains relatively constant, which is probably caused by increased ductility and decreased strain-hardening at elevated temperatures.

\section{Fatigue-Crack-Growth Rate Tests}

Results of the fatigue-crack-growth rate tests of titanium plate in air, using compact tension specimens, are shown in Figures 19 and 20 .

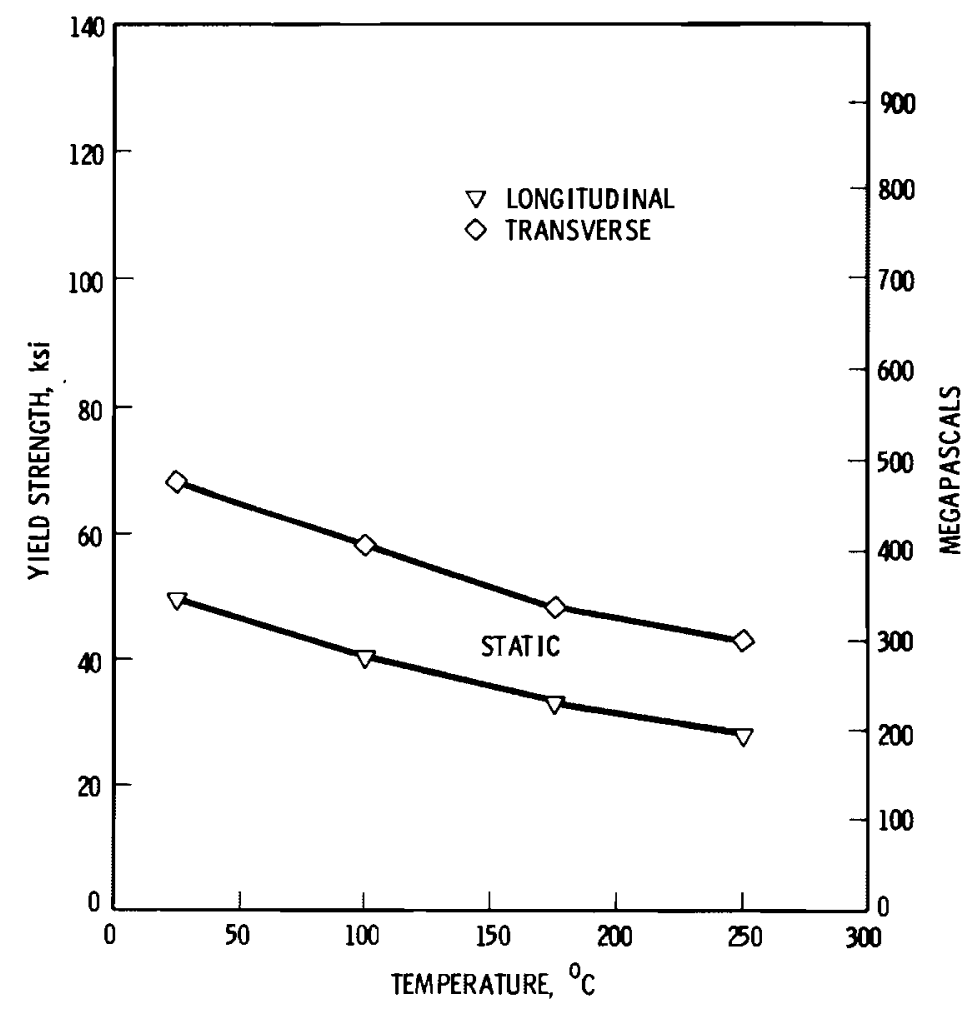

FIGURE 18. Yield Strength as a Function of Temperature for Grade-2 Titanium 
TABLE 3. Summary of Static Tensile Data for Grades-2 and -12 Titanium Plate

\begin{tabular}{|c|c|c|c|c|c|c|}
\hline Material & $\begin{array}{l}\text { Orienta- } \\
\text { tion } \\
\end{array}$ & $\begin{array}{c}\text { Temperature, } \\
{ }^{\circ} \mathrm{C} \\
\end{array}$ & $\begin{array}{l}\text { Ultimate } \\
\text { Tensile } \\
\text { Strength, } \\
\quad \text { psi } \\
\end{array}$ & $\begin{array}{c}\text { Yield } \\
\text { Strength, } \\
\text { psi } \\
\end{array}$ & $\begin{array}{c}\% \\
\text { Reduction } \\
\text { Area } \\
\end{array}$ & $\begin{array}{c}\% \\
\text { Elongation }\end{array}$ \\
\hline $\begin{array}{l}T i-2 \\
T i-2 \\
T i-12 \\
T i-12\end{array}$ & $\begin{array}{l}\text { TL } \\
\text { LT } \\
\text { LT } \\
\text { TL }\end{array}$ & $\begin{array}{l}25 \\
25 \\
25 \\
25\end{array}$ & $\begin{array}{l}66,700 \\
66,900 \\
74,800 \\
86,900\end{array}$ & $\begin{array}{l}48,300 \\
42,400 \\
49,300 \\
68,100\end{array}$ & $\begin{array}{l}58.3 \\
49.3 \\
23.9 \\
36.1\end{array}$ & $\begin{array}{l}24.2 \\
22.6 \\
20.3 \\
16.6\end{array}$ \\
\hline $\begin{array}{l}T i-2 \\
T i-2 \\
T i-12 \\
T i-12\end{array}$ & $\begin{array}{l}\text { TL } \\
\text { LT } \\
\text { TL } \\
\text { LT }\end{array}$ & $\begin{array}{l}100 \\
100 \\
100 \\
100\end{array}$ & $\begin{array}{l}50,000 \\
47,443 \\
73,850 \\
61,517\end{array}$ & $\begin{array}{l}25,419 \\
34,545 \\
58,161 \\
39,888\end{array}$ & $\begin{array}{l}45.2 \\
51.1 \\
41.4 \\
27.5\end{array}$ & $\begin{array}{l}26.6 \\
27.8 \\
13.4 \\
16.6\end{array}$ \\
\hline $\begin{array}{l}\mathrm{Ti}-2 \\
\mathrm{Ti}-2 \\
\mathrm{Ti}-2 \\
\mathrm{Ti}-12 \\
\mathrm{Ti}-12\end{array}$ & $\begin{array}{l}\text { TL } \\
\text { TL } \\
\text { LT } \\
\text { TL } \\
\text { LT }\end{array}$ & $\begin{array}{l}175 \\
175 \\
175 \\
175 \\
175\end{array}$ & $\begin{array}{l}38,920 \\
38,966 \\
35,795 \\
59,091 \\
53,757\end{array}$ & $\begin{array}{l}20,909 \\
20,276 \\
23,580 \\
57,893 \\
32,832\end{array}$ & $\begin{array}{l}51.1 \\
49.0 \\
57.4 \\
50.0 \\
30.0\end{array}$ & $\begin{array}{l}26.4 \\
24.6 \\
27.1 \\
14.7 \\
19.2\end{array}$ \\
\hline $\begin{array}{l}\mathrm{Ti}-2 \\
\mathrm{~T} \mathrm{i}-12 \\
\mathrm{~T} \mathrm{i}-12\end{array}$ & $\begin{array}{l}\text { LT } \\
\text { TL } \\
\text { LT }\end{array}$ & $\begin{array}{l}250 \\
250 \\
250\end{array}$ & $\begin{array}{l}30,508 \\
55,172 \\
48,022\end{array}$ & $\begin{array}{l}19,774 \\
43,391 \\
28,248\end{array}$ & $\begin{array}{l}65.0 \\
60.3 \\
44.6\end{array}$ & $\begin{array}{l}26.1 \\
18.2 \\
18.0\end{array}$ \\
\hline
\end{tabular}

Fatigue-crack-growth rates were higher for the longitudinal (LT) orientation than for the transverse (TL) orientation, although the difference is minor for both materials. The crack-growth rate of Grade 12 titanium is higher than that of Grade 2 for both orientations, although this difference is minor. It is interesting that the fatigue-crack-growth rate of titanium plate varies only slightly with orientation and between alloys because both materials are anisotropic with respect to strength and toughness.

Fatigue-crack-growth rate tests of titanium plate in ground water (thickness $=0.5$ in.) are planned. This approach will be used as a method of evaluating the susceptibility of the alloys to environmental damage. Data from fatigue-crack-growth rate tests of titanium sheet (thickness $=0.30$ to 0.50 in.) are given in Figures 21 to 24 . Environmental fatigue-crack-growth rate tests can be used to evaluate the susceptibility of the alloys to the test environment, and to evaluate the performance of the two alloys in two orientations. 


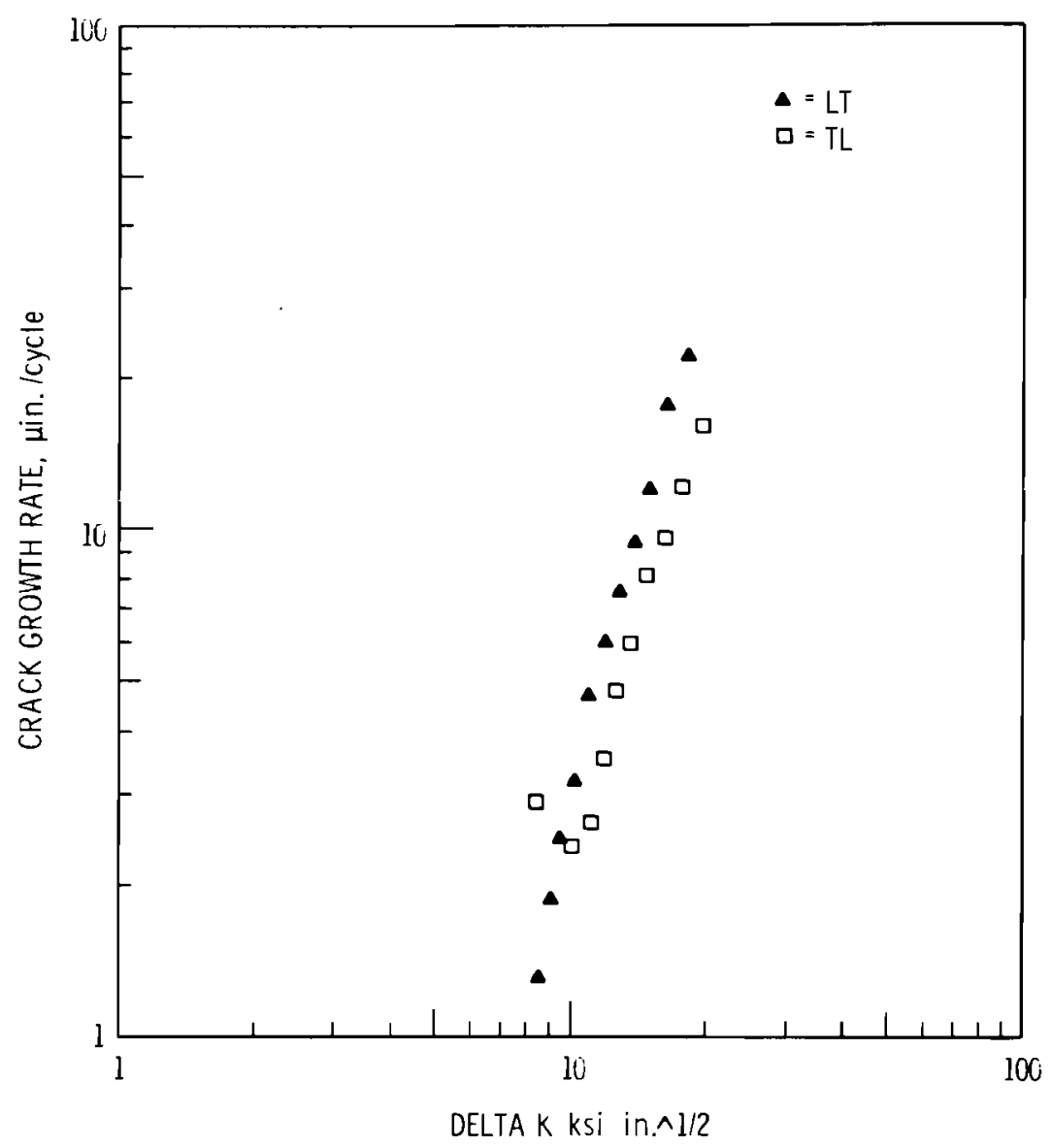

FIGURE 19. Comparison of Fatigue-Crack-Growth Rates of TL and LT Orientations of Grade 2 Titanium Plate (Air Environment, $20^{\circ} \mathrm{C}$ )

The environmental crack-growth rate data of Grade 2 titanium sheet is given in Figure 21. The crack-growth rate in the LT orientation is significantly higher than for the TL orientation. This result is in contrast to the plate material under ambient conditions where the fatigue-crack-growth rate is nearly independent of orientation. Environmental tests of the plate material will determine whether the difference is caused by a different thermomechanical processing or by a chemical or electrochemical difference.

Data from environmental crack-growth tests of Grade-12 titanium sheet are given in Figure 22. The crack-growth rate of the LT orientation appears to be about the same as the TL orientation; however, the TL orientation has a lower 


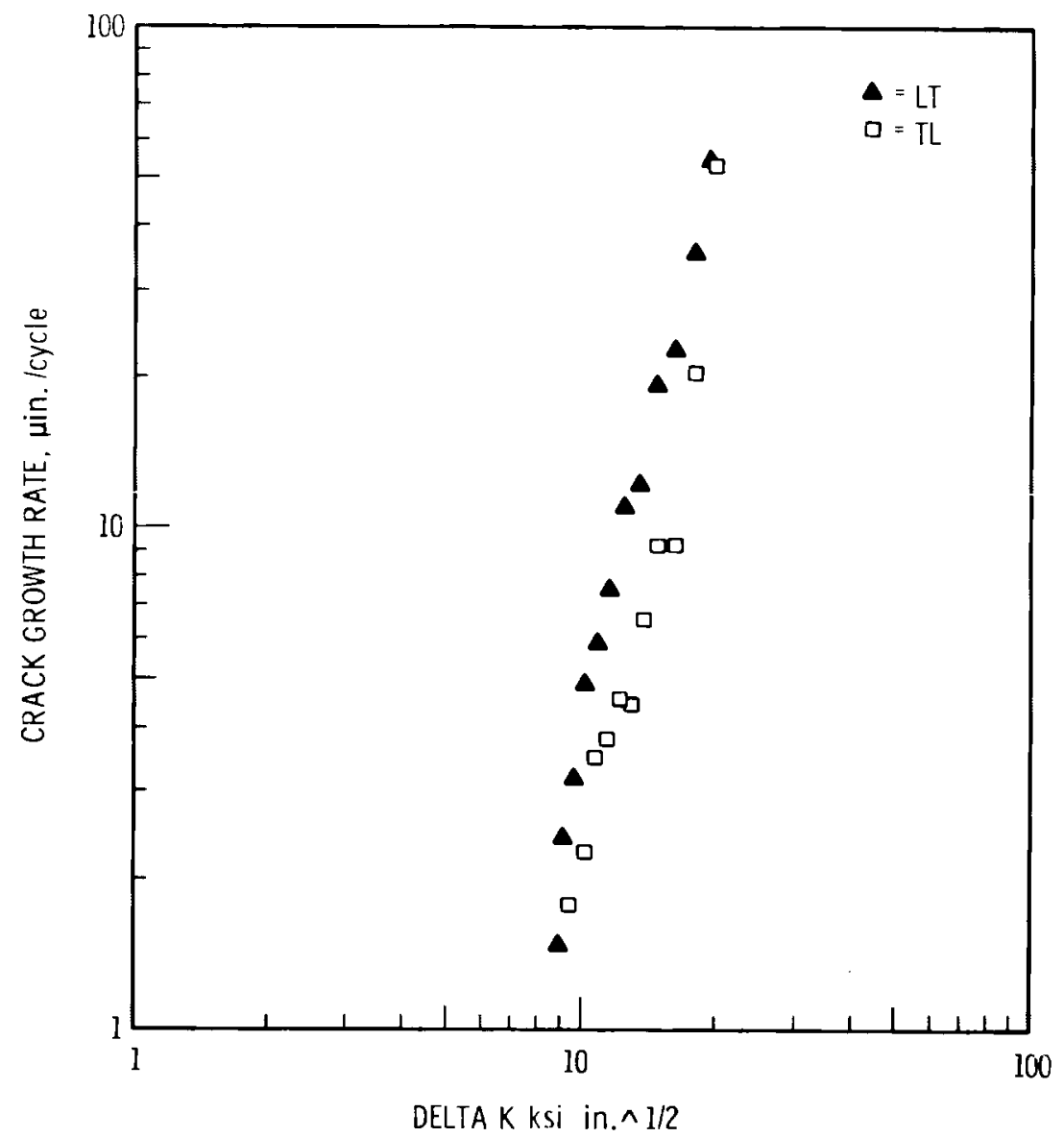

FIGURE 20. Comparison of Fatigue-Crack-Growth Rates of TL and LT Orientations of Grade 12 Titanium Plate (Air Environment, $20^{\circ} \mathrm{C}$ )

slope above $k=18 \mathrm{ksi} \sqrt{\mathrm{in}}$. This knee was not observed in an air environment at about the same temperature; it is not known why the crack-growth rate at high stress intensity is lower in the environmental solution than in air, or why the knee is observed in only the TL orientation.

Another example of environmental effects is given in Figure 23, which compares the LT orientations of Grades 2 and 12 . The crack-growth rate of Grade 12 is higher than that of Grade 2 at low stress intensity, but lower at high stress intensity. When the aqueous environment was removed, crack-growth rate increased significantly. 


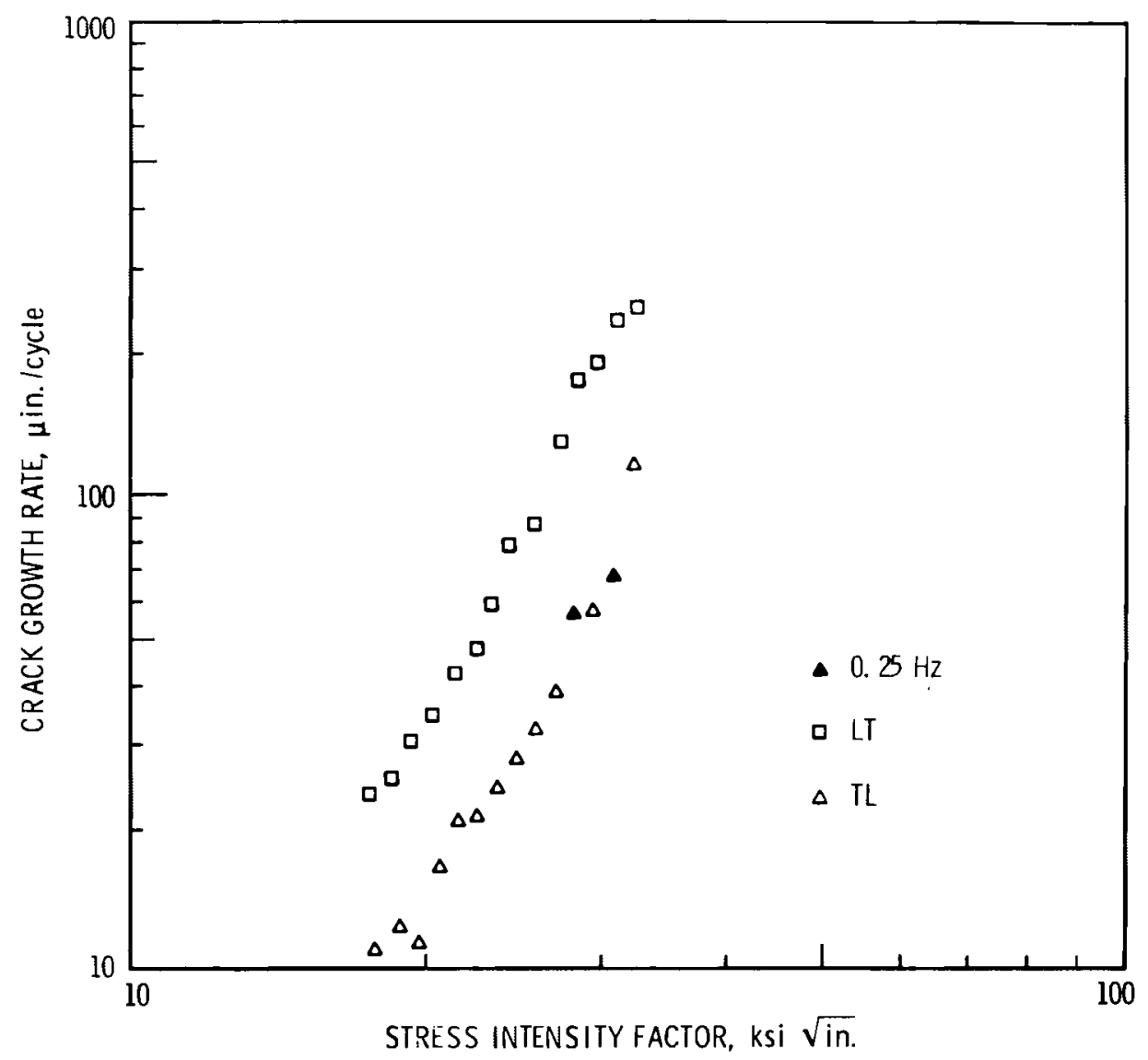

FIGURE 21. Comparison of Environmental Fatigue-Crack-Growth Rates of TL and LT Orientations of Grade 2 Titanium Sheet (Hanford Ground-Water Environment, $90^{\circ} \mathrm{C}$ )

Another measure of environmental effects is the frequency dependence of fatigue-crack-growth rates in environment. Slower frequencies are thought to enhance the ability of environments to increase fatigue-crack-growth rates. Several specimens were tested at low frequencies but no statistically significant frequency effects were found, which is demonstrated in Figure 24 where frequencies as low as $0.1 \mathrm{~Hz}$ were used. Further tests of this nature are planned.

\section{Static Fracture Toughness Tests}

Elastic-plastic (J-integral) tests were performed on Grades 2 and 12 titanium; however, since the tests of Grade 12 are not yet complete, only preliminary results are given here. 


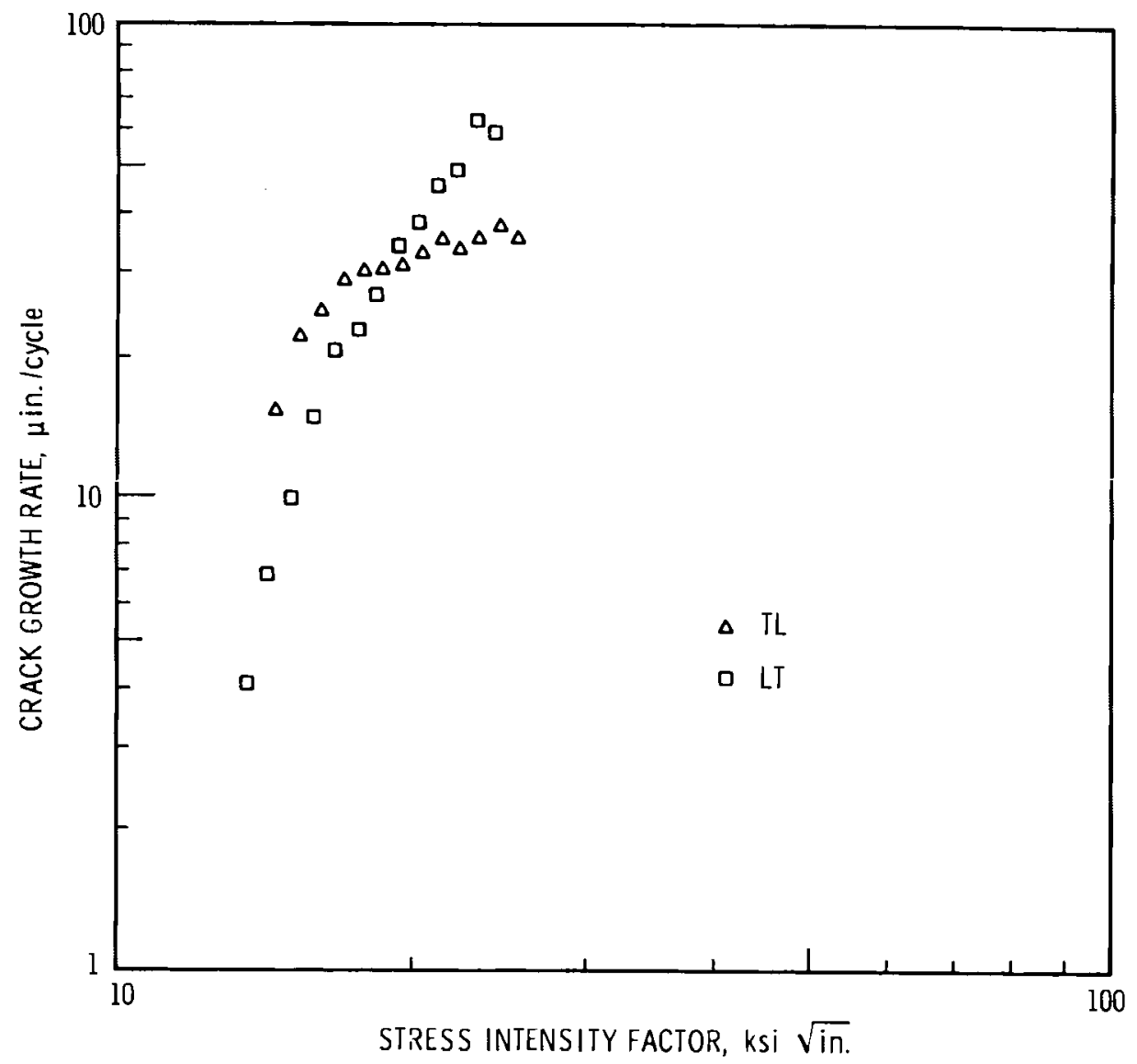

FIGURE 22. Comparison of Environmental Fatigue-Crack-Growth Rates of TL and LT Orientations of Grade 12 Titanium Sheet (Hanford Ground-Water Environment, $90^{\circ} \mathrm{C}$ )

Actual J-integral data from single- and multiple-specimen tests are shown in Figure 25. The intersection of the J-integral R-curve with the blunting line $\left(J=2 \sigma_{f} \Delta a\right)$ gives the value of $J$ at crack initiation, $J_{I C}$. For the $T L$ orientation, $J_{I c}$ is $1,200 \mathrm{lb} / \mathrm{in}$., giving $\mathrm{K}_{\mathrm{Ic}}$ of $134 \mathrm{ksi} \sqrt{\mathrm{in} .}$ Similar tests for the $L T$ orientation yielded results of $\mathrm{J}_{\mathrm{Ic}}=1,040 \mathrm{lb} / \mathrm{in}$. or $\mathrm{K}_{\mathrm{Ic}}(\mathrm{J})=125$.

These results indicate that no significant anisotropy exists with respect to static crack initiation in the Grade-2 titanium at room temperature. The significance of the fracture toughness values $(125$ to $134 \mathrm{ksi} \sqrt{\mathrm{in}}$.) can be described in two ways: critical crack length, and thickness at which plane strain will exist. The titanium Grade 2 is tough by both measures. A critical crack length of about 2 in. can be tolerated at 50,000 psi stress without 


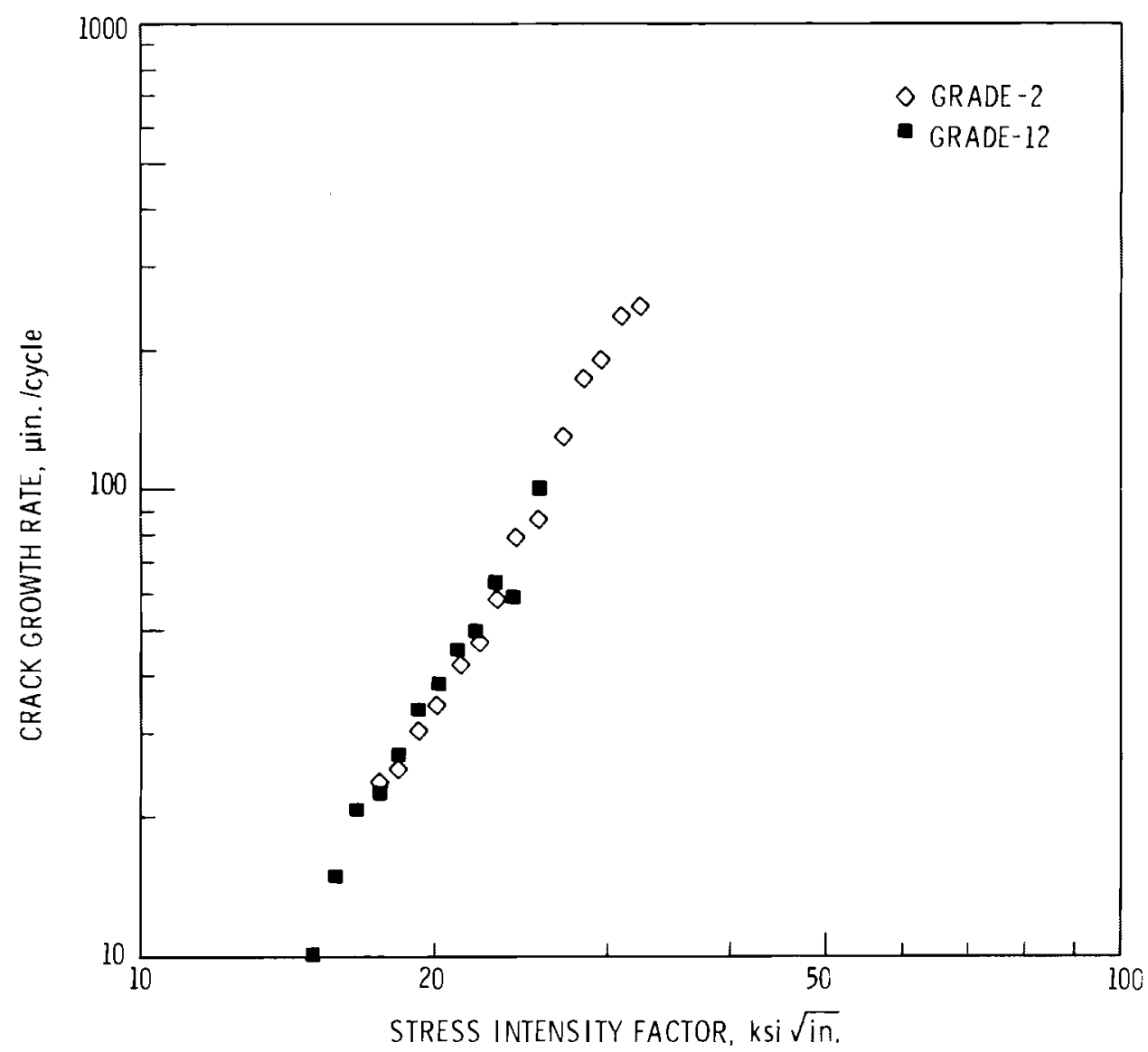

FIGURE 23. Fatigue-Crack-Growth Rate of Grades 2 and 12 Titanium, LT Orientation (Ground-water Environment)

initiating fracture of the material. A thickness of greater than $10 \mathrm{in}$. is necessary for plane-strain conditions to exist in the material, which means that material in the thickness of interest will separate by a ductile tearing mechanism rather than by brittle fracture.

Preliminary tests on titanium Grade 12 found $K_{I c}(J)$ to be $37 \mathrm{ksi} \sqrt{\mathrm{in}}$. for the LT orientation, which given a critical crack length of about 0.2 in. for 50,000 psi stress and a plane-strain thickness of about 1 in. Thus, Grade 12 titanium is much less tough than Grade 2.

Dynamic Fracture Toughness Tests

The energy absorbed by Charpy $V$-notch (CVN) specimens as a function of temperature for Grades 2 and 12 is illustrated in Figures 26 and 27 , 


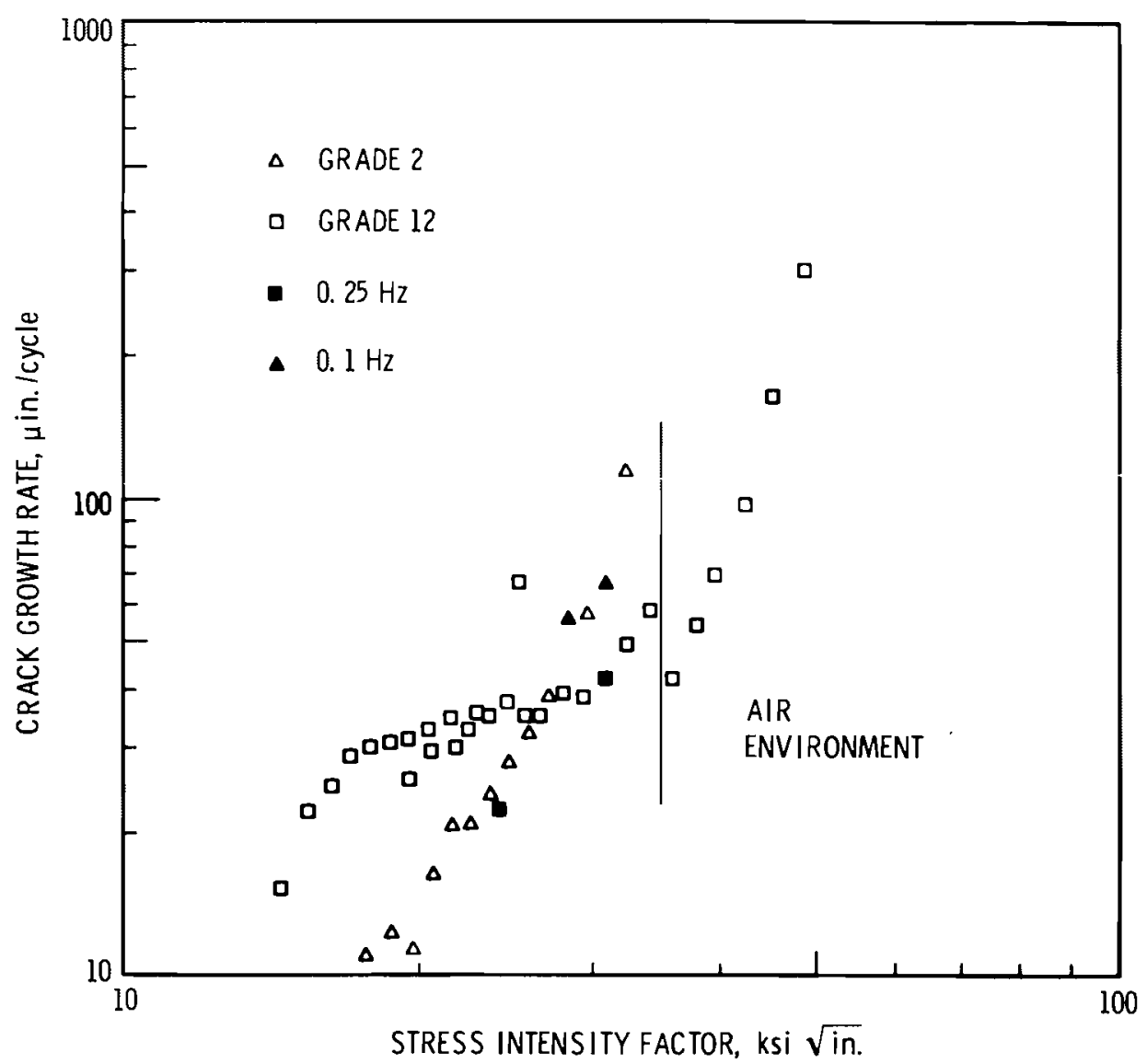

FIGURE 24. Comparison of Fatigue-Crack-Growth Rates Grades 2 and and 12 Titanium, TL Orientation

respectively. For both alloys, the impact energies of the transverse orientations are higher than in the longitudinal orientations. Impact energy of the transverse orientations increased more significantly with temperature than the impact energy of the longitudinal orientations.

Dynamic yield strength was calculated by the relationship (Green and Hundy 1956) $\sigma y=33.3 \mathrm{P}_{\text {gy }}$, where $\sigma y$ is dynamic yield strength in psi and $P_{\text {gy }}$ is general yield in pounds. A comparison of static and dynamic yield strengths as a function of temperature is shown in Figures 28 and 29 . There is a good correlation between the static and dynamic yield trends for Grade 2 in that the yield strength drops most rapidly between $25^{\circ}$ and $100^{\circ} \mathrm{C}$, which indicates that 


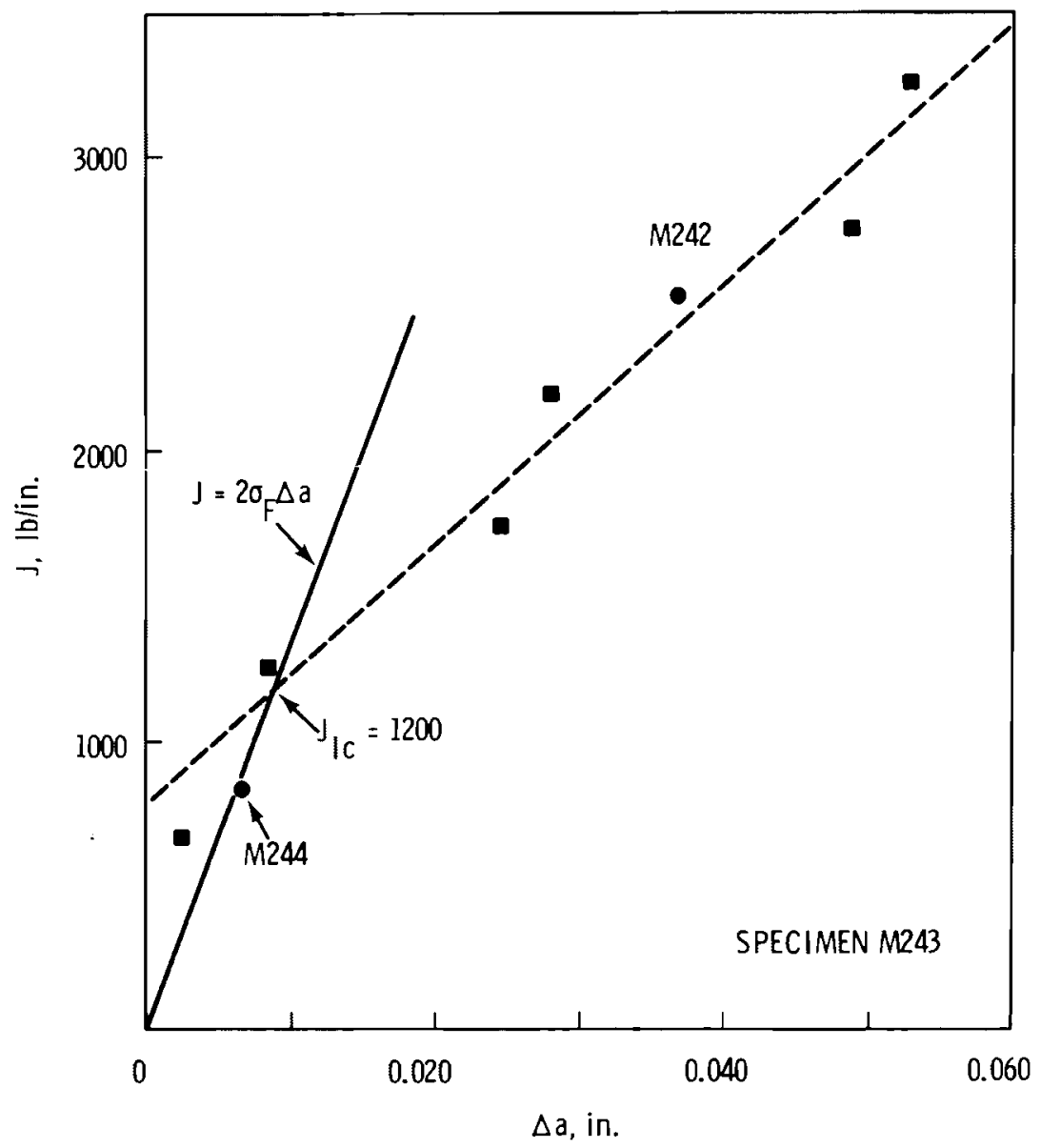

FIGURE 25. J-Integral R-Curve

the decrease in yield strength does not fully acount for the large increase of transverse toughness with increasing temperature.

The static and dynamic fracture toughness of Grades 2 and 12 titanium is shown in Figures 30 and 31 . The dynamic fracture toughness follows trends similar to the impact energy. Both materials have good toughness except the longitudinal orientation of Grade 12 titanium. Further tests are planned to define the toughness transition between $25^{\circ}$ and $250^{\circ} \mathrm{C}$.

\section{Stress-Corrosion Cracking Tests}

Two specimen types were used to detect stress-corrosion cracking in a simulated repository environment: cracked (WOL) and uncracked (residuala. stress) specimens. The specimens were exposed for $89 \mathrm{~d}$ at $250^{\circ} \mathrm{C}$ to a simulated 


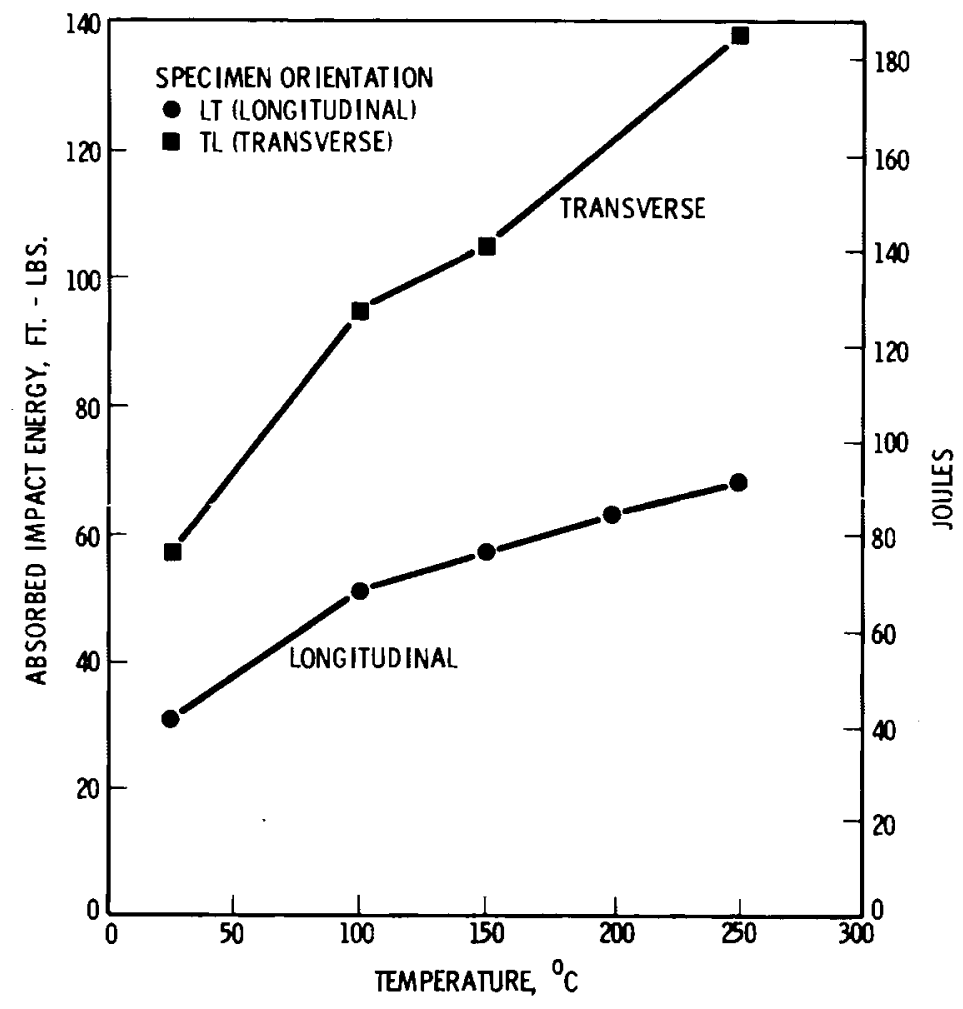

FIGURE 26. The Effect of Temperature on the Impact Energy of Grade 2 Titanium

repository environment circulating through crushed basalt. (The test conditions are described in detail in the following section of this report.)

The WOL specimens, which were loaded to about $50 \mathrm{ksi} \sqrt{\mathrm{in}}$., showed no surface crack growth during the exposure. The stress level was high enough to cause tunnelling(a) to occur in the Grade 12 specimens because of their lower fracture toughness. Measurements of compliance and wedge load before and after the test indicate that no crack growth occurred in any of the specimens; however, it cannot be proved that a slight amount of stress-corrosion crack growth did not occur in the center of the Grade 12 specimens because of experimental innaccuracies.

(a) Tunnelling is interior crack length exceeding surface crack length. This mode of crack growth cannot be detected by visual surface observation. 


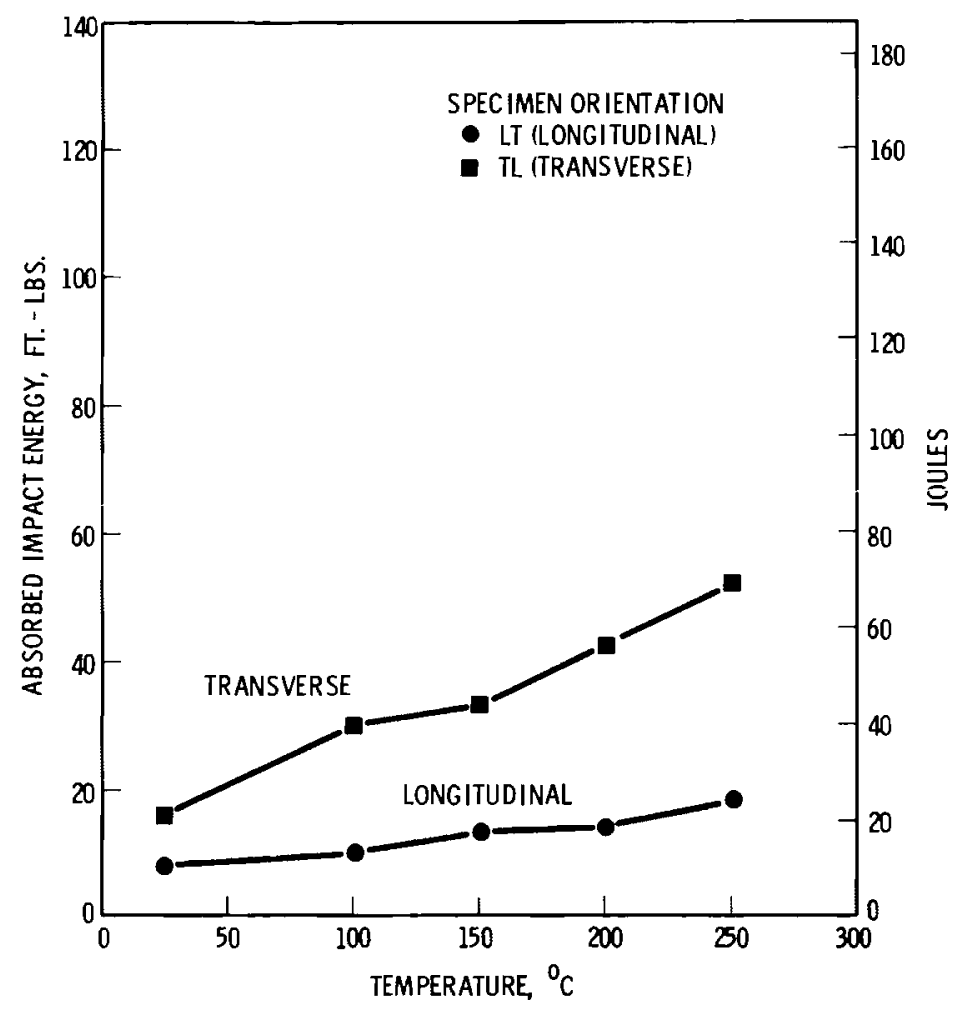

FIGURE 27. The Effect of Temperature on the Impact Energy of Grade 12 Titanium

The residual stress specimens were visually examined following exposure in the simulated repository solution. No cracks were found.

\section{CONCLUSIONS}

1. The mechanical properties of Grade 2 titanium are better than those of Grade 12 titanium, except for the tensile and yield strengths.

These properties include fatigue-crack-growth rate, environmental fatigue-crack-growth rate, fracture toughness, impact toughness, and dynamic fracture toughness.

2. Grade 12 titanium is thought to have better resistance to environmental attack, especially crevice corrosion at elevated temperatures; 


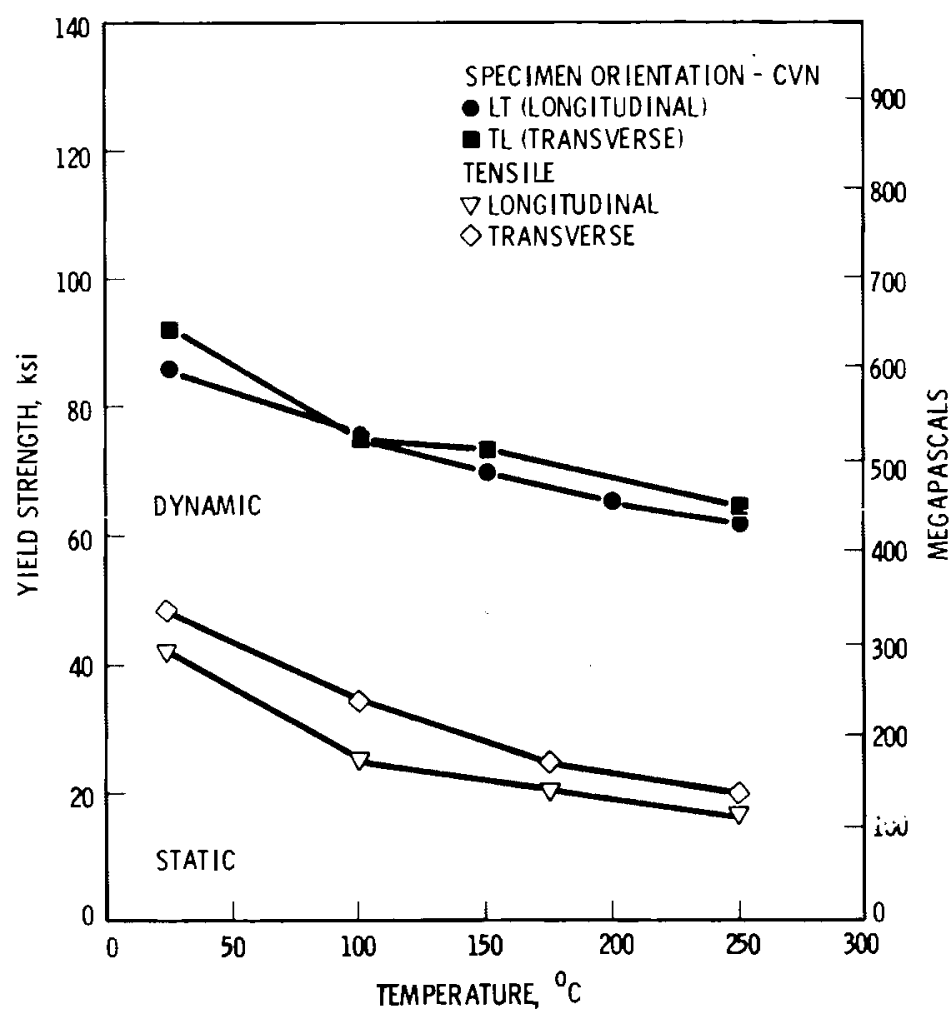

FIGURE 28. The Effect of Temperature on the Static and Dynamic Yield Strengths of Grade 2 Titanium

however, there is no evidence in the current data to indicate that the simulated repository environment is aggressive to either material. This conclusion may change when the materials are tested in a low-oxygen, hightemperature solution.

3. Both alloys have lower toughness and crack-growth resistance in the $L T$ than in the $T L$ orientation. 


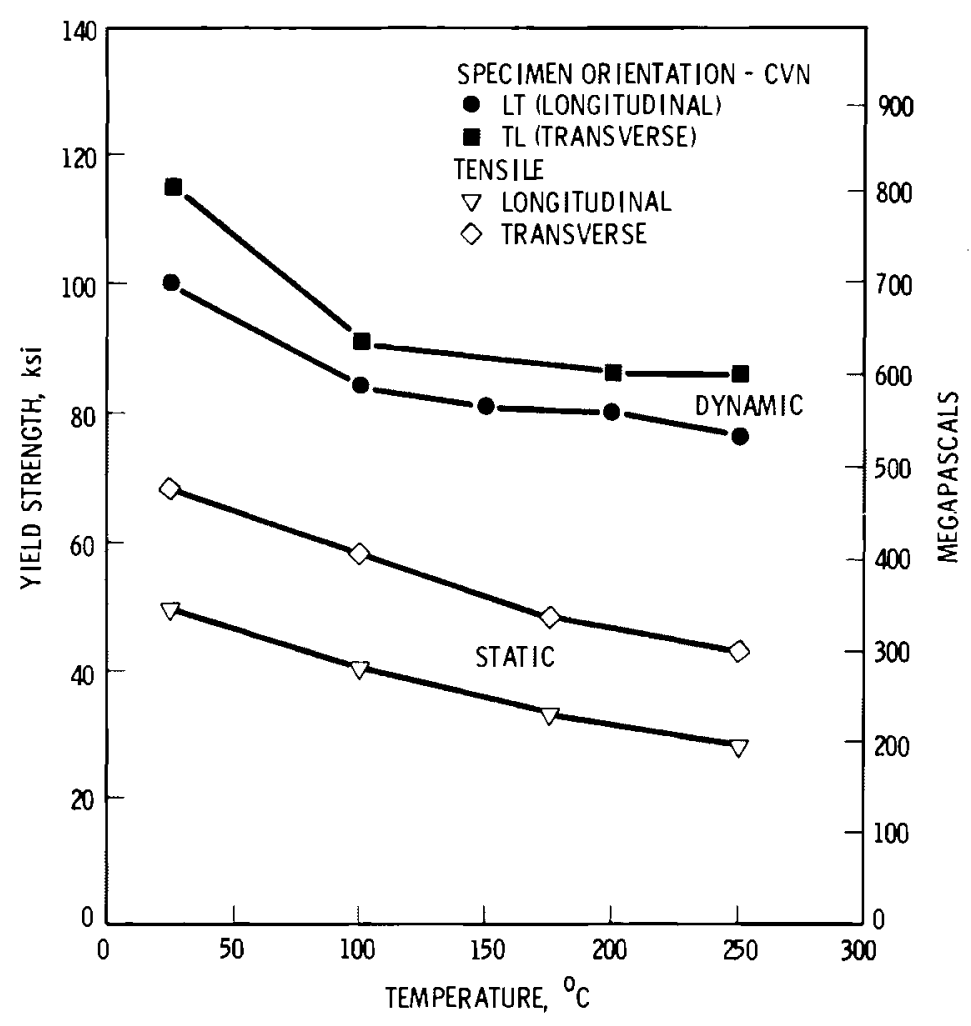

FIGURE 29. The Effect of Temperature on the Static and Dynamic Yield Strengths of Grade 12 Titanium 


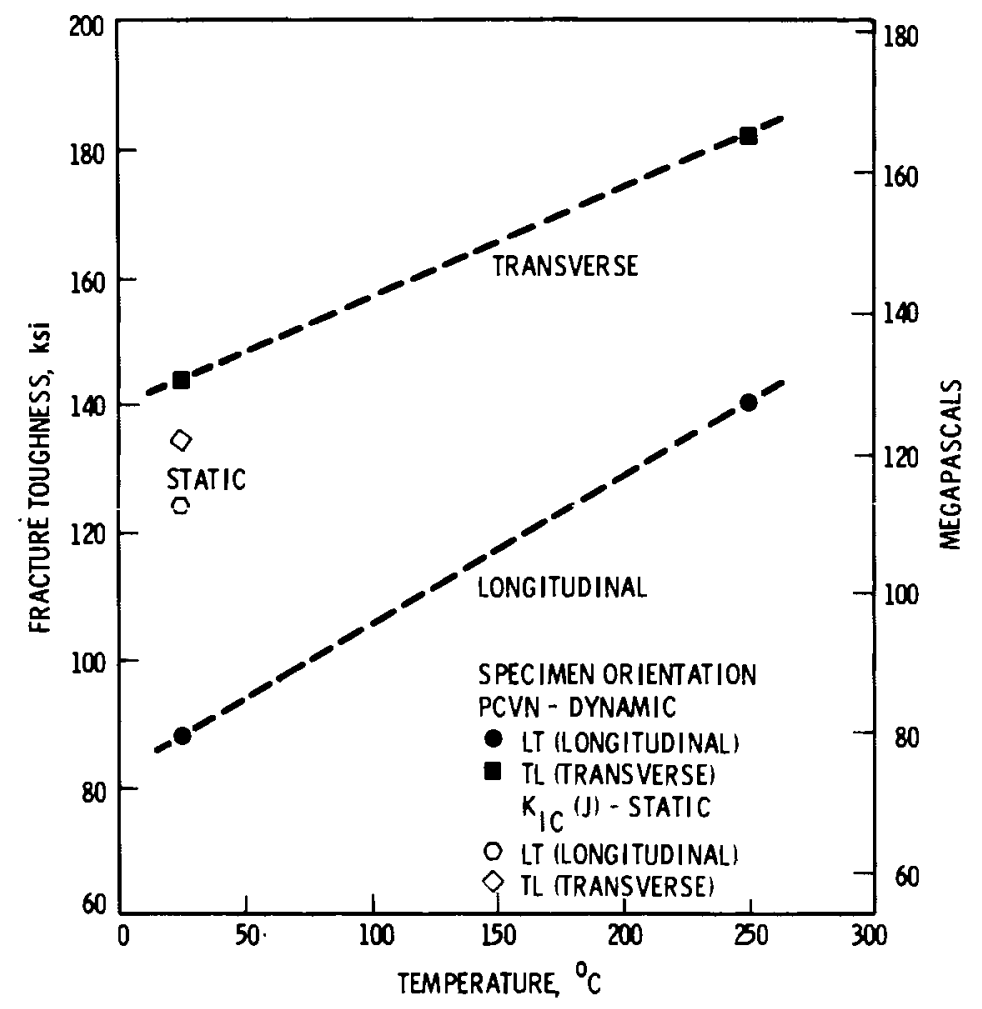

FIGURE 30. The Static and Dynamic Fracture Toughness of Grade 2 Titanium 


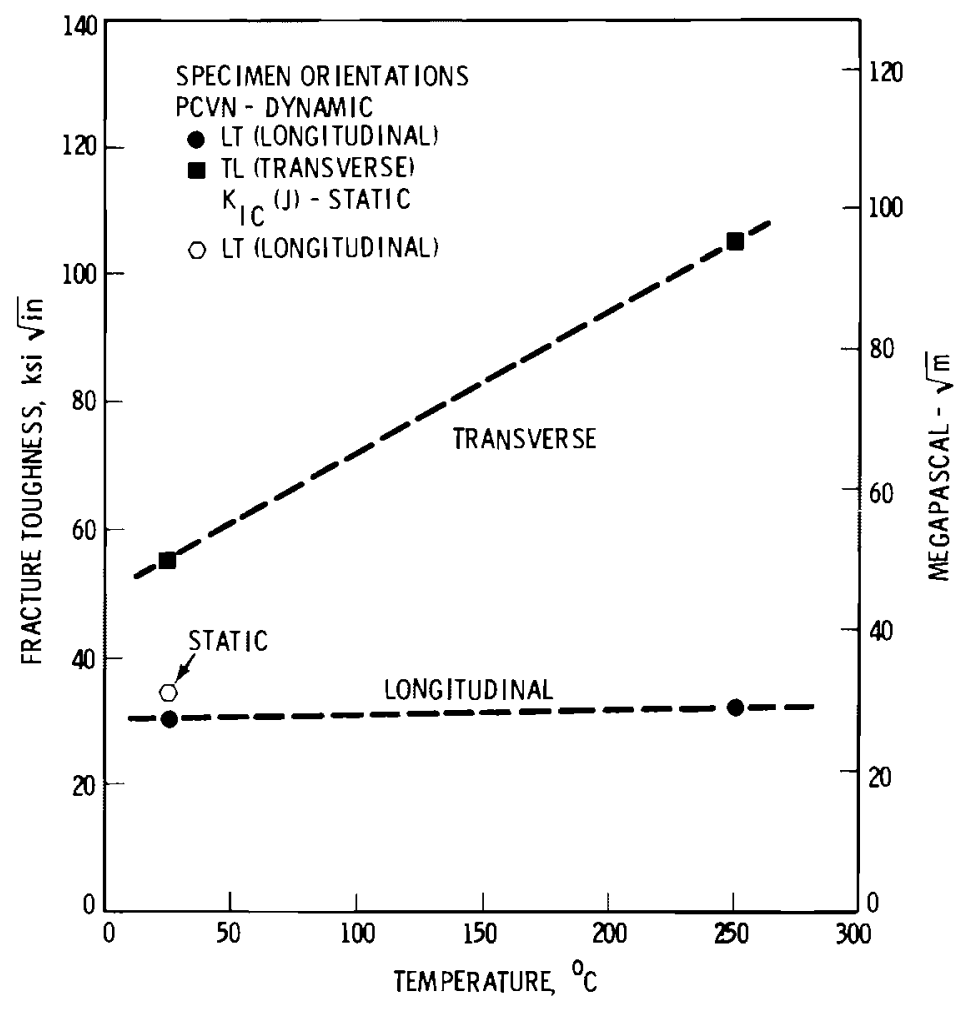

FIGURE 31. The Static and Dynamic Fracture Toughness of Grade 12 Titanium 


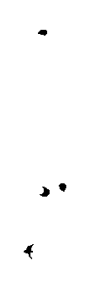

I

. 


\title{
METALLIC MATERIALS CORROSION PROPERTIES EVALUATION
}

\author{
B. Griggs
}

\section{INTRODUCTION}

The design of licensable, long-lived engineered barrier systems for nuclear waste packages requires both 1 ) the selection of materials that have adequate corrosion resistance to last hundreds of years in potentially hostile environments, and 2) the demonstration, with a high degree of assurance, that the materials will indeed perform for the required time periods. The accurate prediction of corrosion behavior of metallic materials for time periods of up to $1,000 \mathrm{yr}$ challenges the ability of corrosion science. Conventional corrosion tests will require time extrapolations of $\sim 10^{3}$. Obviously, an appropriate statistical approach must eventually be involved, with barrier redundancy providing overall package longevity assurance that is not provided within the individual barrier elements.

The experimental tests performed to date in this subtask have been of a screening nature designed to eliminate those materials from consideration that do not exhibit the potential for long life in a repository environment. Future work will place more emphasis on in-depth experimental studies of candidate materials that show superior corrosion resistance in the screening tests, and on methods for extrapolation of the data obtained in the (relatively) shortterm laboratory studies.

A somewhat different approach to ensuring the longevity of barrier systems involves the examination of materials, both natural and man-fabricated, that have existed on or near the earth's surface for very long periods of time. A review of the corrosion behavior of ancient metallic materials over time periods of centuries and millennia has been published by Johnson and Francis (1980) under the auspices of this subtask. This review included observations on the corrosion behavior of meteorite fragments, native copper boulders, and metal objects from tombs, shipwrecks, and archaeological excavations. The authors concluded: 
- Several metals have shown impressive multicentury and multimillennia durability in natural environments.

- Dry or mildly moist environments have been optimum for metal preservation.

- Dry or mildly moist environments appear most amenable to data extrapolation and to preservation of nuclear-waste containers.

The extrapolation of ancient materials data to waste-package design suffers from problems of determining the exact ages and the exact conditions of exposure of the ancient materials. Also, the environments that the ancient materials were exposed to are unlike those expected to exist in a deep geologic nuclear-waste repository; and modern materials, such as titanium alloys, have of course not been exposed to any environment over centuries or millennia. The ancient material data can perhaps best be applied to engineered storage of waste packages where tomb-like environments could be feasibly maintained for some protracted period.

\section{MATERIALS TESTS}

A wide variety of alloys were used in the screening studies. Specimens of the following materials were exposed in one or more of the tests:

- Stainless Steels

304 SS

304 L SS

316 SS

321 SS

405 SS

410 SS

- Cast Irons

No. $180-7^{(a)}$ (ductile iron)

No. 22-8 (ductile iron, with $0.73 \times \mathrm{Cu}$ )

No. 142-12 (gray iron, with $0.68 \% \mathrm{Cr}, 1.34 \% \mathrm{Cu}$ )

No. 166-3 (gray iron)

No. 136-4 (gray iron, with 3.05x Ni)

- Zirconium-Base Alloy Zircaloy-2
- Nickel-Base Alloys

Inconel 600

Inconel 625

Incoloy 800

Hastelloy C-276

$\mathrm{Ni}-200$

- Titanium-Base Alloys

Titanium Code 12

Titanium Grade 2

Titanium 6A1-4V

- Copper-Base Alloys

Copper

Copper-nickel $70-30$

(a) Heat number, At las Foundry, Tacoma, WA. 
These materials, with the exception of the cast-iron specimens, were obtained as sheet stock in thicknesses ranging from 0.029 to $0.200 \mathrm{in}$. The cast-iron specimens were machined from test bars in the form of coupons, 0.030 to 0.040 in. thick.

\section{SAMPLE STOCK TESTING PROCEDURE}

The screening studies used specimens primarily in U-bend configuration so that both uniform corrosion and gross susceptibility to stress-corrosion cracking as revealed by the U-bend specimens ${ }^{(a)}$ could be addressed.

A tungsten-inert gas (TIG) welding torch was used to melt through the sheet material to create a simulated weld bead. The resulting sheet was sawed into 3/4- x 4-1/2-in. samples and bent into U-bends (ASTM-G30-72) using the two-stage stressing method. Prior to bending, the samples were cleaned by etching in $\mathrm{HNO}_{3}$ or an $\mathrm{HNO}_{3} / \mathrm{HF}$ mixture, as appropriate, and were rinsed finally in water and methanol. The samples were insulated from the stressing bolts by means of alumina washers. The typical U-bend specimen arrangement is shown in Figure 32 .

Only one cast iron, the ductile iron No. 180-7, could withstand the bending operation without cracking. Those cast-iron specimens that could not be bent were exposed as flat coupons for weight-change data only.

Environment Simulation

Two basic water chemistries were used in the present study: a Hanford basaltic ground water and a $\mathrm{NaCl}_{-} \mathrm{MgCl}_{2}$ brine considered possible under accident conditions at the WIPP Site. All tests were performed at $250^{\circ} \mathrm{C}$.

The Hanford ground-water (HGW) formulation used in the tests was based on analyses of several deep aquifers that exist in the Hanford Reservation. The

(a) Exposure of U-bend specimens does not constitute the ultimate test of resistance to stress-corrosion cracking (SCC), nor does it provide a means for quantifying important material characteristics, such as $K_{I S C C}$. It is however, an inexpensive and easy screening test method. More elaborate SCC tests are planned for those materials passing these preliminary trials. 

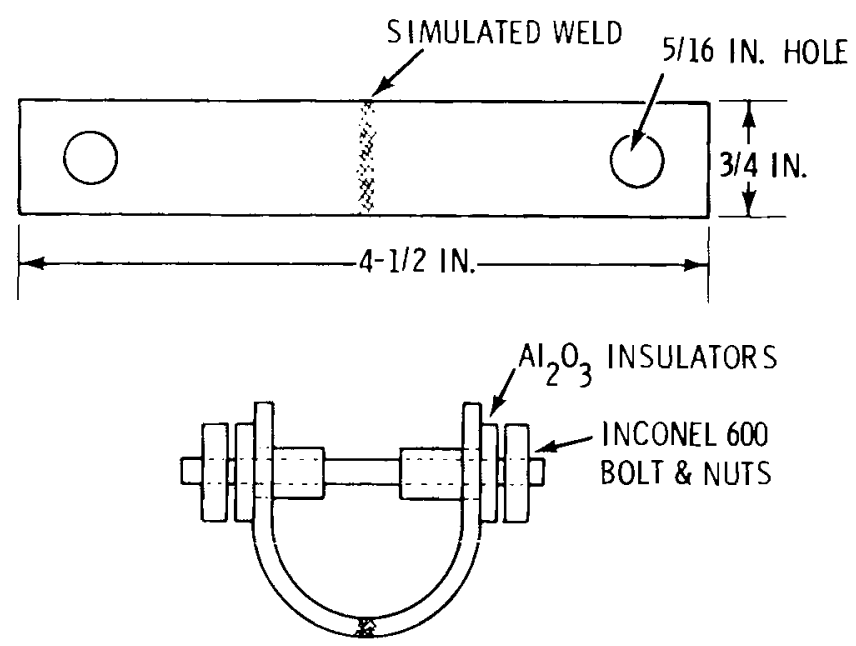

FIGURE 32. Typical U-Bend Test Specimen

composition of this water is given in Table 4. Water made up to this composition was pumped through an autoclave containing crushed basalt rock and the $U$-bend specimens under test (Figure 33 ). The specimens were suspended in the 6.6-L Inconel 600 autoclave by their insulated bolts. The basalt layer was approximately $10 \mathrm{in.}$ thick. The simulated ground water passed upward through the basalt rock layer, over the corrosion specimens, and out of the autoclave through a cooler and back-pressure regulator. The autoclave was held at 800 psi to maintain the liquid phase. Pumping rates were approximately $300 \mathrm{~mL} / \mathrm{h}$ initially and were reduced to $30 \mathrm{~mL} / \mathrm{h}$ in May 1980 with a slight change in water composition (see Table 4). Oxygen control was achieved initially by sparging the 300-L stainless steel storage tanks with nitrogen. Samples of this water frequently read 1 ppm oxygen or less by the Rhodazine-D method. (a) This oxygen content was reduced to less than $50 \mathrm{ppb}$ by changing to a $40-\mathrm{L}$ polythene bottle sparged with argon in May 1980.

The analysis of the autoclave effluent (Table 4) shows the effect that the rock had in the final water chemistry. Briefly, the $\mathrm{Mg}$ and $\mathrm{Ca}$ were almost completely precipitated while $\mathrm{SiO}_{2}$ and $\mathrm{Al}$ were increased. The $\mathrm{pH}$ was lowered. The interaction of the rock with the water at $250^{\circ} \mathrm{C}$ under a slow flow condition

(a) Kit form from Chemetrics Inc., Warrenton, VA 22186. 
IABLE 4. Synthetic Hanford Ground Waters Formulation

\begin{tabular}{|c|c|c|c|c|}
\hline \multirow[b]{2}{*}{ Ion } & \multicolumn{2}{|c|}{ August 1979 to May 1980} & \multicolumn{2}{|c|}{ May 1980 to July 1980} \\
\hline & $\begin{array}{c}\text { Make-up, } \\
\mathrm{mg} / \mathrm{L}\end{array}$ & $\begin{array}{c}\text { Effluent } \\
\text { Analyses, } \\
\text { mg/L } \\
\end{array}$ & $\begin{array}{c}\text { Make-up, } \\
\mathrm{mg} / \mathrm{L} \\
\end{array}$ & $\begin{array}{c}\text { Effluent } \\
\text { Analyses, } \\
\text { mg/L }\end{array}$ \\
\hline A1 & 0 & 10 & 0 & 6 \\
\hline $\mathrm{Na}$ & 139 & 140 & 111 & 127 \\
\hline $\mathrm{Mg}$ & 0.5 & 0.05 & 0.5 & 0.05 \\
\hline $\mathrm{Ca}$ & 1.6 & 0.1 & 2.5 & 0.1 \\
\hline K & 13 & 55 & 13 & 21 \\
\hline $\mathrm{CO}_{3}($ total $)$ & 167 & 210 & 167 & 240 \\
\hline $\mathrm{SiO}_{2}$ & 36 & 210 & 36 & 331 \\
\hline $\mathrm{Cl}^{-2}$ & 52 & 50 & 52 & 58 \\
\hline $\mathrm{F}^{-}$ & 8 & 8 & 8 & 8 \\
\hline $\mathrm{SO}_{4}^{--}$ & 0.8 & --- & 0.8 & 5 \\
\hline $\mathrm{O}_{2}$ & $<1$ & & $<0.05$ & \\
\hline $\mathrm{pH}, \mathrm{ppm}$ & 9.5 & 8.5 & 9.0 & 7.7 \\
\hline Conductivity, $\mu$ Mho & 475 & 55 & 630 & 600 \\
\hline
\end{tabular}

(a) Sample was cooled before sampling. The water passed through a bed of crushed basalt at $250^{\circ} \mathrm{C}$ in the autoclave, which increased the $\mathrm{Al}$ and $\mathrm{Si}$, and decreased $\mathrm{pH}, \mathrm{Ca}$ and $\mathrm{Mg}$.

resulted in a general nonequilibrium condition that was partially dependent on the flow rate of water through the rocks. The two flow rates used, 300 and $30 \mathrm{~mL} / \mathrm{h}$, were practical amounts for the pumping equipment available and did not represent an estimation of ground-water flow. Although slowing the water flow through the rocks increased contact time for saturation, the rate controlling feature is likely to be the distance over which the rock constituents must travel before they can leave the rock particles. The reaction layer on the rock surface, which increases in thickness with time as the leachable materials dissolve out, is shown in Figure 34 . The water flow rate obviously becomes very important in determining the leaching rates expected for certain 


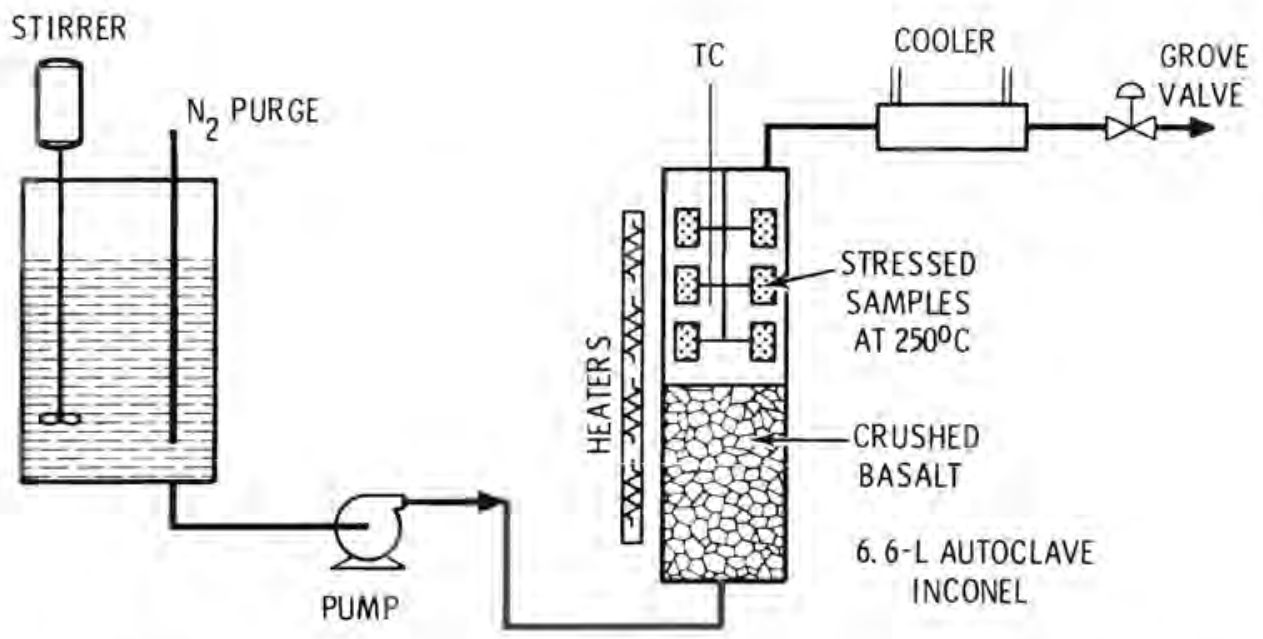

FIGURE 33. Autoclave Facility Used in Hanford Ground-Water Corrosion Tests

minerals, such as available $\mathrm{SiO}_{2}$ and $\mathrm{Al}$, hence the concentration of these species in the water contacting the metal specimens.

The brine chemistry selected for the brine tests was the more aggressive chemistry of those determined for the WIPP site. This chemistry is described by Braithwaite and Molecke (1978) and is detailed in Table 5. This test was run nearly static and thus essentially without oxygen. Samples were held in a 1-L Incone1-625 autoclave and electrically insulated from each other by Teflon spacers. Liquid samples taken from the autoclave reflected the type of specimens in the autoclave prior to sampling, e.g., iron specimens increased the iron level, copper specimens, the copper level, etc.

Specimens were removed from the autoclaves at suitable time intervals, weighed, cleaned, weighed, dye-penetrant-checked for cracks, cleaned, restressed and returned to the autoclave or replaced with new samples. The cleaning operation was intended to remove ony specific layers of materials, such as only the deposited layer or the deposited plus the corrosion product layer. The Inconel, stainless steel, titanium, Zircaloy and Hastelloy samples were treated in $0.5 \% \mathrm{Na}_{2} \mathrm{H}_{2}$ EDTA solution with ultrasonic agitation for 


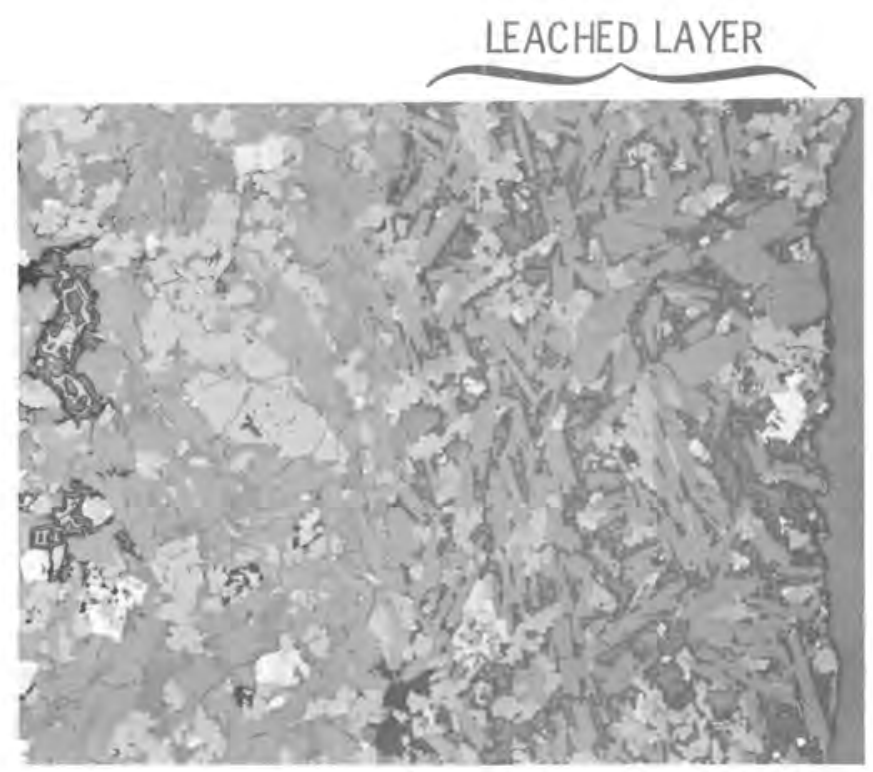

FIGURE 34. Section of Basalt Rock (Grande Ronde-Flow E) After 3 Months in Simulated Hanford Groundwater at $250^{\circ} \mathrm{C}$

TABLE 5. Brine Solution Composition

\begin{tabular}{lcc}
\multicolumn{1}{c}{ Ions } & & Makeup \\
$\mathrm{Mg+}$ & & $34.98 \mathrm{~g} / \mathrm{L}$ \\
$\mathrm{Na}+$ & & 41.34 \\
$\mathrm{~K}+$ & & 29.95 \\
$\mathrm{Ca}++$ & 0.60 \\
$\mathrm{Li}+$ & $20 \mathrm{mg} / \mathrm{L}$ \\
$\mathrm{Rb}^{+}$ & 20 \\
$\mathrm{Sr}^{++}$ & 5.3 \\
$\mathrm{Cs}^{+}$ & 0.8 \\
$\mathrm{Cl}^{+}$ & $191.3 \mathrm{~g} / \mathrm{L}$ \\
$\mathrm{SO}_{4}{ }^{--}$ & $3.51 \mathrm{~g} / \mathrm{L}$ \\
$\mathrm{BO}_{3}$ & $1.24 \mathrm{~g} / \mathrm{L}$ \\
$\mathrm{Br}^{+}$ & $0.39 \mathrm{~g} / \mathrm{L}$ \\
$\mathrm{I}_{-}$ & $10 \mathrm{mg} / \mathrm{L}$ \\
$\mathrm{Fe}^{++}$ & $2 \mathrm{mg} / \mathrm{L}$
\end{tabular}


about 30 min, brushed with mild scouring powder and brush, thoroughly rinsed, dried, and weighed. The process was then repeated. The deposited film was frequently tenacious on the titanium and zirconium alloys, so these were also treated in hot $10 \%$ sodium hydroxide solution followed by concentrated $\mathrm{HCl}$ at room temperature for a few minutes each. This procedure usually removed the film satisfactorily. The nickel, copper-nickel, and copper alloys were treated in $18 \% \mathrm{Hcl}$ for $3 \mathrm{~min}$, brushed with scouring powder, rinsed in an ultrasonic bath, dried, weighed, and the process repeated. This usually removed all of the deposits on the copper and copper-nickel and most of the corrosion film. The nickel film was only partially removed; these samples had to be treated in ammonium citrate solution and sodium hydroxide solutions for short time periods. The cast iron samples were treated in $88 \mathrm{~g} / \mathrm{L}$ ammonium citrate plus $5 \mathrm{~g} / \mathrm{L}$ phenylthiourea at $85^{\circ} \mathrm{C}$ for $30 \mathrm{~min}$, rinsed in an ultrasonic bath, dried, weighed, and the process repeated until a constant rate of loss was established, which was then back-extrapolated to determine the metal lost.

\section{$\underline{\text { RESULTS }}$}

Weight change data for the samples in the HGW tests are shown in Table 6. Table 7 shows the weight change data for samples exposed to the $\mathrm{MgCl}_{2}-\mathrm{NaCl}$ brine. Table 8 covers the weight change behavior of two crevice-type specimens made by bolting together eight $1-i n .^{2}$ samples including titanium Grade 2, titanium Grade 12, Teflon and cast iron (1-in.-round specimens). Crevices were made between all materials. Subsequent to exposure, the samples were weighed, cleaned, weighed and selected samples analyzed for hydrogen to see if the crevices or galvanic contact to iron promoted hydrogen uptake.

Reviewing the corrosion data on Tables 6 and 7 gives one a general picture of HGW corrosion under low oxygen conditions. Having several alloys present in the same autoclave can possibly affect the behavior of some adversely, but refinement of this condition is not readily achievable in a multi-materials 
TABLE 6. Corrosion of Samples in Simulated Hanford Ground Water(a) at $250^{\circ} \mathrm{C}$

\begin{tabular}{|c|c|c|c|c|}
\hline \multirow[b]{2}{*}{ Material } & \multicolumn{2}{|c|}{$\begin{array}{l}\text { Weight Change First } \\
3 \mathrm{Mo}, \mathrm{mg} / \mathrm{dm}^{2}\end{array}$} & \multicolumn{2}{|c|}{$\begin{array}{l}\text { Weight Change Second } \\
3 \mathrm{Mo}, \mathrm{mg} / \mathrm{dm}^{2}\end{array}$} \\
\hline & $\begin{array}{l}\text { Before } \\
\text { Cleaning }\end{array}$ & $\begin{array}{c}\text { After } \\
\text { Cleaning (b) } \\
\end{array}$ & $\begin{array}{l}\text { Before } \\
\text { Cleaning } \\
\end{array}$ & $\begin{array}{c}\text { After } \\
\text { Cleaning }(b)\end{array}$ \\
\hline 304 L S/S & +11 & -0.9 & +4.8 & -1.5 \\
\hline $304 \mathrm{~S} / \mathrm{S}$ & +14 & -3.3 & +7.4 & -0.9 \\
\hline $316 \mathrm{~S} / \mathrm{S}$ & +6 & -5.9 & +15.0 & -1.6 \\
\hline $321 \mathrm{~S} / \mathrm{S}$ & +14 & -2.2 & +4.4 & -2.2 \\
\hline $405 \mathrm{~S} / \mathrm{S}$ & +15 & -3.3 & +2.7 & -3.1 \\
\hline $410 \mathrm{~S} / \mathrm{S}$ & +28 & -5.1 & +18.0 & -4.5 \\
\hline Incone $1-600$ & +13 & -3.3 & +7.6 & -4.2 \\
\hline Incone $1-625$ & +43 & -0.9 & +8.0 & -1.8 \\
\hline Incoloy -800 & +24 & 0.0 & +20.0 & -1.3 \\
\hline Haste 11 oy-C-276 & +14 & -1.8 & +14.0 & -3.5 \\
\hline Nickel-200 & +245 & $+168.0^{(c)}$ & +20.0 & -345.0 \\
\hline Titanium-Grade 2 & +32 & +0.4 & +6.3 & +1.8 \\
\hline Titanium-Grade 12 & +17 & +0.2 & +5.2 & -0.7 \\
\hline Tit an ium-6AL-4V & & & +39.0 & +0.2 \\
\hline Zircaloy-2 & +80 & +23.0 & +3.3 & -11.0 \\
\hline Cast-I ron $180-7$ & +90 & -415.0 & +277.0 & -442.0 \\
\hline Cast-Iron 22-8 & +225 & -345.0 & +263.0 & -476.0 \\
\hline Cast-Iron 142-12 & +345 & -200.0 & +284.0 & -512.0 \\
\hline Cast-Iron 166-3 & +135 & -180.0 & +235.0 & -422.0 \\
\hline Cast-Iron $136-4$ & +32 & -411.0 & +224.0 & -530.0 \\
\hline Copper & & & +168.0 & -171.0 \\
\hline Copper-Nicke1-70-30 & +58 & -89.0 & +268.0 & -580.0 \\
\hline
\end{tabular}

(a) See Table 4 for composition.

(b) Samples of Inconel, stainless steel, titanium, Zircaloy, Incoloy and Hastelloy only had the deposited film removed.

(c) Residual deposited film apparent

(d) Samples of copper, copper-nickel, and cast iron had all deposited and most of the corrosion product film removed. 
TABLE 7. Corrosion of Samples in $\mathrm{MgCl}_{2}-\mathrm{NaCl} \mathrm{Brine}(\mathrm{a})$ at $250^{\circ} \mathrm{C}$

\begin{tabular}{|c|c|c|c|c|c|}
\hline Material & $\begin{array}{c}\text { Weight Change } \\
\text { First Peripd } \\
\mathrm{mg} / \mathrm{dm}^{2}(\mathrm{~b}) \\
\end{array}$ & $\begin{array}{l}\text { Time, } \\
\mathrm{d} \\
\end{array}$ & $\begin{array}{c}\text { Weight Change } \\
\text { Second Period } \\
\mathrm{mg} / \mathrm{dm}^{2}(\mathrm{~b}) \\
\end{array}$ & $\begin{array}{c}\text { Time, } \\
\mathrm{d}\end{array}$ & Remarks \\
\hline $304 \mathrm{~L} S / \mathrm{S}$ & & & -5 & 72 & $\begin{array}{l}\text { Bright HAZ }(c) \\
\text { Black }\end{array}$ \\
\hline $304 \mathrm{~S} / \mathrm{S}$ & & & -5 & 72 & $\begin{array}{l}\text { Bright HAZ-- } \\
\text { Black }\end{array}$ \\
\hline $316 \mathrm{~S} / \mathrm{S}$ & & & -5 & 72 & $\begin{array}{l}\text { Bright HAZ-- } \\
\text { Black }\end{array}$ \\
\hline $321 \mathrm{~S} / \mathrm{S}$ & & & -5 & 72 & $\begin{array}{l}\text { Bright HAZ-- } \\
\text { Black }\end{array}$ \\
\hline $405 \mathrm{~S} / \mathrm{S}$ & & & -351 & 72 & $\begin{array}{l}\text { Broken, in HAZ-- } \\
\text { Black }\end{array}$ \\
\hline $410 \mathrm{~S} / \mathrm{S}$ & & & -354 & 72 & $\begin{array}{l}\text { Broken, in HAZ-- } \\
\text { Black }\end{array}$ \\
\hline Nickel 200 & -486 & 58 & & & \\
\hline Inconel 600 & 12 & 58 & & & \\
\hline Incone 1625 & & & -2 & 72 & Track of tarnish \\
\hline Incoloy 800 & -9 & 58 & & & Light tarnish \\
\hline $\begin{array}{l}\text { Copper-Nickel } \\
70-30\end{array}$ & -996 & 20 & & & Spalling \\
\hline Copper & $-3,858$ & 38 & & & Spalling \\
\hline $\begin{array}{l}\text { Haste lloy- } \\
\text { C276 }\end{array}$ & -6 & 58 & & & \\
\hline $\begin{array}{l}\text { Titanium- } \\
6 A L-4 V\end{array}$ & +0.2 & 58 & & & $\begin{array}{l}\text { Light black } \\
\text { tarnish }\end{array}$ \\
\hline $\begin{array}{l}\text { Titanium- } \\
\text { Code } 12\end{array}$ & +0.9 & 58 & 0 & 72 & $\begin{array}{l}\text { Light straw } \\
\text { tarnish }\end{array}$ \\
\hline Titan ium-50 & +1.0 & 58 & & 72 & $\begin{array}{l}\text { Light straw } \\
\text { tarnish }\end{array}$ \\
\hline Zircaloy-2 & +8.0 & 58 & +10 & 72 & Black \\
\hline $\begin{array}{l}\text { Cast-Iron } \\
22-8\end{array}$ & $-7,713$ & 20 & & & Cleaned to metal \\
\hline $\begin{array}{c}\text { Cast-I ron } \\
22-8\end{array}$ & $-5,501$ & 20 & & & \\
\hline
\end{tabular}

(a) See Table 5 .

(b) Weight change after cleaning in $\mathrm{Na}_{2}$ EDTA solution with ultrasonics to remove deposited scale. Samples of copper, copper-nickel, and nickel were cleaned in $18 \% \mathrm{HCl}$ (room temperature) $3 \mathrm{~min}$. Cast iron cleaned in diammonium citrate plus phenylthiourea $\left(85^{\circ} \mathrm{C}\right)$.

(c) HAZ: Heat-affected zone of weld. 
TABLE 8. Titanium Crevice Specimens Exposed in Hanford Ground Water at $250^{\circ} \mathrm{C}$

\begin{tabular}{|c|c|c|c|}
\hline \multirow[b]{2}{*}{$\begin{array}{c}\text { Material in } \\
\text { Stacking Order }\end{array}$} & \multicolumn{2}{|c|}{$\begin{array}{c}\text { Weight Changes, } \\
\mathrm{mg} / \mathrm{dm}^{2}(\mathrm{a}) \\
\end{array}$} & \multirow[b]{2}{*}{$\begin{array}{c}\text { Hydrogen } \\
\text { Analyses, ppm } \\
\end{array}$} \\
\hline & $\begin{array}{l}\text { Before } \\
\text { Cleaning }\end{array}$ & $\begin{array}{l}\text { After } \\
\text { Cleaning }\end{array}$ & \\
\hline \multicolumn{4}{|l|}{ Bolt 1} \\
\hline $\mathrm{Ti}-50 \mathrm{~A}$ & +0.8 & -0.8 & \\
\hline$T i-12$ & +0.8 & +0.8 & \\
\hline $\mathrm{Ti}-50 \mathrm{~A}$ & +0.8 & 0.0 & 33 \\
\hline $\mathrm{Ti}-12$ & +1.6 & +0.8 & 32 \\
\hline$T i-12$ & +2.4 & +0.8 & 30 \\
\hline \multicolumn{4}{|l|}{ Teflon } \\
\hline $\mathrm{Ti}-50 \mathrm{~A}$ & +0.8 & 0.0 & \\
\hline$T i-12$ & +3.2 & +0.8 & \\
\hline \multicolumn{4}{|l|}{ Bolt 2} \\
\hline$T i-50 A$ & +2.4 & -0.8 & \\
\hline$T i-12$ & +22.0 & +4.0 & 32 \\
\hline Cast-Iron 136-4 & +81.0 & -260.0 & \\
\hline$T i-12$ & +28.0 & +4.0 & 31 \\
\hline$T i-50 A$ & +22.0 & +7.0 & 35 \\
\hline Cast-Iron 136-4 & +4.0 & -212.0 & \\
\hline$T i-50 A$ & +27.0 & +7.0 & 34 \\
\hline $\mathrm{Ti}-12$ & +4.0 & -0.8 & 32 \\
\hline \multicolumn{4}{|l|}{ Unexposed Samples } \\
\hline$T i-12$ & & & 23 \\
\hline$T i-50 A$ & & & 34 \\
\hline
\end{tabular}

(a) Weight changes approximately $+/-0.6 \mathrm{mg} / \mathrm{dm}^{2}$.

screening test. Some conclusions are readily apparent, such as the nearly 100fold difference between the weight changes on cast iron (or copper-nickel) and the other alloys. The other alloys retained some of their corrosion-product oxide after the aforementioned cleaning procedure(s), but it was quite thin. 
Their small weight losses and gains would be increased if all the corrosion product were removed, but it would probably result in a change of less than a factor of five.

Selections obviously cannot be based on weight change alone. For example, the stainless steels appear quite attractive with a very low corrosion rate. However, it is well known that these samples will be subject to stress corrosion cracking when oxygen is added to the test to simulate radiation effects or air access to the repository. The titanium alloys had very low weight changes and appeared not to be sensitive to crevice corrosion at these low oxygen concentrations. The Zircaloy-2 showed weight loss between the first and second test. This might be because the sample was not completely cleaned after the first test or because the oxide layer was removed during the second exposure because of the 8-ppm fluoride concentration in the HGW. Note that the final weight gain of Zircaloy-2 is similar to that of Zircaloy in the brine test (Table 7).

It should be noted that although the weight change data of cast irons shown in Table 6 appear high, an extrapolation of these data to 1,000 yr would lead to an expected loss of only about 1 in. of material, if the corrosion were uniform.

Examination of Table 7 shows the interactions of materials and an aggressive brine postulated to be possible in an accident scenario for salt storage of waste (Braithwaite and Molecke 1978). Once again, there was little middle ground. The contrast of cast iron, copper, copper-nickel and nickel to stainless steel, Inconel or titanium is as much as 1,000-fold. Inconel, Incoloy, Hastelloy, titanium and Zircaloy-2 all had a very low corrosion rate. The contrast between the Zircaloy-2 in the HGW and the brine is interesting and possibly caused by the $8 \mathrm{ppm}$ of fluoride in the HGW. The austenitic stainless steels all looked good from a weight change viewpoint, but would be expected to stress-corrosion-crack if oxygen were present. The 400 series stainless steels lost much more weight and completely cracked through in the heataffected zone near the weld. This cracking is probably a hydrogen-induced cracking in the martensite layer produced by the welding heat. 
Even though the samples (except cast iron and copper) had simulated welds and were stressed in tension in a U-bend, only the two 400 series stainless steel alloys showed any signs of cracking by visual and dye penetrant checking. The lack of cracking must be attributed to low oxygen and/or the presence of an inhibitor. Normally, 50-ppm chloride is sufficient to cause cracking, let alone 19\%. Attempts were made to insure electrical isolation of samples to eliminate galvanic protection.

\section{FUTURE WORK}

In order to predict with any degree of certainty what the corrosion rates of barrier materials will be under actual geologic repository conditions, it is essential that the effects of temperature, pressure, environment chemistry and radiation effects be brought to bear simultaneously on the candidate barrier material(s), which would be maintained in some appropriate flawed and stressed state.

To date, an autoclave test apparatus in a radiation facility has not been available for our program. To remedy this situation, construction of such a facility is currently underway. The radiation will be provided by ${ }^{60}$ Co sources in an existing Hanford Engineering Development Laboratory radiation facility (see Figure 35). Provision is being made for isothermal heating by a steam source, dynamic flow conditions, complete chemical characterization of influent and effluent liquids, and electrochemical monitoring of the specimens and the environment within the reaction vessels (Figure 36 ).

The three autoclaves required for the facility have been ordered, and the preliminary safety assessment has been completed. We expect to have a usable facility by June 1981 .

A slow-strain-rate facility is also under construction. This facility will have two pressure vessels and three constant elongation-rate loading mechanisms. Rupture of metallic specimens under slow-strain-rate conditions in repository-relevant environments, with subsequent fractography and stressstrain analysis, is expected to further define susceptibility of candidate barrier materials to environmentally induced degradation. This facility is expected to be operational in October 1980. 


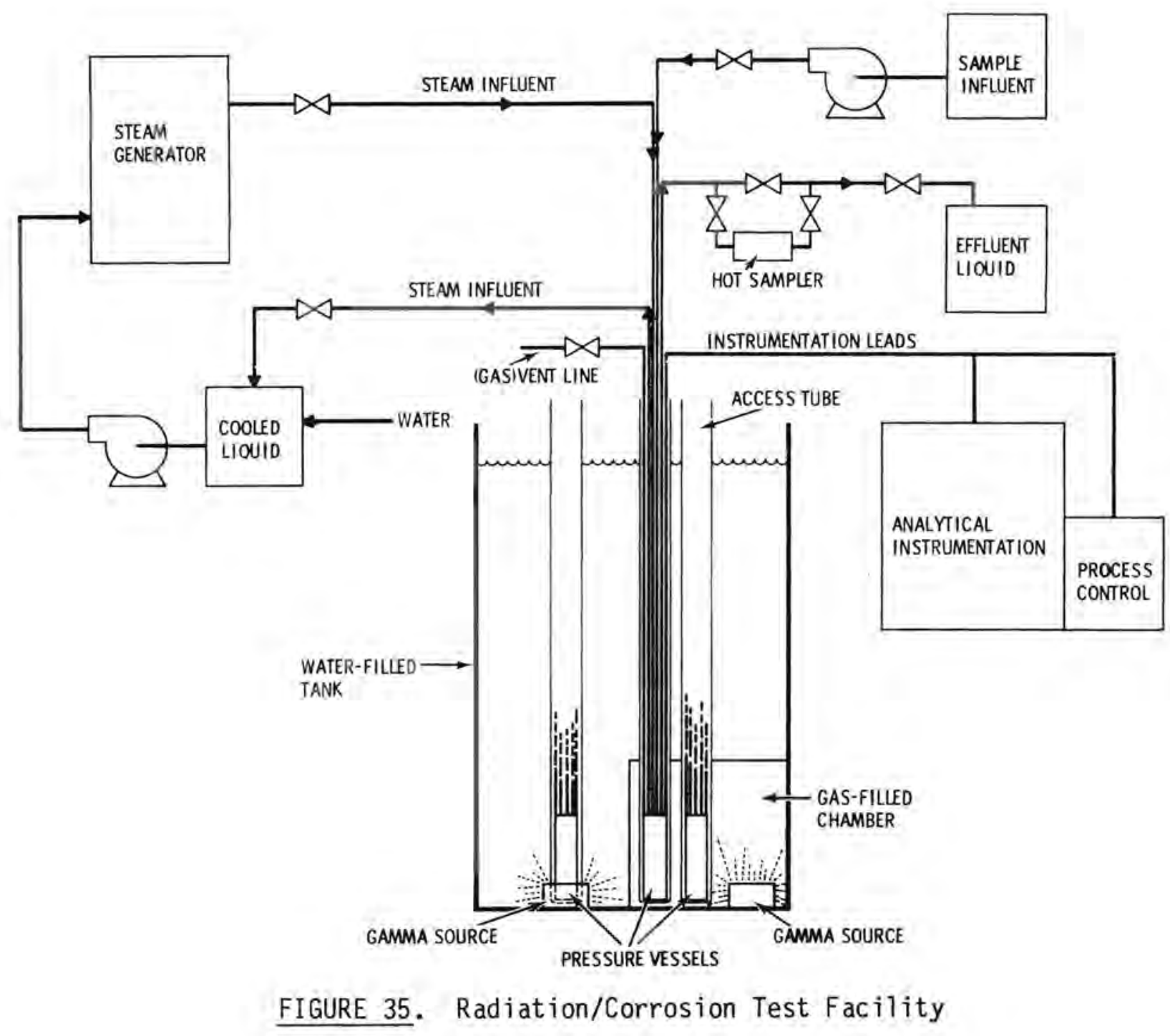




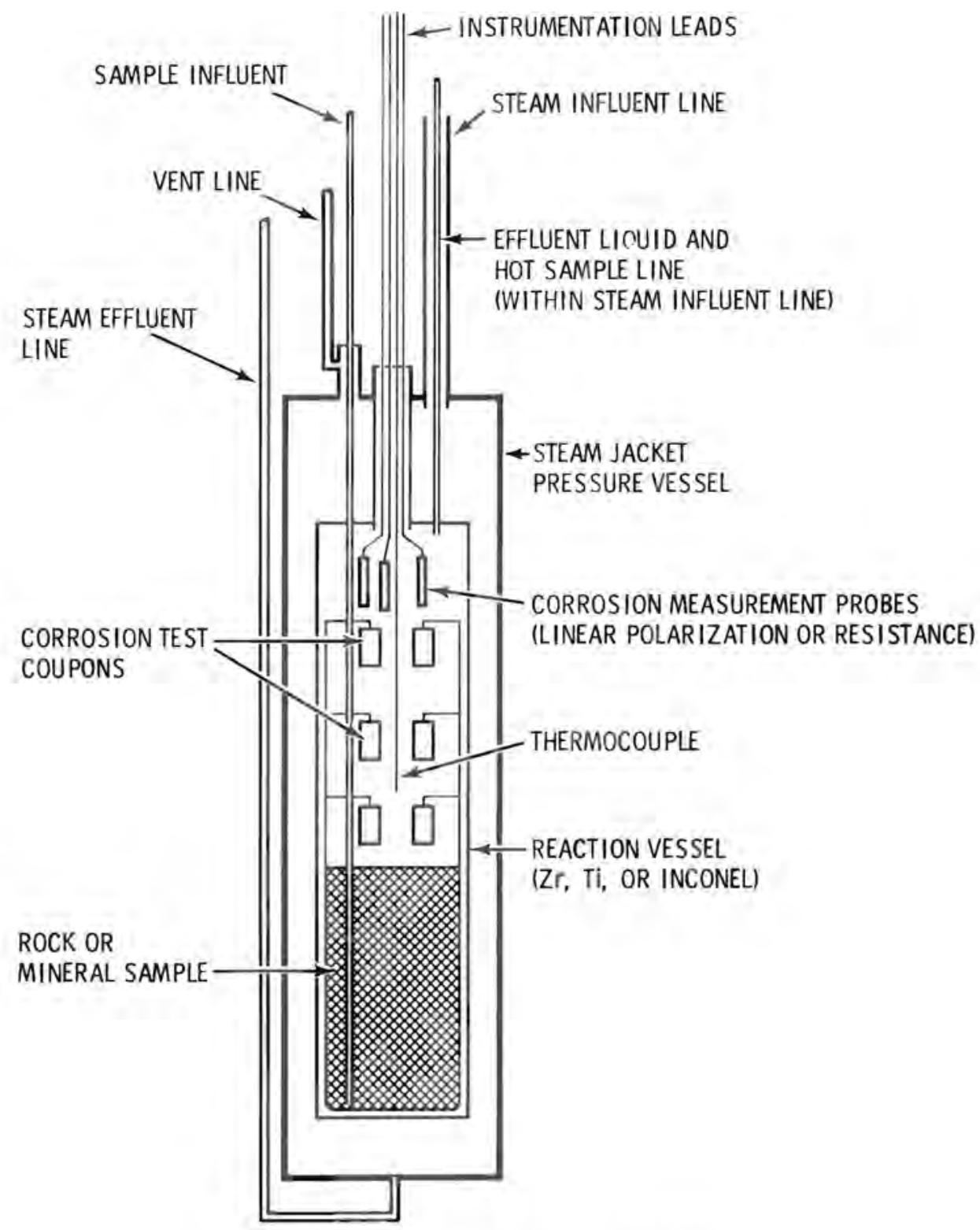

FIGURE 36. Reaction Chamber 


\section{CERAMIC MATERIALS}

H. T. Fullam

\section{INTRODUCTION}

Ceramic materials are being considered for use as elements in such components as the overpack canister and hole sleeve in the proposed engineered barrier system. The ceramic elements would serve to help isolate the primary waste canister from the repository environment for the required protection period. The primary objective of the ceramic materials investigation is to determine if practical ceramic barrier elements can be developed that will provide the required protection of the primary waste canister under the conditions that would be encountered in a geologic repository. The current study is divided into two phases. Phase 1 consists of initial scouting studies whose basic objective is to screen and compare a large number of candidate ceramic materials and to identify the best materials for detailed evaluation. The objective of the second phase is to carry out detailed experimental evaluation of the materials identified in Phase 1 and to determine if practical barrier elements can be developed that will meet design requirements. Continuation of Phase 2 of the study depends on the results obtained in Phase 1 and on the results obtained in the investigation of polymeric and metallic barrier elements. Work on Phase 1 has been completed, and the results obtained are summarized in the following sections. Complete details of the study are provided in Fullam (1980).

\section{EXPERIMENTAL}

Screening of the candidate ceramic barrier materials was carried out through a series of leaching experiments conducted under various temperature and pressure conditions. Solid-solid reactions between the candidate materials and repository media were studied to a limited degree. Initial comparisons of the candidate materials were based on experimentally determined leach rates and observed interactions. Other factors, such as availability, fabricability, 
mechanical and physical properties, and cost were considered in the final comparison and in recommending the best materials for detailed evaluation.

Criteria and design parameters for geologic waste repositories have not been defined. Geologic media still under consideration for use as a repository include bedded salt, salt domes, granite, basalt, shale and volcanic tuffs. Various repository design considerations, such as the age of the waste at the time of disposal, heat-loading, temperature limitations, backfill materials, etc., remain unclear. In this study it was impossible to consider all the geologic alternatives and design parameters that enter into the construction of an engineered barrier system and waste repository. In order to reduce the degree of experimental testing to an acceptable level, it was necessary to formulate a number of assumptions in designing the test matrix:

- Only two repository types were considered: 1) bedded salt of the type found at the WIPP site in New Mexico, and 2) basalt typical of that found at Hanford.

- Aqueous solutions used in the leach tests were limited to:

1) demineralized water, 2) salt brine similar to that found at the WIPP site, and 3) a typical Hanford ground water.

- The maximum temperature for hydrothermal leach tests, corresponding to a "wet" repository, was limited to $250^{\circ} \mathrm{C}$.

- The temperature in a "dry" repository would not exceed $375^{\circ} \mathrm{C}$.

- The possible effects of backfill materials on the reactions between the ceramic materials and repository environs were not considered.

- The effects of the radiation field on the reactions between the ceramic materials and repository environs were not considered.

The ceramic materials to be screened were subjected to five different leach tests:

- a static leach test at $100^{\circ} \mathrm{C}$

- a static hydrothermal leach test at $150^{\circ} \mathrm{C}$ 
- a static hydrothermal leach test at $250^{\circ} \mathrm{C}$

- a dynamic (flow) leach test at $90^{\circ} \mathrm{C}$

- a dynamic (flow) leach test at $250^{\circ} \mathrm{C}$.

In addition, the direct reaction of the ceramic material with the repository medium was studied at $375^{\circ} \mathrm{C}$. Each of the test procedures is described in the following sections.

\section{Static Leach Tests}

The static leach tests at $100^{\circ} \mathrm{C}$ were carried out in the following manner: The ceramic test specimen was measured to determine its geometric surface area and then weighed on a microbalance. The weighed specimen was placed in a 1-L Pyrex flat-bottom flask and a known volume of demineralized water was added. The ratio of the geometric surface area of the test specimen to water volume (S/V) was maintained constant for all of the tests. A water-cooled Pyrex condenser was connected to the Pyrex flask, and a short section of Pyrex capillary tubing was placed on the outlet of the condenser. The water in the flask was heated to boiling on a hotplate and held at boiling for 1,032 $\mathrm{h}$. Samples of the solution were taken at periodic intervals for analysis. The test specimens were also removed from the flask periodically, vacuum-dried, and weighed to monitor the weight change. The solution samples were collected through a 0.3-um Millipore filter using a polypropylene syringe and filter holder. The filter holder was placed in the solution and brought to the solution temperature before the sample was taken. As the solution entered the syringe, it was acidified with thrice-distilled nitric acid. The condenser and its capillary outlet reduced evaporation of water from the flask, but some water had to be added periodically to maintain the level. Blank tests, without ceramic specimens present, were also run in order to determine how much leaching of the Pyrex glassware occurred during the testing.

\section{Static Hydrothermal Leach Tests}

The static hydrothermal leach tests were carried out in sealed gold ampules. The following procedure was used for the tests: A weighed ceramic specimen of known geometric surface area was placed in a gold ampule, and a 
known volume of the leach solution was added. The gold ampule was then sealed by welding. Then, the sealed ampule was placed in an autoclave filled with demineralized water. The autoclave was heated to $150^{\circ}$ or $250^{\circ} \mathrm{C}$ and held at temperature for the required time. The autoclave was cooled and the ampule removed and opened. The test specimen was removed from the ampule, washed, vacuum-dried, and weighed. The solution in the ampule was acidified with $2 \underline{M}$ high-purity hydrochloric acid and allowed to stand for several hours. After the solution was transferred to a sample bottle, the ampule was washed with more $2 \underline{M}$ hydrochloric acid. The original solution and wash solution were then combined and analyzed for dissolved species. The test was then repeated for a different time period using the same test specimen and fresh leach solution. Each specimen was tested for four time periods ( $1 \mathrm{~d}, 7 \mathrm{~d}, 14 \mathrm{~d}$, and $21 \mathrm{~d}$ ), using fresh leach solution for each test. After the final test, the ceramic specimen was subjected to ceramographic examination. The tests were carried out using the three leach solutions described in a subsequent section. An attempt was made to use the same $S / V$ ratio in all of the tests carried out at one temperature, but some minor variations in the ratio were necessary with the different ceramic materials. The gold ampules used in the tests had an inner diameter of $0.50 \mathrm{in.}$, and could hold up to $15 \mathrm{~mL}$ of leach solution.

\section{Dynamic (Flow) Leach Tests $\left(90^{\circ} \mathrm{C}\right)$}

The dynamic (flow) leach tests at $90^{\circ} \mathrm{C}$ were carried out as follows: The weighed test specimen, of known geometric surface area, was placed in a Teflon flask. The flask was placed in a water bath held at $90^{\circ} \mathrm{C}$. Demineralized water was flowed through the flask at a controlled rate using a peristaltic metering pump. The solution exiting the flask was filtered through an in-line 0.3-um Millipore filter and then flowed into a collection flask, which was also contained in the water bath. The average water flow rate was approximately $0.2 \mathrm{~mL} / \mathrm{min}$, and the residence time in the flask was about $20 \mathrm{~h}$. Samples of the solution in the collection flask were taken on a periodic basis and analyzed for dissolved species. The samples were taken using the syringeMillipore filter technique described earlier. The ceramic specimen was also removed form the flask at specific intervals, vacuum-dried, and weighed to 
monitor weight change as a function of exposure time. A multichannel peristaltic pump was used for the experiments, which allowed up to 10 tests to be carried out at one time.

\section{Dynamic (Flow) Leach Tests $\left(250^{\circ} \mathrm{C}\right)$}

The dynamic (flow) leach tests at $250^{\circ} \mathrm{C}$ were carried out in demineralized water within a Hastelloy $C$ autoclave. The weighed ceramic specimens, of known geometric area, were placed in the autoclave. Demineralized water was pumped through the autoclave at a controlled rate while the temperature was raised to $250^{\circ} \mathrm{C}$ and held at the temperature for the duration of the run. At specific intervals the autoclave was cooled and opened, and the ceramic specimens were removed, vacuum-dried, and weighed. The specimens were then returned to the autoclave for additional testing. Each specimen was exposed for the intervals of $1 \mathrm{~d}, 7 \mathrm{~d}, 14 \mathrm{~d}$, and 21 or $23 \mathrm{~d}$--giving a total exposure of 43 or $45 \mathrm{~d}$. After the conclusion of the tests, the specimens were subjected to ceramographic examination. Up to eight ceramic materials were tested at one time, and no attempt was made to analyze the demineralized water leaving the autoclave. The volume of the autoclave was $6.5 \mathrm{~L}$, and the water flow rate was about $1.9 \mathrm{~L} / \mathrm{h}$, givirig a residence time of approximately $3.4 \mathrm{~h}$.

\section{Material/Repository Reaction Test}

In addition to the leaching tests, the ceramic materials were subjected to one additional test. This test was intended to determine if any reaction might occur between a ceramic material and the repository medium--either basalt or salt. In these tests a weighed ceramic specimen was packed in crushed basalt or salt within a silica ampule. A small amount of water, sufficient to give a partial pressure of $4 \mathrm{~mm} \mathrm{Hg}$ (STP) was added to the mixture, and the ampule was sealed. The ampule was then heated to $375^{\circ} \mathrm{C}$ in a muffle furnace and held at temperature for the required time. At the conclusion of the test, the ampule was cooled and opened. The test specimen was visually examined for possible reaction with the basalt or salt and was then weighed. The tests lasted 2,200 and $4,500 \mathrm{~h}$. 


\section{MATERIALS TESTED}

A wide variety of inorganic materials can be considered for use as barrier elements in an engineered barrier system. For a variety of reasons, the materials considered for evaluation in this study were limited to inorganic oxides and graphite. A literature search was conducted to determine what oxide materials might be expected to be most resistant to attack by the aqueous solutions that could be encountered in the two types of geologic waste repositories under consideration. In addition, recommendations on the types of materials to test were solicited from various individuals at PNL and Rockwell-Hanford who have the appropriate expertise. The materials finally selected for evaluation are listed in Table 9. Some naturally occurring complex oxide materials were seriously considered for evaluation, but were dropped because they are being studied in other programs at PNL. These materials include zirconolite, hollandite, and certain types of feldspars.

Specimen Preparation

Wherever possible, the materials to be screened were obtained from commercial sources in the form of dense, low-porosity impervious shapes. Several of the materials could only be obtained as powders and had to be compacted into dense shapes. Depending on the material, hot-pressing or cold-pressing and sintering was used to fabricate the powders into dense test pieces.

Hot-pressing was used to compact several of the powdered materials into dense pellets. The hot press utilized an induction-heated graphite die and hydraulic press. The maximum temperature capability of the press was approximately $1700^{\circ} \mathrm{C}$, while the graphite die limited the maximum pressure to about 5,800 psi. Pellets up to 1 in. in dia could be prepared by varying the die diameter. The maximum pellet length was about 1 in. Very little interaction was observed between the oxide pellets and the graphite die. After removal from the die, the surface of the pellet was discolored with graphite that was easily removed by heating the pellet in air at about $1200^{\circ} \mathrm{C}$ for several hours. 
TABLE 9. Materials Evaluated in the Screening Tests

\begin{tabular}{|c|c|c|c|}
\hline Material & $\begin{array}{l}\text { Method Used to } \\
\text { Fabricate Dense } \\
\text { Test Spectimens } \\
\end{array}$ & $\begin{array}{l}\text { Specimen } \\
\text { Density } \\
\% \text { of To }(a) \\
\end{array}$ & $\begin{array}{c}\text { Surface } \\
\text { Area, } \mathrm{cm}^{2} / \mathrm{g}(\mathrm{b}) \\
\end{array}$ \\
\hline $\mathrm{Al}_{2} \mathrm{O}_{3} \quad(99 \%)$ & Commercial $(c)$ & $>90$ & $<10$ \\
\hline $\mathrm{Al}_{2} \mathrm{O}_{3} \quad(99.8 \%)$ & Commercial & $>92$ & $<10$ \\
\hline Mullite $\left(2 \mathrm{Al}_{2} \mathrm{O}_{3} \cdot \mathrm{SiO}_{2}\right)$ & Commercial & $>90$ & $<10$ \\
\hline Basalt & Naturally Occurring & $3.17 \mathrm{~g} / \mathrm{cm}$ & 100 \\
\hline $\mathrm{BaTiO}_{3}$ & $\begin{array}{l}\text { Cold-Press and } \\
\text { Sinter (d) }\end{array}$ & 89 & 300 \\
\hline $\mathrm{BaZrO}_{3}$ & $\begin{array}{l}\text { Cold-Press and } \\
\text { Sinter }\end{array}$ & 92 & 700 \\
\hline $\mathrm{CaTiO}_{3}$ & Hot-Press $(e)$ & 94 & 500 \\
\hline $\mathrm{CaTiSiO}_{5}$ & $\begin{array}{l}\text { Cold-Press and } \\
\text { Sinter }\end{array}$ & 90 & 900 \\
\hline $\mathrm{CaZrO}_{3}$ & $\begin{array}{l}\text { Cold-Press and } \\
\text { Sinter }\end{array}$ & 91 & $<10$ \\
\hline Vitreous Silica $\left(\mathrm{SiO}_{2}\right)$ & Commercial & 99 & $<10$ \\
\hline $\mathrm{TiO}_{2}$ & Hot-Press & 93 & 200 \\
\hline $\mathrm{ZrO}_{2}$ & Commercial & 91 & 20 \\
\hline $\mathrm{ZrSiO}_{4}$ & Hot-Press & 86 & 1,100 \\
\hline $\operatorname{Graphite}^{(f)}$ & Commercial & $1.80 \mathrm{~g} / \mathrm{cm}^{3}$ & 10,000 \\
\hline Pyroceram $9617(\mathrm{~g})$ & Commercial & $2.50 \mathrm{~g} / \mathrm{cm}^{3}$ & $<10$ \\
\hline $\begin{array}{l}\text { Marcor Glass-Ceramic }(g) \\
\text { (Code 9658) }\end{array}$ & Commercial & $2.54 \mathrm{~g} / \mathrm{cm}^{3}$ & $<10$ \\
\hline
\end{tabular}

(a) Percent of theoretical density.

(b) Effective surface area of the test specimens as determined by the Brunauer, Emmett, and Teller (BET) method using krypton.

(c) Obtained from a commercial source as a high-density shape.

(d) Powder cold-pressed into pellets and sintered.

(e) Powder hot-pressed into pellets.

(f) Toyotanso Graphite IG-11, Toyo-Tanso Co. Ltd.

(g) Corning Glass Works. 
The average densities of the hot-pressed pellets varied from about $86 \%$ of theoretical density for $\mathrm{ZrSiO}_{4}$ to $94 \%$ for $\mathrm{CaTiO}_{3}$. Density variations for pellets of a given material were about $+0.5 \%$.

Attempts to hot-press $\mathrm{BaTiO}_{3}, \mathrm{BaZrO}_{3}, \mathrm{CaZrO}_{3}$ and $\mathrm{CaTiSiO}$ in graphite dies were unsuccessful. Dense pellets of the four materials were prepared by coldpressing and sintering. One-inch-diameter pellets of each material were prepared by cold-pressing the powder at 50 tons/in. ${ }^{2}$ in a hardened split-sleeve steel die. The "green" pellets were then fired at approximately $1200^{\circ} \mathrm{C}$ for $90 \mathrm{~h}$ in an air-atmosphere muffle furnace. Average densities of the cold-pressed and sintered pellets ranged from $89 \%$ of theoretical density for $\mathrm{BaTiO}_{3}$ to $92 \%$ for $\mathrm{BaZrO}_{3}$. Density variations for pellets of a given material were about $\pm 1 \%$.

The basalt specimens used in the study were cut from a sample of basalt taken from Flow $E$ of the Sentinel Bluffs-Grande Ronde Formation in south central Washington.

Test specimens of the appropriate size were cut from the dense shapes using a diamond saw. No attempt was made to polish the cut surfaces. The test specimens were cleaned, rinsed with demineralized water, and vacuum-dried at $180^{\circ} \mathrm{C}$. The specimens were then weighed on a microbalance prior to testing.

Some of the specimens tested, such as the graphite, were quite porous--and some were permeable as well. The effective surface areas of the test specimens were measured by the BET method using krypton and the results obtained are shown in Table 9 .

\section{Leaching Solutions}

The candidate materials were leached in three different solutions: demineralized water, a synthetic Hanford ground water, and a synthetic brine solution. The compositions of the last two solutions were: 
- Synthetic Hanford Groundwater:

$$
\begin{aligned}
& \mathrm{Na}^{+}--33 \mathrm{mg} / \mathrm{L} \quad \mathrm{HCO}_{3}{ }^{-}-63 \mathrm{mg} / \mathrm{L} \quad \mathrm{pH}--8.0 \\
& \mathrm{~K}^{+}--\quad 9 \quad \mathrm{SO}_{4}^{-2}-{ }^{-2} \\
& \mathrm{Ca}^{+2}-\mathbf{6} 6.5 \quad \mathrm{Cl}^{-}--\quad 16 \\
& \mathrm{Mg}^{+2}-\mathrm{F}^{-} \mathrm{F} \quad 0.7
\end{aligned}
$$

- Synthetic Brine Solution:

$$
\begin{aligned}
& \mathrm{Na}^{+}--115,000 \mathrm{mg} / \mathrm{L}^{-} \quad \mathrm{Cl}^{-}--175,000 \mathrm{mg} / \mathrm{L} \\
& \mathrm{K}^{+}--\quad 18 \quad \mathrm{SO}_{4}^{-2}--4,200 \\
& \mathrm{Mg}^{+2}-\mathrm{I} \quad 10 \quad \mathrm{I}--\quad 10 \\
& \mathrm{Ca}^{+2}-\mathrm{9} \quad 900 \quad \mathrm{HCO}_{3}{ }^{-}-{ }^{-} \quad 12 \\
& \mathrm{Sr}^{+2}-15 \quad \mathrm{Br}^{-}--\quad 400 \\
& \mathrm{Rb}^{+}--\quad 1 \quad \mathrm{BO}_{3}{ }^{-3}-{ }^{-} \quad 10 \\
& \mathrm{Cs}^{+} \text {-- } 1 \text { Density } \\
& \mathrm{Fe}^{+3}-\mathrm{2} \quad 2 \quad \mathrm{pH}-\mathrm{O}
\end{aligned}
$$

The demineralized water used in the leach tests was prepared using a Corning Model LD-5 water purifier. The treated water had a resistivity greater than $2 M_{\Omega}$, and its $\mathrm{pH}$ was approximately 6.2. Analys is of the demineralized water by induction-coupled plasma spectroscopy (ICP) showed that cation concentrations in the water were below the detectable limits for the instrument except for silicion, which averaged about $0.03 \mathrm{ppm}$.

The synthetic ground water used was based on the analys is of a groundwater sample taken from the Umtanum basalt flow on the Hanford Reservation (Ames 1978). Analyses of ground-water samples taken from various sites on the Reservation show significantly different composition, but the composition used represents the one that has been widely used in various experimental programs at PNL, including radionuclide adsorption studies.

The synthetic salt brine used was a predominantly $\mathrm{NaCl}$ brine whose composition was representative of the brine encountered in the bedded salt at the WIPP site (Braithwaite and Molecke 1978). Brine of this composition has been and is being used in a variety of leaching tests at PNL and Sandia Laboratories. 
Average leach rates were determined using the weight change measurements and solution analysis. The weight changes were monitored by weighing the test specimens on a microbalance before and after testing. The various aqueous samples were analyzed for dissolved cations using an ICP. Analysis of the brine samples was complicated by the ir high $\mathrm{NaCl}$ content, but analysis of the samples at various dilutions gave fairly reproducible results.

After testing, the ceramic test specimens were subjected to ceramographic examination using standard techniques. The photomicrographs obtained were used to determine if localized attack or alteration reactions had occurred during leaching.

\section{RESULTS}

The primary objective of this study was to screen a large number of candidate ceramic materials and to determine which materials would be most resistant to attack by the repository environments. The principal method of material screening involved subjecting test specimens of each material to a variety of leach tests and determining their relative resistances to attack. An initial comparison of the materials can be obtained by determining their average leach rates under the various test conditions. The average leach rates can be determined from weight change measurements and from analyses of the leach solutions. However, average leach rates can be misleading. Localized attack of the test specimens, such as the leaching of impurities from grain boundaries, can result in far more serious attack than is evident from average leach rate determinations. In addition, alteration reactions at a specimen's surface can result in extensive attack that may not be apparent from either the solution analyses or the weight change measurements.

Determining if localized attack or alteration reactions are a problem requires that the ceramic specimens be subjected, after testing, to additional analyses such as ceramographic examination and scanning electron microscopy (SEM). The scope of the study and the large number of specimens tested precluded detailed examination of the specimens. Therefore, it was necessary to limit the analysis to ceramographic examination of selected specimens--primarily those tested at the higher temperatures. 
The photomicrographs obtained showed that several of the ceramic materials were susceptible to localized attack or alteration reactions. For this reason, the average leach rate data should not be used as a final basis for ranking the candidate materials. The final comparison and ranking of the candidate materials must consider the effect of localized attack and alteration reactions, as well as a number of other factors, which include cost availability, mechanical and physical properties, and the availability of demonstrated technology for fabricating dense, impervious bodies of the size required for an engineered barrier system.

\section{Leach Rates}

The average leach rates for the ceramic materials tested were calculated fom the solution analysis data and/or weight loss measurements. With some of the materials there were discrepancies in the leach rates as determined from the two types of data. In general, the discrepancies were relatively greater for the more leach-resistant materials such as aluminum oxide than for the more soluble materials such as Pyroceram 9617. Where discrepancies did occur, the maximum leach rate was reported

Two other factors affect the leach rate measurements. First, all of the dense test specimens had some porosity. Although some of the materials were impervious, others were somewhat permeable, and the effective areas available for leaching were much greater than were the respective geometric surface areas of the test specimens used to calculate the average leach rates. For example, the effective surface area of a typical graphite test specimen, as determined by the BET method, was about $7,000 \mathrm{~cm}^{2}$, while the geometric surface area was about $3 \mathrm{~cm}^{2}$.

Second, the permeability of the specimens presented an additional problem when they were leached in the brine solution. At the conclusion of a test, it was very difficult to completely wash the brine solution from the interstices of the permeable specimens--especially the graphite. When the specimens were vacuum-dried before weighing, the dissolved solids in the residual brine precipitated in the voids, affecting the final weight measurement. In some 
cases, it was necessary to wash the specimens several times before a constant weight was attained, and even then there was no assurance that all of the dissolved solids in the brine had been completely removed from the specimens. Since the leach rates were usually very low, the presence of a small amount of precipitate from the brine would have a pronounced effect on the weight change measurements.

\section{Dynamic (Flow) Leach Test $\left(250^{\circ} \mathrm{C}\right)$}

All of the materials tested, except two, exhibited the ir highest leach rates in the dynamic (flow) test at $250^{\circ} \mathrm{C}$. The two exceptions were graphite and $\mathrm{TiO}_{2}$ which had slightly higher leach rates in some of the static tests at $250^{\circ} \mathrm{C}$. In the dynamic tests at $250^{\circ} \mathrm{C}$, samples of the candidate materials were exposed to flowing demineralized water in a Hastelloy $C$ autoclave. The 16 materials were tested in two groups of eight, and each group of specimens was exposed for four time periods- $-1 d, 7 d, 14 d$, and 21 or $23 d$ (43 or 45 d total exposure). After the final exposure, each specimen was subjected to ceramographic examination. The average leach rates were calculated from weight loss measurements. The concentrations of dissolved species were too low to permit reliable determination of leach rates from analyses of the leach solution leaving the autoclave. In addition, eight materials, all of which contained common cations either as primary constituents or impurities, were tested at one time which precluded the use of solution analyses to determine leach rates. The complete leach rate data for the flow tests at $250^{\circ} \mathrm{C}$ are provided in Fullam (1980), and are summarized in Table 10. In general, the leach rates were high initially and decreased with time, and in some instances appeared to reach a constant rate after prolonged exposure. The values given in Table 10 represent the average leach rates for the total exposure time of 43 or $45 d$, and the reader is referred to Fullam (1980) to see how the leach rates varied with time.

The leach rates for all the materials tested differ by about a factor of 1,200 with, graphite and $\mathrm{TiO}_{2}$ exhibiting much lower leach rates than the other materials tested. The leach rate for $\mathrm{TiO}_{2}$ in flowing demineralized water at $250^{\circ} \mathrm{C}$ was about the same as the rate measured in flowing demineralized water 
TABLE 10. Average Leach Rates for Ceramic Materials Exposed to Flowing Demineralized Water at $250^{\circ} \mathrm{C}(\mathrm{a})$

\begin{tabular}{|c|c|c|c|}
\hline Material & $\begin{array}{c}\text { Exposure } \\
\mathrm{d}\end{array}$ & $\begin{array}{l}\text { Ayerage Leach } \\
\text { Rate }(\mathrm{b}) \mathrm{g} / \mathrm{cm}^{2}--\mathrm{d}(\mathrm{c})\end{array}$ & Remarks \\
\hline $\begin{array}{l}\text { Graphite } \\
\mathrm{TiO}_{2}\end{array}$ & $\begin{array}{l}43 \\
45\end{array}$ & $\begin{array}{l}7.0 \times 10^{-6} \\
6.7 \times 10^{-6}\end{array}$ & Radial Cracks \\
\hline $\mathrm{ZrO}_{2}^{2}$ & 43 & $1.4 \times 10^{-4}$ & \\
\hline $\mathrm{Al}_{2} \mathrm{O}_{3}(99.8 \%)$ & 43 & $1.3 \times 10^{-4}$ & Localized Attack \\
\hline $\mathrm{A}_{2} \mathrm{O}_{3}(99 \%)$ & 43 & $1.8 \times 10^{-4}$ & Localized Attack \\
\hline Vitreous Silica & 43 & $5.0 \times 10^{-4}$ & \\
\hline $\mathrm{CaZrO}_{3}$ & 45 & $4.4 \times 10^{-4}$ & Alteration Reaction \\
\hline $\mathrm{CaTiSiO}_{5}$ & 45 & $7.0 \times 10^{-4}$ & \\
\hline $\mathrm{BaTiO}_{3}$ & 44 & $5.1 \times 10^{-4}$ & $\begin{array}{l}\text { Alteration Reaction } \\
\text { Specimen Shattered }\end{array}$ \\
\hline $\mathrm{CaTiO}_{3}$ & 45 & $7.2 \times 10^{-4}$ & Alteration Reaction \\
\hline Mullite & 43 & $1.3 \times 10^{-3}$ & Alteration Reaction \\
\hline $\mathrm{ZrSiO}_{4}$ & 45 & $1.1 \times 10^{-3}$ & Alteration Reaction \\
\hline $\mathrm{BaZrO}_{3}$ & 45 & $1.4 \times 10^{-3}$ & Alteration Reaction \\
\hline Basalt & 45 & $3.0 \times 10^{-3}$ & Alteration Reaction \\
\hline Marcor-9658 & 42 & $8.3 \times 10^{-3}$ & $\begin{array}{l}\text { Alteration Reaction } \\
\text { Sample Shattered }\end{array}$ \\
\hline Pyroceram 9617 & 43 & $8.3 \times 10^{-3}$ & Alteration Reaction \\
\hline
\end{tabular}

(a) Test carried out in $6.5-\mathrm{L}$ autoclave at a water flow of $21.9 \mathrm{~L} / \mathrm{h}$.

(b) Calculated from weight loss measurements.

(c) Based on the initial geometric surface area.

at $90^{\circ} \mathrm{C}$. Examination of the cylindrical $\mathrm{TiO}_{2}$ specimen tested at $250^{\circ} \mathrm{C}$ did show, however, that it had developed radical cracks to a considerable depth. There is evidence that the cracking may have resulted from fabrication problems rather than attack by the leach solution.

The other materials tested had much higher leach rates than the graphite and $\mathrm{TiO}_{2}$. In addition, most of the materials suffered localized attack or alteration reactions, which affected the specimens to considerable depths. Estimates of the extent of the localized attack or alteration reactions, as determined from photomicrographs of the specimens, are given in Table 11 . In 
TABLE 11. Extent of Localized Attack or Alteration Reactions in Ceramic Materials Exposed to Flowing Demineralized Water at $250^{\circ} \mathrm{C}(\mathrm{a})$

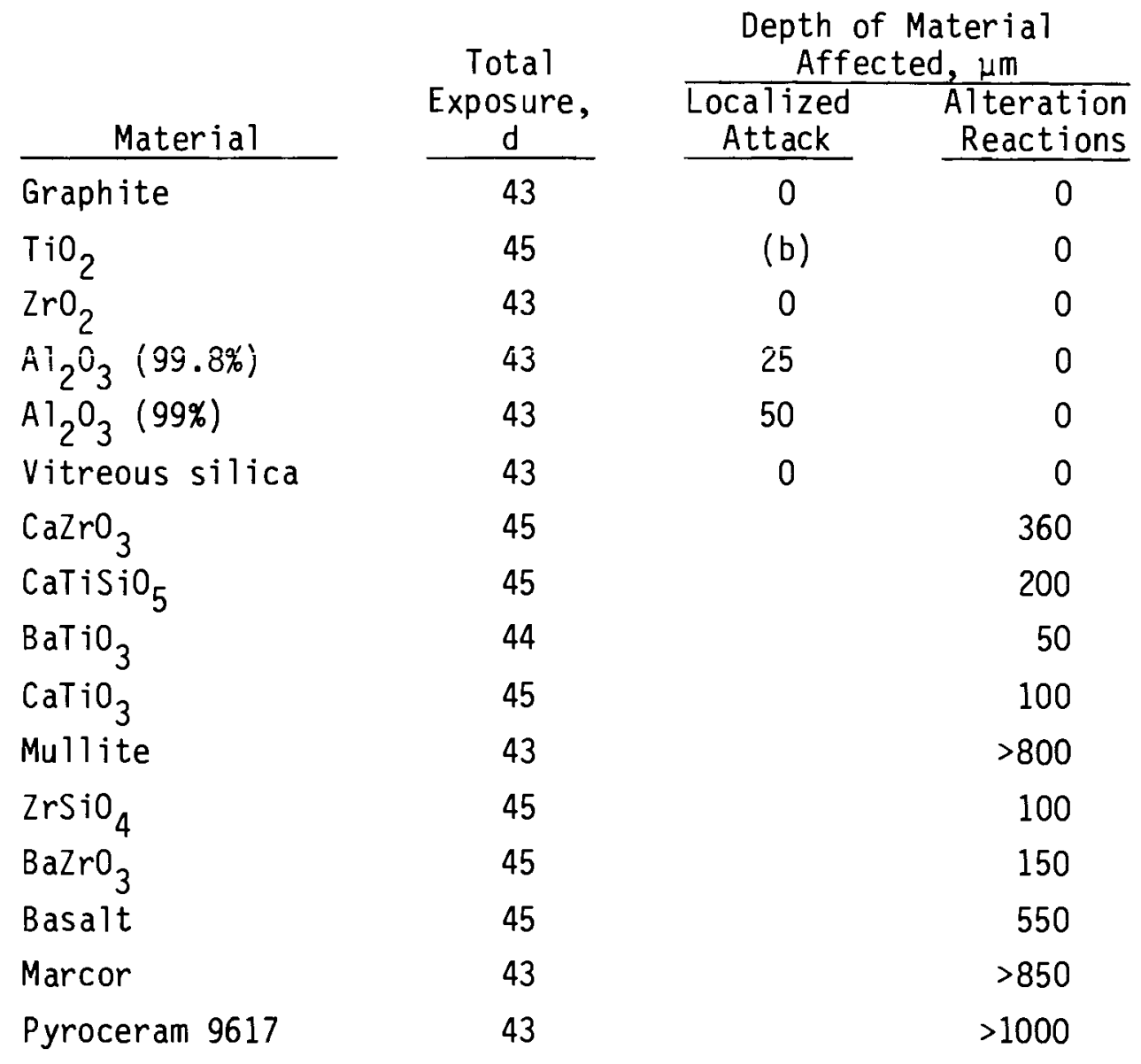

(a) Estimated from photomicrographs.

(b) Specimens exhibited radial cracks to a considerable depth.

the case of the Pyroceram 9617, the reaction layer that formed on the surface crumbled and flaked away when the specimen was dried for weighing. In order to get a reliable weight, it was necessary to remove the reaction layer before weighing, making it impossible to obtain a reliable measure of the depth of the alteration reaction layer.

Complete results of the other leach tests are given in Fullam (1980) and are summarized below. 
Dynamic (Flow) Leach Tests at $90^{\circ} \mathrm{C}$

The dynamic (flow) tests at $90^{\circ} \mathrm{C}$ were carried out using demineralized water as the leach solution. Each test lasted $35 \mathrm{~d}$, and the average leach rates were determined from weight loss measurements. Most of the materials tested exhibited a high leach rate initially that decreased with time, and some appeared to achieve a relatively constant leach rate after prolonged exposure. Overall, the leach rates for the various materials differed by about a factor of 240 , from about $4 \times 10^{-7} \mathrm{~g} / \mathrm{cm}^{2}-d$ for graphitite to $9.6 \times 10^{-5}$ $\mathrm{g} / \mathrm{cm}^{2}-\mathrm{d}$ for $\mathrm{BaZrO}_{3}$.

Static Leach Tests $\left(100^{\circ} \mathrm{C}\right)$

The static leach tests at $100^{\circ} \mathrm{C}$ were carried in Pyrex glassware using demineralized water. The leach rates were determined from weight loss measurements. Analyses of the leach solutions proved to be an unreliable method for determining the leach rates because of the leaching of material from the glassware. Silicon was the principal cation leached from the glassware together with lesser amounts of boron, sodium, aluminum, potassium, and calcium. Most of these cations were also present in the candidate materials either as primary constituents or impurities. In the tests, the leach rates were high initially and decreased with time. This is to be expected in static tests involving materials whose constituents have a low solubility in water (leaching of glassware components would also affect the results). Overall, the leach rates varied by about a factor of 500, from about $6 \times 10^{-7} \mathrm{~g} / \mathrm{cm}^{2}-d$ for graphite to $3 \times$ $10^{-4} \mathrm{~g} / \mathrm{cm}^{2}-\mathrm{d}$ for $\mathrm{CaZrO}_{3}$. In general, the leach rates were slightly higher than those measured in the dynamic test at $90^{\circ} \mathrm{C}$.

Static Leach Tests $\left(150^{\circ} \mathrm{C}\right.$ and $\left.250^{\circ} \mathrm{C}\right)$

The static leach tests at $150^{\circ}$ and $250^{\circ} \mathrm{C}$ were carried out in sealed gold ampules heated in autoclaves. Samples of each material were tested with each of the three leach solutions for four different time periods of $1 \mathrm{~d}, 7 \mathrm{~d}, 14 \mathrm{~d}$, and $21 \mathrm{~d}$ or $23 \mathrm{~d}$. A single specimen was used for each of the four exposures, but the leach solution was replaced after each exposure. After the final exposure, each specimen was subjected to ceramographic examination. The average 
leach rates were determined from weight loss measurements and/or analysis of the leach solutions. In the $150^{\circ} \mathrm{C}$ tests the leach rates calculated from the weight loss measurements were generally higher than those determined from the solution analyses, while the reverse was true in the $250^{\circ} \mathrm{C}$ tests. This was because many of the materials tested at $250^{\circ} \mathrm{C}$ suffered alteration reactions that affected the weight change measurements. Alteration reactions were not a problem with most materials in the $150^{\circ} \mathrm{C}$ tests. In almost all of the static tests at $150^{\circ}$ and $250^{\circ} \mathrm{C}$ the leach rate decreased with increasing exposure time. This is to be expected in static tests where the leach solution can become saturated with the dissolved species, especially in the tests under consideration where the solution volume is small and the $S / V$ ratio is high. Analys is of the leach solutions indicated that saturation effects did serve to control the leach rates of most of the materials tested under static conditions at $150^{\circ}$ and $250^{\circ} \mathrm{C}$. The solution analyses also showed that impurities accounted for up to $90 \%$ of the material leached from some of the candidate materials (i.e., $\mathrm{ZrO}_{2}, \mathrm{TiO}_{2}$ ). Overall, the leach rates were highest in the demineralized water and lowest in the brine solution, with the Hanford ground water giving intermediate results. The average ieach rates for the maximum exposure period of 21 or 23 d ranged from a low of about $10^{-6} \mathrm{~g} / \mathrm{cm}^{2}-d$ to a high of $10^{-3} \mathrm{~g} / \mathrm{cm}^{2}-d$ with graphite and alumina exhibiting the lowest leach rates in most of the tests.

Comparison of Materials

It is difficult to make precise rankings of the candidate materials based on the leach rate data obtained in the various tests. In most of the tests the leach rates of the ceramic materials varied with time. It was possible, however, to make some qualitative comparisons of the materials tested based on the leach rate data obtained in the various tests. This has been done, and in Table 12 the candidate materials are listed in order of their estimated leach resistance for each of the leach tests. It must be remembered that the rankings given in Table 12 are not absolute. The leach resistance of any given material should definitely be greater than that of a material several positions lower on the scale. In the case of adjacent materials, however, it is unusually impossible in most cases to say that one is more leach-resistant than the other. 
TABLE 12. Relative Resistance of Ceramic Materials to Leaching Under Various Test Conditions-in Order of Decreasing Resistance

\begin{tabular}{|c|c|c|c|c|c|c|c|c|c|}
\hline \multirow{2}{*}{\multicolumn{2}{|c|}{$\begin{array}{c}\text { Static Leach } \\
\text { Test at } 100^{\circ} \mathrm{C} \\
\text { Demineralized } \\
\text { Water }\end{array}$}} & \multirow{2}{*}{$\begin{array}{c}\text { Dynamic Leach } \\
\text { Test at } 90^{\circ} \mathrm{C}, \\
\text { Demineralized } \\
\text { Water } \\
\end{array}$} & \multirow{2}{*}{$\begin{array}{l}\text { Dynamic Leach } \\
\text { Test at } 250^{\circ} \mathrm{C}, \\
\text { Demineralized } \\
\text { Water } \\
\end{array}$} & \multicolumn{3}{|c|}{ Static Leach Test at $150^{\circ} \mathrm{C}$} & \multicolumn{3}{|c|}{ Static Leach Test at $250^{\circ} \mathrm{C}$} \\
\hline & & & & $\begin{array}{c}\text { Demineralized } \\
\text { Water }\end{array}$ & $\begin{array}{c}\text { Hanford } \\
\text { Ground Water } \\
\end{array}$ & Brine & $\begin{array}{c}\text { Demineralized } \\
\text { Water }\end{array}$ & $\begin{array}{l}\text { Hanford } \\
\text { Ground Water }\end{array}$ & Brine \\
\hline \multirow{16}{*}{$\varpi$} & Graphite & Graphite & Graphite & Graphite & $\mathrm{Al}_{2} \mathrm{O}_{3}(99.8 \%)$ & $\operatorname{Graphite}^{(a)}$ & $\mathrm{Al}_{2} \mathrm{O}_{2}\left(99.8 \%^{\prime}\right)$ & $\mathrm{Al}_{2} \mathrm{O}_{2}(99.8 \%)$ & Graphite $^{(a)}$ \\
\hline & $\mathrm{Al}_{2} \mathrm{O}_{3}(99.8 \%)$ & $\mathrm{Al}_{2} \mathrm{O}_{3}$ (99.8x) & $\mathrm{TiO}_{2}$ & $\mathrm{Al}_{2} \mathrm{O}_{3}(99.8 \%)$ & Graphite & $\mathrm{TiO}_{2}^{(\mathrm{a})}$ & Graphite & Graphite & $\mathrm{Al}_{2} \mathrm{O}_{3}$ (99.8\%) \\
\hline & $\mathrm{Al}_{2} \mathrm{O}_{3}(99 \%)$ & Mullite & $\mathrm{Al}_{2} \mathrm{O}_{3}(99.8 \%)$ & $\mathrm{Al}_{2} \mathrm{O}_{3} \quad(99 \%)$ & $\mathrm{Al}_{2} \mathrm{O}_{3}(99.8 \%)$ & $\mathrm{Al}_{2}{ }^{0}{ }_{3}(99.8 \%)$ & $\mathrm{Al}_{2} \mathrm{O}_{3}(99 \%)$ & $2 \mathrm{rO}_{2}$ & $2 \mathrm{rO}_{2}$ \\
\hline & Pyroceram 9617 & $\mathrm{Al}_{2} \mathrm{O}_{3}$ (99x) & $\mathrm{ZrO}_{2}$ & Mullite & Mullite & $\mathrm{Al}_{2} \mathrm{O}_{3}(99 \%)$ & $\mathrm{TiO}_{2}$ & $\mathrm{Al}_{2} \mathrm{O}_{3}(99 \%)$ & $\mathrm{Al}_{2} \mathrm{O}_{3} \quad(99 \%)$ \\
\hline & Vitreous Silica & $\mathrm{TiO}_{2}$ & $\mathrm{Al}_{2} \mathrm{O}_{3}(99 x)$ & Vitreous Silica & $\mathrm{ZrO}_{2}$ & Mullite & $\mathrm{CaTiO}_{3}$ & $\mathrm{TiO}_{2}$ & $\mathrm{TiO}_{2}$ \\
\hline & $\mathrm{TiO}_{2}$ & $\mathrm{ZrO}_{2}$ & Vitreous Silica & $\mathrm{ZrO}_{2}$ & Pyroceram 9617 & Vitreous Silica & $\mathrm{ZrO}_{2}$ & $\mathrm{CaTiO}_{3}$ & $\mathrm{CaTiO}_{3}$ \\
\hline & Basalt & Pyroceram 9617 & $\mathrm{CaZrO}_{3}$ & Pyroceram 9617 & $\mathrm{CaZrO}_{3}$ & Pyroceram 9617 & Vitreous Silica & $\mathrm{CaTiSiO}_{5}$ & Mullite \\
\hline & $\mathrm{CaTiO}_{3}$ & $\mathrm{CaTiO}_{3}$ & $\mathrm{CaTiSiO}{ }_{5}$ & $\mathrm{TiO}_{2}$ & $\mathrm{ZrSiO}_{4}$ & $\mathrm{ZrO}_{2}$ & Basalt & $\mathrm{BaZrO}_{3}$ & $\mathrm{BaZrO}_{3}$ \\
\hline & $\mathrm{ZrO}_{2}$ & $\mathrm{CaZrO}_{2}$ & $\mathrm{BaTiO}_{3}$ & $\mathrm{CaTiSiO}_{5}$ & $\mathrm{CaTiO}$ & $\mathrm{CaTiO}_{3}$ & $\mathrm{CaTiSi0_{5 }}$ & $\mathrm{Ca}_{2} \mathrm{rO}_{3}$ & Vitreous Silica \\
\hline & $\mathrm{ZrSiO}_{4}$ & Basalt & $\mathrm{CaTiO}_{3}$ & $\mathrm{ZrSiO}_{5}$ & $\mathrm{TiO}{ }_{2}$ & $2 \mathrm{rSiO}_{4}$ & Mullite & Mullite & Pyroceram 9617 \\
\hline & Marcor & Vitreous Silica & Mullite & $\mathrm{CaTiO}_{3}$ & $\mathrm{CaTiSiO}_{5}$ & Marcor & $\mathrm{CazrO}_{3}$ & Basalt & $\mathrm{ZrSiO}_{4}$ \\
\hline & $\mathrm{BaTiO}_{3}$ & Marcor & $\mathrm{ZrSiO}_{4}$ & Basalt & Vitreous Silica & $\mathrm{BaTiO}_{3}$ & $\mathrm{ZrSiO}_{4}$ & Vitreous Silica & Marcor \\
\hline & $\mathrm{Ba}_{2} \mathrm{rO}_{3}$ & $\mathrm{ZrSiO}_{4}$ & $\mathrm{BaZrO}_{3}$ & Marcor & $\mathrm{BaTiO}_{3}$ & $\mathrm{BaZrO}_{3}$ & Pyroceram 96.17 & Pyroceram 9617 & $\mathrm{BaTiO}$ \\
\hline & $\mathrm{CaTiSiO}$ & $\mathrm{BaTiO}_{3}$ & Basalt & $\mathrm{CaZrO}_{3}$ & Basalt & & $\mathrm{BaZrO}_{3}$ & $\mathrm{ZrSiO}_{4}$ & \\
\hline & Mullite & $\mathrm{CaTiSiO}_{5}$ & Marcor & $\mathrm{Ba} \mathrm{rO}_{3}$ & Marcor & & $\mathrm{BaTiO} \mathrm{O}_{3}$ & Marcor & \\
\hline & $\mathrm{Ca}_{3} \mathrm{rO}_{3}$ & $\mathrm{BazrO}_{3}$ & Pyroceram 9716 & $\mathrm{BaTiO}_{3}$ & $\mathrm{BaZrO}_{3}$ & & Marcor & $\mathrm{BaTiO}_{3}$ & \\
\hline
\end{tabular}

(a) Test specimens exhibited weight gains due to incomplete removal of brine prior to drying. 
A cursory examination of Table 12 shows that five materials--namely graphite, the two grades of $\mathrm{Al}_{2} \mathrm{O}_{3}, \mathrm{TiO}_{2}$, and $\mathrm{ZrO}_{2}$--exhibit the greatest resistance to leaching in most of the tests. The experimental data also show that none of the five materials is susceptible to alteration reactions at exposure temperatures up to $250^{\circ} \mathrm{C}$. Some of the other materials tested may exhibit a high leach resistance in one or two tests, but on an overall basis they are much inferior to the five materials mentioned. In addition, most of the materials with lower leach resistance are also susceptible to alteration reactions at temperatures above $150^{\circ} \mathrm{C}$.

It is not possible to show photomicrographs of all the materials tested in this status report. Some typical examples of the types of attack observed are shown in Figure 37, while micrographs of all the materials are provided in Fullam (1980). Figures $37 \mathrm{a}$ and $37 \mathrm{~b}$ show specimens of $\mathrm{Al}_{2} \mathrm{O}_{3}$ (99\%) before testing and after exposure to flowing demineralized water at $250^{\circ} \mathrm{C}$ for $43 \mathrm{~d}$. Localized attack of the alumina in the form of leaching of impurities from the grain boundaries is readily apparent in Figure 37b. Figures 37c and 37d show mullite specimens before testing and after exposure to demineralized water at $250^{\circ} \mathrm{C}$ for $43 \mathrm{~d}$. The extent of the alteration reaction is obvious in the micrograph (37d). Figures $37 \mathrm{e}$ and $37 \mathrm{f}$ show $\mathrm{TiO}_{2}$ specimens before testing and after exposure to flowing demineralized water at $250^{\circ} \mathrm{C}$ for $45 \mathrm{~d}$. The tested specimen exhibited several radial cracks, some of which penetrated into the specimen up to 3,000 to $4,000 \mu \mathrm{m}$, which may be due to fabrication problems rather than attack by the leach solution.

\section{REACTIONS WITH REPOSITORY MEDIA}

A limited number of experiments were carried out to determine if the ceramic materials would react with the repository media in a "dry" system. In the tests, a sample of the candidate material was contacted with the repository medium (either synthetic WIPP salt or crushed basalt) in a sealed silica ampule at $375^{\circ} \mathrm{C}$. The tests lasted for 2,200 and $4,500 \mathrm{~h}$. At the conclusion of the test, the silica ampule was opened, and the sample carefully separated fom the bulk of the salt or basalt. The sample was then examined visually for evidence of possible reaction with the salt or basalt, after which it was weighed. In 
$\mathrm{Al}_{2} \mathrm{O}_{3}(99 \%)$

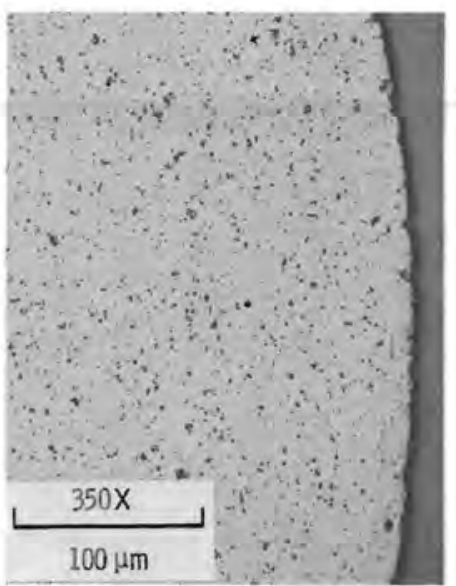

(a) AS RECEIVED

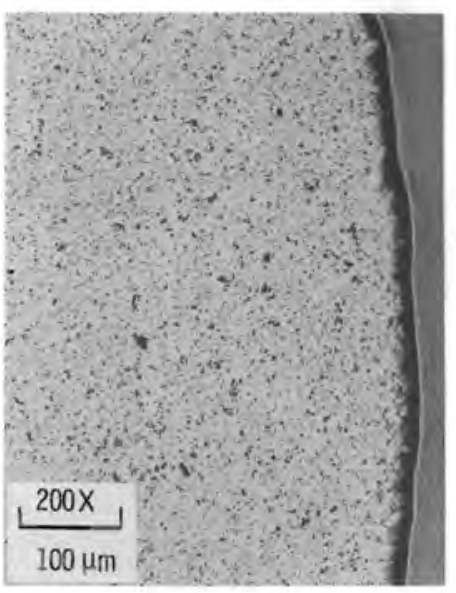

(b) FLOWING DEMINERALIZED WATER 43 DAYS AT $250^{\circ} \mathrm{C}$
MULLITE

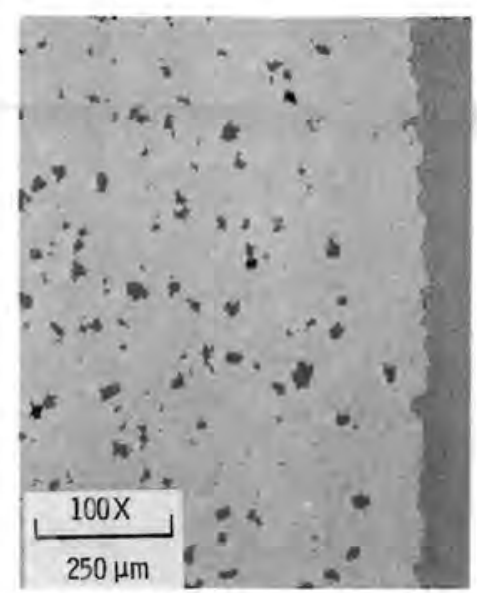

(c) AS RECEIVED

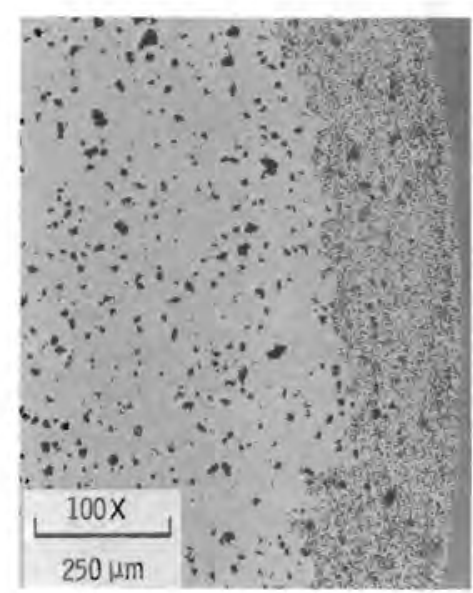

(d) STATIC TEST - DEMINERALIZED WATER - 43 DAYS AT $250^{\circ} \mathrm{C}$
$\mathrm{TiO}_{2}$

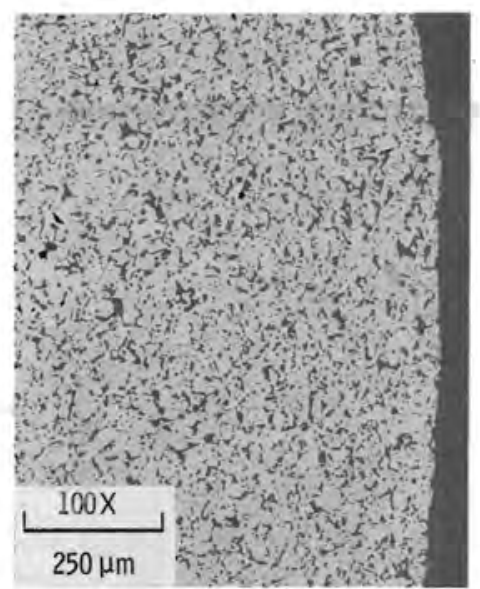

(e) AS FABRICATED

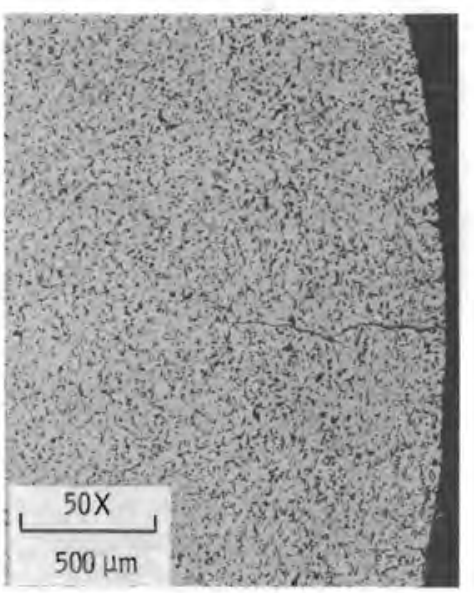

(f) FLOWING DEMINERALIZED WATER 45 DAYS AT $250^{\circ} \mathrm{C}$

FIGURE 37. ( $a, b, c, d, e, f)$ Photomicrographs of Ceramic Specimens Before and After Testing 
none of the tests was there any visual evidence of reaction between the test specimen and the salt or basalt. None of the specimens exhibited any significant weight changes.

\section{ESTIMATES OF LONG-TERM ATTACK}

In order for a ceramic element to be of use in an engineered barrier system, it must help provide isolation of the primary waste canister from the repository environment for the required time of $1,000 \mathrm{yr}$ or longer. It is impossible to estimate, with any degree of reliability, the long-term leach resistance of the materials tested using the limited amount of data obtained in this study. Extrapolation of the measured leach rates to very-long exposure times is difficult because in almost all of the tests the leach rates varied with time. In many of the dynamic leach tests the leach rates continued to decrease with time, and steady-state conditions were not attained. In the static tests the leach rates varied with time as expected, and in many of the tests the concentrations of dissolved species in the leach solutions did appear to reach saturation levels. In a static system, however, the extent of attack of the ceramic material will depend upon the volume of aqueous phase present and the S/V ratio for the system, and this parameter is unknown for a geologic repository. In addition, ceramographic examination of the test specimens was limited to samples that had been exposed for a single time period. Therefore, it was impossible to reliably estimate how localized attack or alteration reactions would vary with exposure time.

While it is impossible to make accurate estimates of long-term attack of the ceramic materials, it is possible to make some very conservative estimates of the attack expected in a repository environment over a 1,000-yr exposure period. In general, the materials tested exhibited their highest leach rates and maximum localized attack and alteration reactions in the dynamic tests at $250^{\circ} \mathrm{C}$. Therefore, extrapolation of the results from the dynamic tests at $250^{\circ} \mathrm{C}$ should provide conservative estimates of long-term attack (this is especially true because the repository temperature would be much below $250^{\circ} \mathrm{C}$ for most of the 1,000-yr period). This had been done, and the resuts obtained are given in Table 13. The average corrosion of each material for a 1,000-yr exposure 
TABLE 13. Estimated Corrosion of Ceramic Materials Exposed to Flowing Demineralized Water at $250^{\circ} \mathrm{C}$

\begin{tabular}{|c|c|c|}
\hline \multirow[b]{2}{*}{ Material } & \multicolumn{2}{|c|}{ Corrosion, $\mathrm{cm} / 1,000 \mathrm{yr}$} \\
\hline & Average (a) & $\begin{array}{r}\text { Alteration } \\
\text { Reactions }(b)\end{array}$ \\
\hline $\mathrm{TiO}_{2}$ & 0.6 & (c) \\
\hline Graphite & 1.5 & None \\
\hline $\mathrm{ZrO}_{2}$ & 7.5 & None \\
\hline $\mathrm{Al}_{2} \mathrm{O}_{3}(99.8 \%)$ & 13 & 21 \\
\hline $\mathrm{Al}_{2} \mathrm{O}_{3}(99 \%)$ & 18 & 42 \\
\hline $\mathrm{BaTiO}_{3}$ & 35 & 42 \\
\hline $\mathrm{CaZrO}_{3}$ & 40 & 290 \\
\hline $\mathrm{CaTiO}_{3}$ & 70 & 85 \\
\hline $\mathrm{CaTiSiO}$ & 80 & 160 \\
\hline Vitreous Silica & 85 & None \\
\hline $\mathrm{BaZrO}_{3}$ & 90 & 130 \\
\hline $\mathrm{ZrSiO}_{4}$ & 100 & 1000 \\
\hline Mullite & 170 & $>700$ \\
\hline Basalt & 350 & 450 \\
\hline Marcor & 500 & $>720$ \\
\hline Pyroceram 9617 & 1,200 & $>1000$ \\
\hline
\end{tabular}

\footnotetext{
(a) Based on the average leach rates measured in the screening tests.

(b) Based on the linear extrapolation of resuts obtained in the screening tests.

(c) Test specimens developed radial cracks to considerable depths. Long-term effects could not be estimated.
}

was estimated using the average leach rate determined for the maximum exposure time ( 43 or $45 \mathrm{~d}$, depending on the material). The extent of localized attack or alteration reactions was estimated by linear extrapolation of the results given in Table 11.

The estimates given in Table 13 show that, except for $\mathrm{TiO}_{2}$ and graphite, all of the materials tested would suffer extensive corrosion when exposed to 
flowing demineralized water at $250^{\circ} \mathrm{C}$ for $1,000 \mathrm{yr}$. The estimated element thickness required with most materials to provide the required level of isolation would probably be greater than could be fabricated with existing technology. In the case of $\mathrm{TiO}_{2}$, the thickness required, based on the estimate of average corrosion, would not be a problem, but the problem of cracking observed with the $\mathrm{TiO}_{2}$ specimens would have to be resolved before $\mathrm{TiO}_{2}$ could be considered for barrier use.

In a static system the long-term corrosion of the candidate materials should be much less than the values given in Table 13. Decreasing the temperature would also decrease the corrosion rate markedly, and at temperatures below $150^{\circ} \mathrm{C}$, localized attack and alteration reactions should not be a major problem with most of the candidate materials.

\section{CONCLUSIONS AND RECOMMENDATIONS}

Based on the results obtained in the various leach tests there are several general conclusions that $c$ an be reached regarding the leach resistance of the candidate materials evaluated in this study:

- On an overall basis, graphite exhibited the greatest leach resistance of the materials tested. Attack of the graphite appeared to depend primarily upon the dissolved oxygen in the leach solution.

- All of the ceramic materials tested suffered extensive attack in one or more of the leach tets. Overall, the two grades of alumina appeared to be the most leach-resistant of the ceramic materials tested. Zirconium dioxide and $\mathrm{TiO}_{2}$ were the best of the remaining materials.

- Localized attack or alteration reactions become a serious problem at temperatures above $150^{\circ} \mathrm{C}$ with most of the candidate materials. Only graphite, $\mathrm{ZrO}_{2}$, and $\mathrm{TiO}_{2}$ did not appear to suffer from localized attack or alteration reactions, although some of the $\mathrm{TiO}_{2}$ specimens exhibited cracking that may have resulted from fabrication problems rather than attack by the leach solutions. 
- The leach rates increased with temperature as expected, but in some cases the increases were not as great as one might anticipate. For example, in the tests with flowing demineralized water the leach rates for several materials, including graphite, $\mathrm{TiO}_{2}$, and $\mathrm{ZrO}_{2}$, increased tenfold or less as the leaching temperature was increased from $90^{\circ}$ to $250^{\circ} \mathrm{C}$. For other materials, however, such as mullite and Pyroceram 9617, the leach rates increased 500 to 1,000 times over the same temperature range.

- In the static tests at $150^{\circ}$ and $250^{\circ} \mathrm{C}$ the leach rates were generally highest in the demineralized water and lowest in the brine solution, with the Hanford ground water giving intermediate results.

- In most of the tests the leach rates varied with time, although in some of the dynamic tests it appeared that steady-state conditions were attained. In most of the static tests it was apparent that saturation of dissolved species in the leach solutions served to limit dissolution of the ceramic materials.

The conclusions stated above are based on an overall evaluation of the test results, and may not be valid for a specific repository environment where conditions could be quite different from those used in the leach tests.

Insufficient data were obtained in this work to show that any of the materials tested would be acceptable for use in the engineered barrier system. An extensive research and development program would be required to demonstrate that one or more of the candidate materials could be used in the barrier application. The results obtained do show, however, which of the candidates offer the best chance of developing an acceptable barrier element. Based on the experimental results obtained, and considering other factors such as cost, availability, fabricability, mechanical and physical properties, etc., graphite appears to be the primary choice for the barrier application, with alumina as the second choice. If the problem of cracking can be overcome, $\mathrm{TiO}_{2}$ would also be a likely choice. Zirconium oxide also appears to be quite resistant to the leach solutions, but does not appear to warrant further consideration 
because of its thermal-shock sensitivity and fabrication difficulties. None of the other materials tested appear to warrant further consideration for the barrier application.

If the decision is made to continue with the development of ceramic barrier elements, it is recommended that graphite and high-purity alumina be the materials considered. 
POLYMERIC MATERIALS

W. E. Skiens

\section{$\underline{\text { INTRODUCTION }}$}

Polymers represent one of the fastest growing areas of material development in the chemical industry over the past 30 to $40 \mathrm{yr}$. Polymers have found application in almost all areas of industry, commerce, business, agriculture, and the home environment. Although their utility is very broad, one specific application of interest to this program has been their ability to protect metals and other materials in a wide range of corrosive environments. In general, polymers are impermeable and have good stability to many chemicals and systems that are extremely corrosive and destructive to metals, ceramics or glasses.

Unfortunately, polymers have received relatively little attention as materials of containment for nuclear wastes, possibly because it has been felt that they can stand neither the environmental nor radioactive conditions for this application. However, a number of polymer systems appear to be potentially stable for long periods under the temperature and radiation conditions expected in waste repositories. Thus, with a combination of proper polymer selection, appropriate design criteria and maintenance of the exposure conditions within those anticipated, polymeric materials can contribute an important component to barrier containment systems.

In addition to the corrosion protection offered by polymers, these materials may also provide economic advantages as well as ease of fabrication and handling. By their inherent properties, polymeric materials may also act to prevent shock fracture or stress cracking of the component system. Because of the extensive capabilities of formulating specific properties into polymeric materials, it should be possible to tailor polymer components to fit the peculiar needs of this application.

To qualify as a long-lived component for barrier systems, a polymer's degradation mechanisms, whether by ionizing radiation, thermal energy, or chemical attack, must be well understood. Although extensive data is 
available on the thermal stability of polymers as well as information concerning their resistance to chemicals (solvents), frequently little information concerning radiation stability of many of these materials (in the expected dose ranges) can be obtained from manufacturers or suppliers. Also, studies of the degradation of polymers exposed to the combined environment of brine (or groundwater), temperature, and radiation have not been developed to any degree. Indeed, since most synthetic polymers of interest in this program have been prepared within the past $30 \mathrm{yr}$, information related to long-term environmental stability of these products is not available.

Candidate materials from all three general classes of polymers--thermoplastics, thermosets, and elastomers--were considered in the careful screening and selection of samples for experimental study in this program. The maximum storage conditions assumed as the basis of polymer selection, and in some cases for initial testing, were: 1) storage time--1,000 yr; 2) maximum radiation dose--1 $\times 10^{10}$ rads; 3) storage conditions--contact with ground water or brine in conjunction with water vapor or steam; and 4) temperature maximum--250 $\mathrm{C}$. It was also assumed that some of these conditions, such as the temperature and radiation levels, might be lower than the maximums suggested, and that potentially promising polymers should not be given absolute pass/fail ratings based on $250^{\circ} \mathrm{C}$ and $10^{10}$ rads. None of the materials described in this report has been tested under the combined set of conditions described above, and, consequent $1 y$, the assessments made from the isolated test results cannot reflect the possibility of synergistic effects on the polymers as a result of the total environment.

Two general types of effects (or degradation) are likely to occur as polymers are exposed to heat and ionizing radiation--chain scission and crosslinking. The first of these mechanisms is caused by thermal degradation and/or very high radiation levels in all polymers. In other polymers radiation at certain levels may primarily cause crosslinking rather than chain scission. In a radiation field, although both of these mechanisms are occurring as any polymer is irradiated, usually one mechanism predominates and the resultant polymer either degrades to lower molecular weights by chain scission or increases in molecular weight as crosslinking occurs. Both mechanisms 
cause changes in the properties of the irradiated polymer, and in many cases these changes are undesirable. Some types of polymers are much more resistant to radiation doses than others (that is, their "G values"(a) are much lower). In general, polymeric structures containing a high degree of aromatic character are much more resistant to radiation (and usually also to thermal) exposure than aliphatic structures. However, radiation and thermal resistance or the inverse does not always imply chemical resistance or instability.

Another factor which must be considered in this application is the chemical products (species) produced by the radiolysis of any aqueous system which may surround the buried package. The influence of these species on a polymeric barrier element must be considered in conjunction with the radiation, thermal, and normal chemical environment encountered in a repository.

\section{CONTAINMENT OF NUCLEAR WASTES BY POLYMERIC MATERIALS}

Consideration of polymeric materials in engineered barrier system design suggests possible utilization of a number of fabrication methods commonly used in polymer technology. These techniques include coating of a canister, an overpack, or a hole sleeve by painting, dipping, spraying, etc., or slipping the canister into a pre-molded container, or placing the canister (or hole sleeve) inside an extruded bag or sheet which is then subsequently sealed. Each candidate polymer system should be individually assessed for the best method of encapsulant formation. Other techniques such as using polymer/polymer or polymer/metal laminates may effectively combine the best properties of two or more materials. These and other engineering design considerations must be followed up as the study of this concept progresses.

(a) $G$ value--A quantitative measure of the efficiency of a radiation-chemical effect determined by the number of molecules changed (destroyed or produced) for each $100 \mathrm{eV}$ of energy absorbed. 
POLYMERS

The materials that have been considered for this application are generally commercially available; however, no economic restrictions have been placed on materials in this preliminary study. Thus, materials costing from a few cents to many dollars per pound have been considered.

All of the generic families of plastics and elastomers have been considered with an attempt to understand what their response will be to the environment expected--radiation, thermal, and chemical--in underground repositories. The polymers included in the initial screening stage of this study were selected after studying data obtained from reports, journal articles, books, manufacturers' literature, and verbal information from manufacturers' technical representatives.

The polymers that have been selected for evaluative screening are listed. This list is not intended to be exhaustive, and, in fact, during the early stages of the program, additional polymers were added as information concerning their properties, and samples, became available. Polymers are not prioritized here; however, recommendations concerning specific polymers will be made at the end of this report.

\begin{tabular}{|c|c|}
\hline Thermoplastics & Thermosets \\
\hline Polyolefins & Epoxies \\
\hline Polyamides & Polyimide \\
\hline Polyamide-imide & Polyurethane \\
\hline Polysulfone & Polyfuran \\
\hline \multicolumn{2}{|l|}{ Polyphenylsulf one } \\
\hline Polyphenylene sulfide & Elastomers \\
\hline Polyphenylene oxide & Polysiloxane (silicone rubber) \\
\hline $\begin{array}{l}\text { Polyarylene ether } \\
\text { Fluorocarbon copolymer }\end{array}$ & $\begin{array}{l}\text { Ethylene-propylene terpolymer } \\
\text { (EPDM) rubber }\end{array}$ \\
\hline
\end{tabular}

Polymers in this application require little structural strength, and it appears that considerable radiation damage to the material could occur in many cases without loss of function of the polymer in its role as part of the containment system. 


\section{EXPERIMENTAL SYSTEMS}

Samples of the selected polymers in the form of tensile-test or deflection bars were either obtained from manufacturers or prepared from resins in the Pacific Northwest Laboratory. As an initial screening step, the testing of weighed and measured samples was initiated in an autoclave under the following conditions: temperature was held at $150^{\circ}, 200^{\circ}$, or $250^{\circ} \mathrm{C}$ (depending upon sample properties); the testing period was $7 \mathrm{~d}$; and the system contained deionized water which flowed through the autoclave at $\sim 1 \mathrm{~L} / \mathrm{h}$. Samples that remained intact through this test were evaluated by measuring tensile strengths and elongations on the recovered samples together with controls. Polymers were further evaluated by exposing samples to gamma radiation. The materials were given a dose of $5 \times 10^{8}$ rads after which they were removed and tested, as were the autoclaved samples. Additionally, those samples that appeared promising in the above tests were further evaluated by subjecting samples (wherever possible) to impact testing. Impact tests on polymers are frequently used to ascertain radiation or thermal degradation since significant degradation is frequently quite apparent in this test.

\section{RESULTS}

\section{Autoclave Tests}

A selected group of polymers were placed in the flowing autoclave system and tested at $150^{\circ} \mathrm{C}$ in deionized water for $7 \mathrm{~d}$. It was felt that many of these polymers, although having a number of desirable properties, would not withstand temperatures above $150^{\circ} \mathrm{C}$. Those that withstood the $150^{\circ} \mathrm{C}$ test, along with other high-temperature polymers, were tested at $200^{\circ}$ and $250^{\circ} \mathrm{C}$. The polymers tested, their tensile strengths, percent elongation, and comments are listed in Table 14.

Of the approximately 18 different generic polymers tested (33 different formulations), a number appeared suitable for further testing after exposure at the indicated temperatures. Generally, those samples were exposed at the next higher temperature conditions (up to $250^{\circ} \mathrm{C}$ ) unless it was known that the materials would not take the higher temperature. At $150^{\circ} \mathrm{C}$ the polymethylpentene 
TABLE 14. Polymers Autoclaved in Flowing Deionized Water at Various Temperatures (exposure time $7 \mathrm{~d}$ )

A. $150^{\circ} \mathrm{C}$ Autoclave

\begin{tabular}{|c|c|c|c|c|}
\hline Sample $e^{(a)}$ & $\begin{array}{r}\text { Tensile } \\
p\end{array}$ & $\begin{array}{l}\text { e Strength, } \\
\text { psi(b) }\end{array}$ & $\begin{array}{c}\text { Elongation, } \\
\%\end{array}$ & Comments \\
\hline $\begin{array}{l}\text { ABS (Kralastic-- } \\
2 \text { types) } \\
\text { (acrylonitrile- } \\
\text { butadiene-styrene } \\
\text { MV-1801 MHA 1801) }\end{array}$ & & & & $\begin{array}{l}\text { Samples were swollen } \\
\text { and partially melted. }\end{array}$ \\
\hline $\begin{array}{l}\text { Polyethylene (high- } \\
\text { density Marlex) } \\
\text { (2 types) }\end{array}$ & & & & $\begin{array}{l}\text { Samples softened and } \\
\text { flowed under these } \\
\text { conditions. }\end{array}$ \\
\hline $\begin{array}{l}\text { Polyphenylene oxide } \\
\text { (Noryl 300) } \\
731 \text { ) }\end{array}$ & $\begin{array}{l}9,300 \\
9,200\end{array}$ & $\begin{array}{r}(10,200) \\
(7,000)\end{array}$ & $\begin{array}{l}16(62) \\
11(21)\end{array}$ & $\begin{array}{l}\text { Sample appearance good. } \\
\text { Tensile strength } \\
\text { unchanged, drop in } \\
\text { elongation. }\end{array}$ \\
\hline $\begin{array}{l}\text { Polyimide (PI-740) } \\
\text { (glass-fiber filled) }\end{array}$ & 6,860 & $(8,200)$ & $1(1)$ & $\begin{array}{l}\text { Sample appears } \\
\text { unchanged, slight drop } \\
\text { in tensile. }\end{array}$ \\
\hline $\begin{array}{l}\text { Polyphenylene sulfone } \\
\text { (Rade1) }\end{array}$ & 11,500 & $(9,000)$ & $21(18)$ & $\begin{array}{l}\text { Sample unchanged, } \\
\text { slight increase in } \\
\text { tensile. }\end{array}$ \\
\hline Polysulfone (Udel) & 12,200 & $(9,000)$ & $6(90)$ & $\begin{array}{l}\text { Increase in tensile, } \\
\text { large drop in } \\
\text { elongation. }\end{array}$ \\
\hline Polyamide-imide (Torlon) & & & & $\begin{array}{l}\text { Sample greatly } \\
\text { embrittled and broke } \\
\text { before testing. }\end{array}$ \\
\hline Polymethylpentene (TPX) & & $(3,400)$ & (25) & $\begin{array}{l}\text { Looks quite good and } \\
\text { should be further } \\
\text { tested. }\end{array}$ \\
\hline $\begin{array}{l}\text { Polyethersulf one } \\
\text { (PES-300P) }\end{array}$ & 13,400 & $(12,100)$ & $6(12)$ & $\begin{array}{l}\text { Sample looks good, no } \\
\text { drop in tensile, loss } \\
\text { in elongation. }\end{array}$ \\
\hline $\begin{aligned} \text { Epoxy } & (\text { DEN 431) } \\
& \text { (DEN 438) } \\
& \text { (Epocast 202) }\end{aligned}$ & & $\begin{array}{l}(8,200) \\
(2,000)\end{array}$ & & $\begin{array}{l}\text { All of these samples } \\
\text { crazed or bubbled and } \\
\text { broke before testing. }\end{array}$ \\
\hline
\end{tabular}


B. $200^{\circ} \mathrm{C}$ Autoclave

Polyphenylene oxide
(Noryl 300)
Polysulfone (Udel)
$(10,200)$
$(7,000)$
$(9,000)$
$(8,950)$
Polyphenylene sulfone
(Radel)
Polyimide (Kinel 5504)
(PI 740)
$(8,200)$
Polyarylene
(Arylon T-300)

Polyphenylene sulfide (Ryton) (R4)

$1,900(15,700)$ $3,000(8,000)$ $4,400(10,300)$
(62) Both samples softened

(21) and flowed--embrittled.

(90) Sample melted into mass--untestable.

(18) Sample seems to be softened and distorted--not tested.

All samples appeared to be degraded and brittle--untestable. Swollen, discolored, embrittled and untestable.

0.8 (1.4)-- Sample embrittled. $0.6(0.8)--$ Samples intact and 0.8 (1.2) fairly good but have lost tensile and elongation.

Silicon rubber (Slygard) (186)

$5,200(5,800)$

Polyethylenepolytetrafluoroethylene (Tefzel)

Metal-filled epoxy (Belzona)

C. $250^{\circ} \mathrm{C}$ Autoclave

EPDM rubber (Nordel)

(HRC 3250)
$700(1,800)$
$650(225)$

Sample crumbled and fell apart in autoc lave.

Sample apparently little affected by these conditions.

Samples very brittle and broke in test grips.

150 (>370) Significant drop in tensile and elongation. 


\section{TABLE 14. (contd)}

C. $250^{\circ} \mathrm{C}$ Autoclave (contd)

(HRC 3251)

(HRC 3257)

(HRC 3258)

$\begin{aligned} 300(1,500) & 110(>370) \\ 1,900(2,000) & 100(190) \\ 500(1,800) & 110(>360)\end{aligned}$

Polyphenylene sulfide (Ryton R4)

R8)

R10)
$3,100(15,700)$

$1,400(8,000)$

$2,300(10,300)$
$0.1(1.4)$

$0.2(0.8)$

$0.1(1.2)$

Polymide

(PI-740) (Fiberite PI-740)

(Vespel)

Poly(ethylenetetrafluoroethylene) (Tefzel)

$2,700(5,800)$

Silicone rubber (Silastic $\mathrm{J})$ (3-6548)

Epoxy (metal-filled)

(Belzona)

Polyfurfuryl alcohol (Quaker-RP100A)

$(3,300)$

(26)
Highly swollen, decreased properties. Looks good, only slight drop in elongation. Highly swollen, drop in tensile and elongation.

Samples seem embrittled, have lost both tensile and elongation.

Samples have lost strength and are crumbling--untestable.

Tensile drop to $1 / 2$ origina 1,1 arge decrease in elongation.

Sample swollen, great loss in tensile and tear strength. Sample disintegrated in autoclave.

Sample embrittled, broke in tensile machine before test.

Samples appear intact but apparently embrittled and broke during mounting in test equipment.

(a) Generic name (trade name)

(b) (): control samples--tested where deemed needed.

and polyethersulfone appeared good, but it was known that these materials could not withstand $200^{\circ} \mathrm{C}$ and autoclave testing was stopped. 
At $200^{\circ} \mathrm{C}$ exposures a relatively large number of materials appeared to be unsuitable, either because of swelling, melting, or complete loss of properties or integrity. Polyphenylene sulfone was borderline and should be further considered. A small number of the materials, however appeared as candidates for further testing.

The $250^{\circ} \mathrm{C}$ exposures were reserved for a relatively small number of the polymers, and of those tested under these conditions, only four materials appeared suitable for additional testing. Those four are EPDM rubber (HRC 3257), polyphenylene sulfide, poly(ethylene-tetrafluoroethylene) copolymer, and a polyfurfuryl alcohol material. Although all four of these materials do show changes in their properties after the exposure at $250^{\circ} \mathrm{C}$ in deionized water, they appear as suitable candidates for further consideration as components in engineered barrier systems design.

\section{Radiation Tests}

After the autoclave testing, a number of the polymers that had appeared to have potential were further evaluated by exposure to radiation. Samples of selected polymers were exposed to gamma radiation from a ${ }^{60}$ Co source to a dose of $5 \times 10^{8}$ rads (temperature $\sim 45^{\circ}$ to $50^{\circ} \mathrm{C}$ ). The results of these exposures as revealed by subsequent tensile and elongation measurements are detailed in Table 15.

Samples varied widely in their response to this level of radiation dose. The response varied from that of silicone rubber which lost most of its integrity to polyphenylene sulfides and polyimides which showed little or no change in tensile and slight increases in elongation. Radiation exposure of some of the materials resulted in crosslinking the polymer chains, and although in some cases there was little change in tensile strength, the elongation dropped significantly. This was true of the EPDM rubber, the polyethersulfone, and the fluoro-copolymer.

It would be highly desirable to test these materials not only to higher radiation levels but also simultaneously at the higher temperatures, pressures, and in the aqueous environment potentially expected in the repository. 
TABLE 15. Testing of Polymers Exposed to Gamma Radiation (total dose $5 \times 10^{8}$ rads $-50^{\circ} \mathrm{C}$ in air)

\begin{tabular}{|c|c|c|c|}
\hline Sample(a) & $\begin{array}{c}\text { Tensile Strength, } \\
\text { psi (b) }\end{array}$ & $\begin{array}{c}\text { Elongation } \\
\%\end{array}$ & Comments \\
\hline $\begin{array}{l}\text { Polymethy lpentene } \\
\text { (TPX) }\end{array}$ & $1,200(3,360)$ & $3(25)$ & $\begin{array}{l}\text { Sample appeared sticky } \\
\text { and degraded-- } \\
\text { discolored. }\end{array}$ \\
\hline $\begin{array}{l}\text { Polyphenylene oxide } \\
\text { (Noryl 300) }\end{array}$ & $3,000(10,150)$ & $<1 \quad(62)$ & $\begin{array}{l}\text { Sample lost tensile and } \\
\text { much elongation. }\end{array}$ \\
\hline $\begin{array}{l}\text { Polyphenylene sulfone } \\
\text { (Radel) }\end{array}$ & $8,600 \quad(9,000)$ & $37 \quad(18)$ & $\begin{array}{l}\text { Color change but little } \\
\text { change in properties. }\end{array}$ \\
\hline Polysulfone (Udel) & $2,600(9,000)$ & $18(90)$ & $\begin{array}{l}\text { Color change and loss } \\
\text { in both tensile and } \\
\text { elongation. }\end{array}$ \\
\hline $\begin{array}{l}\text { Polyphenylene sulfide } \\
\text { (Ryton R4) } \\
\text { R10) }\end{array}$ & $\begin{array}{r}18,400(15,700) \\
9,000(10,300)\end{array}$ & $\begin{array}{l}6(1.4) \\
3(1.2)\end{array}$ & $\begin{array}{l}\text { No apparent change in } \\
\text { properties except } \\
\text { slight elongation } \\
\text { increase. }\end{array}$ \\
\hline $\begin{array}{l}\text { Polyimides } \\
\text { (Fiberite PI 740) }\end{array}$ & $8,100(8,200)$ & $4(1)$ & $\begin{array}{l}\text { No change in tensile, } \\
\text { elongat ion increased, } \\
\text { appearance unchanged. }\end{array}$ \\
\hline $\begin{array}{l}\text { EPDM rubber (Nordel) } \\
\text { (HRC 3250) } \\
\text { (HRC 3257) } \\
\text { (HRC 3258) }\end{array}$ & $\begin{aligned} & 700(18,000) \\
& 1,100(2,000) \\
& 600(1,800)\end{aligned}$ & $\begin{aligned} 11 & (>370) \\
3 & (190) \\
8 & (>360)\end{aligned}$ & $\begin{array}{l}\text { Some decrease in ten- } \\
\text { sile but large decrease } \\
\text { in elongation caused by } \\
\text { crosslinking. }\end{array}$ \\
\hline $\begin{array}{l}\text { Polyether sulf one } \\
\text { (PES-300P) }\end{array}$ & $12,000(12,100)$ & $2(12)$ & $\begin{array}{l}\text { No change in tensile, } \\
\text { drop in elongation, } \\
\text { color change. }\end{array}$ \\
\hline $\begin{array}{l}\text { Epoxy (metal-filled) } \\
\text { (Belzona) }\end{array}$ & 744 & $<0.1(<<1)$ & $\begin{array}{l}\text { No change in } \\
\text { appearance, material } \\
\text { too brittle to handle. }\end{array}$ \\
\hline $\begin{array}{l}\text { Poly(ethylene- } \\
\text { tetrafluoroethylene) } \\
\text { (Tefzel) }\end{array}$ & $4,900(5,800)$ & $3(225)$ & $\begin{array}{l}\text { Little change in ten- } \\
\text { sile, highly cross- } \\
\text { linked drop in } \\
\text { elongation. }\end{array}$ \\
\hline $\begin{array}{l}\text { Silicone rubber } \\
\text { (Sylgard } 186 \text { ) }\end{array}$ & &.- & $\begin{array}{l}\text { Sample degraded, broke } \\
\text { or tore before testing. }\end{array}$ \\
\hline $\begin{array}{l}\text { Polyfurfuryl alcohol } \\
\text { (Quaker RP 100A) }\end{array}$ & $3,800(3,300)$ & $17(26)$ & Sample unchanged. \\
\hline
\end{tabular}

(a) Generic name (trade name).

(b) (): control samples--values where needed. 
Radiation effects at higher temperatures and any synergistic response from the total exposure environment must be studied to further evaluate those polymers of continuing interest.

Impact Tests

Another series of tests carried out on a few of these materials were notched-Izod impact tests, which were performed on instrumented impact equipment in accordance with ASTM D256. Degradation, due either to thermal or radiation exposure, usually shows up significantly in impact-type testing where change in toughness of a sample is demonstrated. Table 16 shows impact measurements for a small group of the polymers evaluated in this program. Further impact testing of exposed samples is expected as this program continues.

These initial data show the response of these polymers to radiation exposure. Examples of three distinct levels of radiation effects on the properties

TABLE 16. Impact Testing of Selected Polymers (Izod impact ASTM-D256-room temperature)

\begin{tabular}{|c|c|c|c|c|}
\hline Sample $(a)(c)$ & $\begin{array}{c}\text { Impact } \\
\text { Strength } \\
\text { 1b/in. (b) }\end{array}$ & $\begin{array}{l}\text { Maximum } \\
\text { Load }\left(P_{\text {max }}\right. \\
\text { lb/in. })(b) \\
\end{array}$ & $\begin{array}{l}\text { Energy } \\
\text { Absorbed } \\
\text { ft- } \\
\text { lb/in. (b) }\end{array}$ & $\begin{array}{c}\text { Fracture } \\
\text { Mode } \\
\end{array}$ \\
\hline Polymethylpentene (TPX) & $0.05(0.4)$ & $65(240)$ & $0.05(0.5)$ & Elastic \\
\hline $\begin{array}{l}\text { Polyphenylene sulfide } \\
\text { (Ryton) } \\
\text { (R4-radiation) } \\
\text { (R4-autoclave } 250^{\circ} \mathrm{C} \text { ) }\end{array}$ & $\begin{array}{l}1.3(1.1) \\
1.3(1.1)\end{array}$ & $\begin{array}{ll}820 & (790) \\
740 & (790)\end{array}$ & $\begin{array}{ll}1.4 & (1.8) \\
1.5 & (1.8)\end{array}$ & $\begin{array}{l}\text { Elastic } \\
\text { Elastic }\end{array}$ \\
\hline $\begin{array}{l}\text { Polyphenylene oxide } \\
\text { (Noryl 300) }\end{array}$ & $(3.4)$ & $(700)$ & $(3.7)$ & $\begin{array}{l}\text { Elastic- } \\
\text { Plastic }\end{array}$ \\
\hline $\begin{array}{l}\text { Polyethylene- } \\
\text { polytetraf luoroethylene } \\
\text { (Tefzel) }\end{array}$ & 0.9 (no break) & $250(280)$ & $0.8(1.3)$ & Elastic \\
\hline $\begin{array}{l}\text { Polyfurfuryl alcohol } \\
\text { (Quaker RP-100A) }\end{array}$ & $(0.15)$ & $(150)$ & $(0.14)$ & Elastic \\
\hline
\end{tabular}

(a) Generic name (trade name).

(b) ( ): control samples--no exposure.

(c) Samples were radiation-exposed unless otherwise indicated. 
are observed with the polymethylpentene losing most of its impact strength, the fluoro-copolymer changing significantly with exposure but still retaining much of its original strength, while the polyphenylene sulfide showed little effect from radiation exposure (or to thermal exposure). Further studies of a number of these promising polymeric materials are needed to properly evaluate their potential.

\section{CONCLUSIONS}

After testing more than 30 different polymer samples for their potential as components in engineered barriers for the containment of nuclear wastes under repository conditions, four materials have appeared as candidates for further evaluation at the extremes of conditions set for this study $\left(250^{\circ} \mathrm{C}\right.$, aqueous system, radiation exposure). Although it would appear that a number of polymers might be suitable at somewhat lower temperatures, the four materials suggested for additional evaluation are EPDM rubbers, polyphenylene sulfide, poly(ethylene-tetrafluoroethylene) copolymer, and polyfurfuryl alcohol polymers.

These materials need to be studied further, especially in a system where these currently isolated conditions of temperature, chemical environment, and radiation can be imposed simultaneously upon the samples. Only this type of system will permit the proper evaluation of these materials for this application.

Polymers can be applied as containment-system components in a number of forms (coatings, films or sheets, molded or extruded containers), and their application of any of these techniques can be both economically and technically feasible. However, the actual design and study of these barrier systems must be developed considerably further before specific polymer application techniques can be defined, as the techniques selected will depend upon the system and the polymer itself. 


\section{REFERENCES}

Ames, L. L. 1978. Low Temperature Radionuclide Kd Values for Basalt, Heulandite and Nontronite. PNL-2817, Pac if ic Northwest Laboratory, Richland, Washington.

ASTM Standard Test Method E399-78. "Plane-Strain Fracture Toughness of Metallic Materials." American Society for Testing and Materials, Philadelphia, Pennsylvania.

Braithwaite, J. W. and M. A. Molecke. 1978. High-Level Waste Canister Corrosion Studies Pertinent to Geologic I solation. SAND78-2111, Sandia Laboratories, Albuquerque, New Mexico. (Presented at the conference on High-Level Radioactive Solid Waste Forms, sponsored by the NRC, Denver, Colorado, December 19-21, 1978.)

Braithwaite, J. W., N. J. Magnani and J. W. Munford. 1979. Titanium Alloy Corrosion in Nuclear Waste Environments. SAND79-2023C, Sandia Laboratories, Albuquerque, New Mexico.

Braithwaite, J. W. and M. A. Molecke. 1979. Nuclear Waste Canister Corrosion Studies Pertinent to Geologic I solation. SAND79-1935J, Sandia Laboratories, ATbuquerque, New Mexico.

Clarke, G. A. et al. 1979. "A Procedure for the Determination of Ductile Fracture Toughness Values Using J-Integral Techniques." Journal of Testing and Evaluation. $7(1)$ : 49-56.

Fullam, H. T. 1980. Use of Ceramic Materials in Waste Package Systems for the Geologic Disposal of Nuclear Wastes. PNL-3447, Pacific Northwest Laboratory, Richland, Washington.

Green, A. P. and B. B. Hundy. 1956. "Initial Plastic Yielding in Notch Bend Tests." Journal of Mechanics and Physics in Solids. 4:128-144.

Johnson, A. B. and B. Francis. 1980. Durability of Metals from Archaeological Objects, Metal Meteorites, and Native Metals. PNL-3198, Pac if ic Northwest Laboratory, Richland, Washington.

Landes, J. D. and J. A. Begley. 1974. "Test Results from J-Integral Studies: An Attempt to Establish a JIC Testing Procedure." Fracture Analysis, ASTM STP 560, American Society for Testing and Materials, p. 170.

Merk le, J. G. and H. T. Corten. 1974. "A J-Integral Analysis for the Compact Specimen, Considering Axial Force as Well as Bending Effects." J.Press. Ves. Tech., Trans. Am. Soc. Mech. Eng. 286-292. 
Tada, H., P. C. Paris and G. R. Irwin. 1973. The Stress Analysis of Cracks Handbook. Del Research Corp., Hellertown, Pennsylvania.

Westinghouse Electric Corporation. 1978. Development of Standard Methods of Testing and Analyzing Fatique Crack Growth Rate Data. AFML-TR-78-40, Westinghouse Electric Corporation, Pittsburgh, Pennsylvania. 


\section{DISTRIBUTION}

No. of

Copies

UNITED STATES

2 S. W. Ahrends

Oak Ridge Operations Office

U.S. Department of Energy

Oak Ridge, TN 37830

T. C. Chee

Office of Waste Operations and Technology

DOE Nuclear Waste Management

Washington, DC 20545

A. A. Churm

DOE Chicago Patent Division

9800 South Cass Avenue

Argonne, IL 60439

C. R. Cooley

Office of Waste Isolation

DOE Nuclear Waste Management

(NE-331)

Washington, DC 20545

2 G. H. Daly

Office of Waste Operations and Technology

DOE Nuclear Waste Management

(NE-322)

Germantown, MD 20545

J. E. Dieckhoner

Office of Waste Operations and Technology

DOE Nuclear Waste Management (NE-321)

Germantown, MD 20545
No. of

Copies

2 E. S. Goldberg

Savannah River Operations Office

U.S. Department of Energy

P.0. Box A

Aiken, SC 29801

J. P. Hamric

Idaho Operations Office

U.S. Department of Energy

Idaho Falls, ID 83401

2 S. G. Harbinson

San Francisco Operations

U.S. Department of Energy

1333 Broadway

Oakland, CA 94612

C. A. Heath

Office of Waste Isolation

DOE Nuclear Waste Management

(NE-330)

Germantown, MD 20545

T. B. Hindman, Jr.

Savannah River Operations

Office

U.S. Department of Energy

P. 0. Box A

Aiken, SC 29801

Los Alamos Scientific Laboratory (DOE)

P.0. Box 1663

Los Alamos, NM 87544

2 R. Y. Lowrey

Albuquerque Operations Office

U.S. Department of Energy

Albuquerque, NM 87115 
No. of

Copies

S. A. Mann

Chicago Operations and Regional office

U.S. Department of Energy

Argonne, IL 60439

D. J. McGoff

Office of Waste Operations and Technology

DOE Nuclear Waste Management

(NE-323)

Germantown, MD 20545

S. Meyers/R. Romatowski

DOE Nuclear Waste Management (NE-30)

Germantown, MD 20545

W. E. Mott

DOE Division of Environmental Control Technology

Washington, DC 20545

J. Neff, Program Manager

Department of Energy

Columbus Program office

$505 \mathrm{King}$ Avenue

Columbus, $\mathrm{OH} \quad 43201$

G. Oertel, Director

Office of Waste Operations

and Technology

DOE Nuclear Waste Management (NE-320)

Germantown, MD 20545

A. F. Perge

DOE Nuclear Waste Management

(NE-30)

Washington, DC 20545

John Van Cleve

DOE Oak Ridge Operations Office

P.0. Box $X$

Oak Ridge, TN 37830
No. of

Copies

R. D. Walton

MSB-107

Division of Waste Products

U.S. Department of Energy

Germantown, MD 20545

R. E. Cunningham

Deputy Director for Fuels and Materials

Nuclear Regulatory Commission

Silver Springs, MD 20910

D. M. Rohrer

United States Nuclear Regulatory Commission

Washington, DC 20555

2 J. B. Whitsett

Idaho Operations Office

U.S. Department of Energy

550 2nd Street

Idaho Falls, ID 83401

27 DOE Technical Information Center

J. R. Berreth

Exxon Nuclear Idaho Corp.

P. 0. Box 2800

Idaho Falls, ID 83401

Exxon Nuclear Corpoation

(File Copy)

P. 0. Box 2800

Idaho Falls, ID 83401

A. Williams

Allied-General Nuclear Service P.0. Box 847

Barnwel1, SC 29812

J. L. Jardine

Argonne National Laboratory

9700 South Cass Avenue

Argonne, IL 60439 
No. of

Copies

J. H. Kittel

Office of Waste Management Programs

Argonne National Laboratory 9700 South Cass Avenue

Argonne, IL 60439

M. J. Steindler Chemical Engineering Div. Argonne Nationa! Laboratory 9700 South Cass Avenue Argonne, IL 60439

M. M. Steindler/L. E. Trevorrow Argonne National Laboratory 9700 South Cass Avenue Argonne, IL 60439

2 J. F. Kircher Office of Nuclear Waste I solation Battelle Memorial Institute 505 King Ave.

Columbus, $\mathrm{OH} 43201$

Bever ly Rawles

Office of Nuclear Waste I solation Battelle Memorial Institute 505 King Ave.

Columbus, $\mathrm{OH} 43201$

2 D. T. Moak

Office of Nuclear Waste Isolation Battelle Memorial Institute 505 King Ave.

Columbus, $\mathrm{OH} 43201$

2 J. Carr

Office of Nuclear Waste Isolation Battelle Memorial Institute 505 King Ave. Columbus, $\mathrm{OH} 43201$

J. W. Voss

Office of Nuclear Waste Isolation Battelle Memorial Institute 505 King Ave.

Columbus, $\mathrm{OH} 43201$
No. of

Copies

Wayne Carbiener

Office of Nuclear Waste Isolation Battelle-Columbus Laboratories 505 King Ave.

Columbus, $\mathrm{OH} 43201$

Brookhaven National Laboratory

Reference Section

Information Division

Upton, NY 11973

Hayne Palmour, II I

2140 Burlington Engineering

Laboratories

North Carolina State University

Raleigh, NC 27607

H. Henning

Electric Power Research Institute 3412 Hillview Avenue

P.0. Box 10412

Palo Alto, CA 94301

Environmental Protection Agency

Technology Assessment Division (AW-559)

Office of Radiation Programs

Washington, DC 20460

Larry L. Hench

Dept. of Materials Science and Engineering

University of Florida

Gainesville, FL 32611

R. G. Barnes

General Electric Company

175 Curtner Avenue (M/C 858)

San Jose, CA 95125

3 John D. Tewhey

Lawrence Livermore Laboratory

P. 0. Box 808

Livermore, CA 94550 
No. of

Copies

J. G. Cline, General Manager

NYS ERDA

Agency Building \#2

Empire State Plaza

Albany, NY 12233

J. P. Duckworth

Plant Manager

Nuclear Fuel Services, Inc.

P.0. Box 124

West Valley, NY 14171

E. H. Kobisk

Solid State Division

Oak Ridge National Laboratory

Oak Ridge, TN 37830

Oak Ridge National Laboratory (DOE)

Central Research Library

Document Reference Section

P.0. Box $X$

Oak Ridge, TN 37830

A. L. Lotts

Oak Ridge National Laboratory

P. 0. Box X

Oak Ridge, TN 37830

R. Roy

Pennsylvania State University

202 Materials Research Laboratory

University Park, PA 16802

2 A. B. Martin

Rockwell International

Energy Systems Group

8900 DeSoto Avenue

Conoga Park, CA 91304

R. G. Kepler

Organic and Electronic

Department 5810

Sandia Laboratories

Albuquerque, NM 87185
No. of

Copies

2 N. J. Magnani

Sandia Laboratories

Division 5831

P.0. Box 5800

Albuquerque, NM 87185

M. A. Molecke

Sandia Laboratories

P.0. Box 5800

Albuquerque, NM 87185

M. D. Boersma

E. I. duPont DeNemours and Company

Savannah River Laboratory

Aiken, SC 29801

J. L. Crandal1, Director

E. I. duPont DéNemours and Company

Savannah River Laboratory

Aiken, SC 29801

3 R. G. Garvin

Savannah River Laboratory

P.0. Box A

Aiken, SC 29801

D. E. Gordon

E. I. duPont DeNemours and Company

Savannah River Laboratory

Aiken, SC 29801

Jim Howe 1

E. I. duPont DeNemours and Company

Savannah River Laboratory

Aiken, SC 29801

H. L. Hull

E. I. duPont DeNemours and Company

Savannah River Laboratory

Aiken, SC 29801 
A. S. Jennings

E. I. duPont DeNemours and Comp any

Savannah River Laboratory

Aiken, SC 29801

J. A. Kelley

E. I. duPont DeNemours and Comp any

Savannah River Laboratory

Aiken, SC 29801

R. Maher, Program Manager Waste Management Programs

Savannah River Plant

E. I. duPont DeNemours \& Co.

Aiken, SC 29801

D. L. McIntosh

E. I. duPont DeNemours and Company

Savannah River Laboratory

Aiken, SC 29801

P. H. Permar

E. I. duPont DeNemours and Comp any

Savannah River Laboratory

Aiken, SC 29801

S. Mirshak

E. I. duPont DeNemours and Company

Savannah River Laboratory

Aiken, SC 29801

R. E. Blanco

Union Carbide Corporation (ORNL)

Chemical Technology Division

P.0. Box Y

Oak Ridge, TN 37830

J. 0. Blomeke

Union Carbide Corporation (ORNL)

Chemical Technology Division

P.0. Box Y

Oak Ridge, TN 37830
D. E. Ferguson

Union Carbide Corporation (ORNL)

Chemical Technology Division

P.0. Box $Y$

Oak Ridge, TN 37830

H. W. Godbee

Union Carbide Corporation (ORNL)

Chemical Technology Division

P.0. Box $Y$

Oak Ridge, TN 37830

ONSITE

3 DOE Richland Operations Office

P. A. Craig

H. E. Ransom

M. J. Zamorski

9 Rockwe 11 Hanford Operations

W. J. Anderson

L. Brown

M. J. Kupfer

E. L. Moore

G. Reep

M. J. Smith

D. D. Wodrich

B. J. Wood

File Copy

\section{Exxon Nuclear Company}

S. J. Beard

3 West inghouse Hanford

Company

A. G. Blasewitz

R. J. Cash

R. L. Fish

79 Pacific Northwest Laboratory

W. F. Bonner

L. A. Charlot 
No. of

Copies

Pac if ic Northwest Laboratory (contd)

T. D. Chikalla

M. 0. Cloninger

S. D. Dahlgren

R. L. Dillon

H. T. Fullam

B. Griggs

C. R. Hann

A. J. Haverfield

J. H. Jarrett

A. B. Johnson, Jr.

M. R. Kreiter

W. L. Kuhn

L. T. Lakey

D. E. Larson

G. B. Long (5)

J. L. MCElroy (3)

M. D. Merz (3)

J. E. Mende 1

R. D. Nelson

R. E. Nightingale

N. J. 01 son

S. G. Pitman

A. M. Platt

D. L. Prezbindowski (2)

J. R. Serne

F. A. Simonen

W. E. Skiens

S. C. Slate

R. P. Smith

W. A. Ross

J. M. Rusin

R. T. Treat

R. P. Turcotte

R. E. Westerman (25).

G. E. Zima

Technical Information (5)

Publishing Coordination $\mathrm{YO}(2) \cdot$ 